\title{
Continuity of care and client satisfaction in the community : a study of professional and non- professional care for the chronically ill
}

Citation for published version (APA):

van Achterberg, M. (1997). Continuity of care and client satisfaction in the community : a study of professional and non-professional care for the chronically ill. [Doctoral Thesis, Maastricht University]. Universiteit Maastricht. https://doi.org/10.26481/dis.19970117ma

Document status and date:

Published: 01/01/1997

DOI:

10.26481/dis.19970117ma

Document Version:

Publisher's PDF, also known as Version of record

Please check the document version of this publication:

- A submitted manuscript is the version of the article upon submission and before peer-review. There can be important differences between the submitted version and the official published version of record.

People interested in the research are advised to contact the author for the final version of the publication, or visit the DOI to the publisher's website.

- The final author version and the galley proof are versions of the publication after peer review.

- The final published version features the final layout of the paper including the volume, issue and page numbers.

Link to publication

\footnotetext{
General rights rights.

- You may freely distribute the URL identifying the publication in the public portal. please follow below link for the End User Agreement:

www.umlib.nl/taverne-license

Take down policy

If you believe that this document breaches copyright please contact us at:

repository@maastrichtuniversity.nl

providing details and we will investigate your claim.
}

Copyright and moral rights for the publications made accessible in the public portal are retained by the authors and/or other copyright owners and it is a condition of accessing publications that users recognise and abide by the legal requirements associated with these

- Users may download and print one copy of any publication from the public portal for the purpose of private study or research.

- You may not further distribute the material or use it for any profit-making activity or commercial gain

If the publication is distributed under the terms of Article 25fa of the Dutch Copyright Act, indicated by the "Taverne" license above, 


\section{Continuity of care and client satisfaction in the community}

A study of professional and non-professional care for the chronically ill 



\title{
Continuity of care and client satisfaction in the community
}

\author{
A study of professional \\ and non-professional care \\ for the chronically ill
}

PROEFSCHRIFT

ter verkrijging van de graad van doctor aan de Universiteit Maastricht op gezag van de Rector Magnificus, Prof.mr. M.J. Cohen, volgens het besluit van het College van Decanen, in het openbaar te verdedigen op vrijdag 17 januari 1997 om 14.00 uur

door

Matheus van Achterberg 


\section{Promotores:}

Prof.dr. H. Philipsen

Prof.dr. H.F.J.M. Crebolder

\section{Co-promotor:}

Dr. F.C.J. Stevens

Beoordelingscommissie:

Prof.dr. C. Spreeuwenberg (voorzitter)

Prof.dr. J.Th.M. van Eijk (Vrije Universiteit, Amsterdam)

Prof.dr. H. Huijer Abu-Saad

Dr. A. Kerkstra (NIVEL, Utrecht)

Prof.mr. F.C.B. van Wijmen

ISBN:

9090100954

\section{Colofon:}

omslag en binnenwerk: Nora Oosting, gra tische vormgeving, Maastricht druk: Unigraphic, Maastricht 
Promotores:

Prof.dr. H. Philipsen

Prof.dr. H.F.J.M. Crebolder

Co-promotor:

Dr. F.C.J. Stevens

Beoordelingscommissie:

Prof.dr. C. Spreeuwenberg (voorzitter)

Prof.dr. J.Th.M. van Eijk (Vrije Universiteit, Amsterdam)

Prof.dr. H. Huijer Abu-Saad

Dr. A. Kerkstra (NIVEL, Utrecht)

Prof.mr. F.C.B. van Wijmen

ISBN:

9090100954

\section{Colofon:}

omslag en binnenwerk: Nora Oosting, grafische vormgeving. Maastricht druk: Unigraphic, Maastricht 


\section{Contents}

1 OVERVIEW 9

1.1 Introduction 9

1.2 Research model 11

1.3 Study I: Implementation and effects of

1.4 Study II: Explaining diversity of care, client satisfaction and the course of client satisfaction in a population of care dependent adults 28

1.5 Discussion 36

2 IMPLEMENTING COORDINATION OF CARE: TASK PERFORMANCE

AND PROBLEMS ENCOUNTERED $\quad 47$

2.1 Introduction 49

2.2 The project 'Coordination of care in the community' $\quad 50$

2.3 Methods 52

2.4 Results 55

2.5 Discussion $\quad 60$

3 Coordination of care: EfFects on the continutTy AND QUALITY OF CARE

3.1 Introduction 67

$\begin{array}{lll}3.2 & \text { Methods } & 69\end{array}$

$\begin{array}{lll}3.3 & \text { Results } & 73\end{array}$

$\begin{array}{lll}3.4 & \text { Discussion } & 77\end{array}$

4 PREDICTORS OF PROFESSIONAL AND NON-PROFESSIONAL COMMUNITY CARE FOR CARE-DEPENDENT ADULTS

$\begin{array}{lll}4.1 & \text { Introduction } & 85\end{array}$

$\begin{array}{ll}4.2 \text { Methods } & 86\end{array}$

4.3 Results 91

4.4 Discussion 96

5 EXPLAINING CLIENT SATISFACTION IN CARE-DEPENDENT ADULTS 103

5.1 Introduction 105

$\begin{array}{ll}5.2 \text { Methods } & 107\end{array}$

5.3 Results 109

$\begin{array}{ll}5.4 \text { Discussion } & 118\end{array}$ 
6 PREDICTORS OF CUIENT SATISFACTION IN CARE-DEPENDENT ADULTS:

A LONGITUDINAL ANALYSIS

6.1 Introduction

6.2 Methods

6.3 Results

6.4 Discussion

Summary

Samenvatting

Appendix

Met dank aan..

Curriculum vitae 




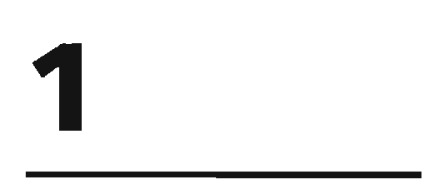

OVERVIEW

\subsection{Introduction}

This thesis describes the central focus, methods, results, and conclusions of two studies within the field of community care. Both studies were performed at the department of Medical Sociology of the Maastricht University in the period from 1990 through 1995. The first study was funded by and carried out in cooperation with the Dutch Institute of Care and Welfare (NIZW). In this project, the implementation and the effects of the appointment of care-coordinators for chronically ill elderly clients were studied. The intervention that was used in this study was simple in nature. Coordination of care was operationalized within the existing community care structure; coordinators were recruited from care-givers who were already involved in client situations, and were not provided with formal authority or special budgets. The choice for this type of intervention was based on (1) the idea that non-professionals should be able to perform as care-coordinators, (2) the belief that a provision for the conrdination of care should not result in more complexity and (3) reasons of feasibility; an intervention that would alter existing structures or authorities was less acceptable to professional care givers..

The second study was performed on commission of the North Limburg Community Care Foundation (STEL Noord-Limburg) and was funded by the Provincial Government of Limburg. This study addressed more fundamental questions than the first study. The introduction of coordination of care in the first study resulted in some effects on the continuity of care. However, there was a lack of effects on the diversity of care and client satisfaction. The second study was used to identify (other) factors that could be used in the explanation of both satisfaction and diversity.

Together, the two studies were a rich source of information on various relevant topics in community care: diversity, coordination and continuity of care, and client satisfaction. The information resulted from a variety of data 
collection methods, such as repeated interviews with community care clients and coordinators, minutes from coordinator meetings, client care-plans and logbooks, and a community survey among clients.

Current developments in community care make the above mentioned topics all the more relevant. The number of people over 85 years of age -now approximately half of all care-dependent clients- has been predicted to increase with $76 \%$ by the year 2010 (Baldock \& Evers 1992). The average client in community care is becoming more and more impaired and care-dependent as institutions such as nursing homes and homes for the elderly become more selective in their admission of new clients. As a result, the strain on both formal and informal community care-givers will increase. The larger number of community care clients and the higher case load per client make efficiency and quality assurance increasingly important. Furthermore, continuity of care is threatened by the growing complexity in health care (Weiss 1987). Not only will clients in community care deal with more types of care-givers, dealing with more care-givers within the same discipline wili often be inevitable. In one of the studies that is presented here, a client who received care from 35 different community nurses within one year was encountered. Although his case was rather extreme, client logbooks (notebooks that were used in monitoring client care) showed that the involvement of many different care-givers was not exceptional. The average client in this study met 16 different professional and non professional care-givers within one year. A permanent provision for the coordination of health care services is often seen as one of the means to guarantee efficient use of scarce resources and to promote the continuity and quality of care for clients. In the Netherlands (and in other Western countries), a standard solution to the issue of coordination of care still needs to be identified. However, there is a wide variety of initiatives that aim at improving the coordination and continuity of care (Knapen \& Puts 1990). The first study, which is reported in chapters 2 and 3 of this book, aimed at implementing one possible variant of coordination of care in the community. The implementation of this coordination model is described in chapter 2, the effects of the intervention are described in chapter 3. An overview of the nature and the results of this study will be given later in this section. The intervention study was designed to affect outcome variables such as the use of care resources, continuity of care and (indirectly) the clients'satisfaction with the care they received. While studying the effects of the intervention, the researchers came to realize that there was still a lack of insight into the determinants of the use of both professional and non-professional community care. Furthermore, the knowledge of factors related to client satisfaction was found to be limited. While there was some knowledge of correlates of the use of and clients' satisfaction with professional community care, the number of studies that addressed these topics for non-professional care were extremely limited. Therefore, the second study that is described here was not a 'follow-up study' by nature. In fact, the study could more appropriately be characterized as 'back to basics'. In a (longitudinal) 
study among care-dependent community residents, topics such as the use of care resources, continuity of care and client satisfaction were addressed for both professional and non-professional community care. Chapters 4 to 6 describe the results of this study with regard to correlates of the diversity of care, client satisfaction, and the course of client satisfaction scores. Again, an overview of the design, methods and results of this second study will be given below.

\subsection{Research model}

Several aspects of community care were dealt with in the two studies that are described in chapters 2 through 6 . The emphasis of these studies, however, was on the effects of coordination of care and on correlates of diversity of care and client satisfaction. A research model that incorporates both studies was derived from a more general organizational model. The concepts that refer to this general model are presented in the column on the right of figure 1.1. According to Alter and Hage's Conceptual Framework for Studying Interorganizational Networks (Alter \& Hage 1993) outcomes of inter-organizational cooperation (such as potential conflicts, effectiveness and quality) can be predicted by aspects of both network structure and operational process. The concept of structure refers to characteristics of the co-operational effort, such as size (numbers of organizations and persons involved), complexity, and task differentiation. The operational process refers to the actual process taking place, e.g. the actual degree of cooperation between participants. Structure and operational process are in turn influenced by external controls and technology. Among other things, technology can refer to the clients that care-givers encounter. In organizational terms, these clients might be referred to as 'inputs' or 'raw materials' (Scott 1975; Stanfield 1976). In the studies that are described here, other essential aspects of technology such as 'knowledge' and 'techniques' were not addressed. Therefore, the concept of technology was replaced by the more appropriate and more specific term 'client characteristics'. The proposition that client characteristics are essential to both the structure of care networks and the actual outcome was based on the model by Andersen and empirical evidence (see below).

Several theoretical insights were used to provide the operational concepts within the five dimensions of the conceptual framework (figure 1.1). Client satisfaction was used as the operational concept of 'outcome'. Two (groups of) explaining factors were derived from the Andersen Behavioral Model of Health Services (Andersen, Cravats \& Anderson 1975, Andersen 1995). It was proposed that client satisfaction is influenced by the structure concept 'diversity of care' and the client characteristics 'predisposing, enabling and need factors'. Furthermore, a relationship between predisposing, enabling and need factors and the structure concept 'diversity of care' was derived from the same model. 
Originally, Andersen developed his model to explain the use of medical and dental care services. In the 20 years of its existence however, the model has frequently been used to explain the use of several types of medical and nonmedical care (Coulton \& Frost 1982; Evashwick, Rowe, Diehr \& Branch 1984; Frederiks, Te Wierik, Van Rossum, Visser, Volovics \& Sturmans 1992).

Furthermore, Andersen himself extended the model to include the explanation of the outcome concept of 'client satisfaction' as well. Although the original model did not describe a direct relationship between predisposing, enabling and need factors and client satisfaction, it was proposed that this relationship could indeed exist. This proposition was based on the results of studies that identified relationships between client satisfaction and characteristics such as age (Hull \& Hull 1984; Weiss 1988), educational level

(Zastowny, Roghmann \& Kafferata 1989; Fitzpatrick 1991) and health (Linn, Linn \& Stein 1982; Weiss 1988; Hall \& Feldstein 1990). Though it is not difficult to identify studies that can be used to contradict these effects, and some of the studies even contradict the results of one or more other studies, there is at least some evidence of a possible direct relationship between client characteristics such as predisposing, enabling and need factors and the clients' satisfaction.

Apart from the diversity of care, a second operational concept of structure was derived from Litwak's task specifity model (Litwak 1985). According to Litwak's model, the use of professional and non-professional care is influenced by the nature of the specific tasks that need to be carried out. Litwak describes care-tasks according to dimensions for classifying care-tasks. One can, for instance, distinguish tasks that require continual proximity from tasks that allow for some (geographical) distance or make a distinction between tasks that require long term and tasks that require short-term commitment. The type of care-tasks involved might especially be relevant to whether the client will receive more professional or more non-professional care. This implies that the diversity of care does not only result from overall 'severity' or 'dependency', but that the exact nature of the care that is needed is at least equally important.

Continuity of care (Wall 1981; Rogers \& Curtis 1980) was used to represent the dimension of 'operational process'. Continuity of care was seen as a relevant factor in the explanation of client satisfaction. It was expected that client satisfaction would be higher when there was more continuity of care. Finally, the implementation of coordination of care, as described in the first two chapters, was indirectly aimed at improving client satisfaction and not so

12 much at improving efficiency in community care. It was expected that coordination of care could indirectly affect client satisfaction by its potential impact on the diversity and continuity of care. Since the coordination of care intervention was not a part of the regular care networks and could affect caregivers' status and autonomy, it could be seen as an operationalization of 'external control' factors within the conceptual framework (figure 1.1). 
Although professional and non-professional care were not separate concepts in the research model, the terms were used throughout the two studies (e.g. diversity of professional and non-professional care, satisfaction with professional and non-professional care). The terms refer to all professional and non-professional care that is received by community residents. This does not necessarily refer to persons who are commonly seen as community care workers. Care-givers who work in or for institutions, such as medical specialists or care providers at day care centers can also fit the description, as long as their clients are 'community based'. The difference between professionals and non-professionals is perhaps not as obvious as it seems. Where it is clear that physicians and community nurses are professionals, this is less obvious for home helpers and privately hired cleaning ladies. Since there is not one best solution for these problems of definition at hand, a choice was made to define professional community care as all medical or non-medical care that is: a) provided by persons who are trained, organized and/or paid for, and b) available to clients who live independently in the community. Non-professional community care on the other hand, was defined as all informal care by persons from the client's own social/informal network. This implies that family members, neighbours and friends are seen as non-professionals, while organized volunteers, privately hired cleaning ladies and home helpers can be classified as distinguishable categories of professionals along with physicians, community nurses and social workers.

An overview of the conceptual framework, the more operational concepts and the proposed relationships that were addressed in the two studies is given in figure 1.1. Related research questions for the two studies are given underneath. The different components of the model are discussed in the following sections.

\subsubsection{Client satisfaction}

Client satisfaction can be seen as an important aspect of quality of care, or as one goal of health care delivery (Linder-Pelz \& Streuning 1985). Quality of care and client satisfaction (or consumer satisfaction, or patient satisfaction) are sometimes even used as synonyms. This would imply that client satisfac. tion would cover every aspect of quality of care. However, it is reasonable to believe that some aspects of care cannot be evaluated by (every) client. Care or treatment that requires expert knowledge is one possible example of such care aspects. For this reason, the term 'client satisfaction' seems more appropriate here than 'quality of care'. As a term, 'client satisfaction' is not used as often as the term 'patient satisfaction' (Linder-Pelz 1982; Ware \& Davies 1988). This, however, can easily be explained by the fact that the term satisfaction is usually addressed in regard to medical care services. Since non-medical and non-professional care are addressed here, the more neutral 'client' is preferred over 'patient'. Linder-Pelz (1982) defines client satisfaction as positive evaluations of distinct dimensions of the (health) care. Ware et al. (1983) describe client satisfaction as personal evaluations of health care 


\section{Figure 1.1}

Research model.

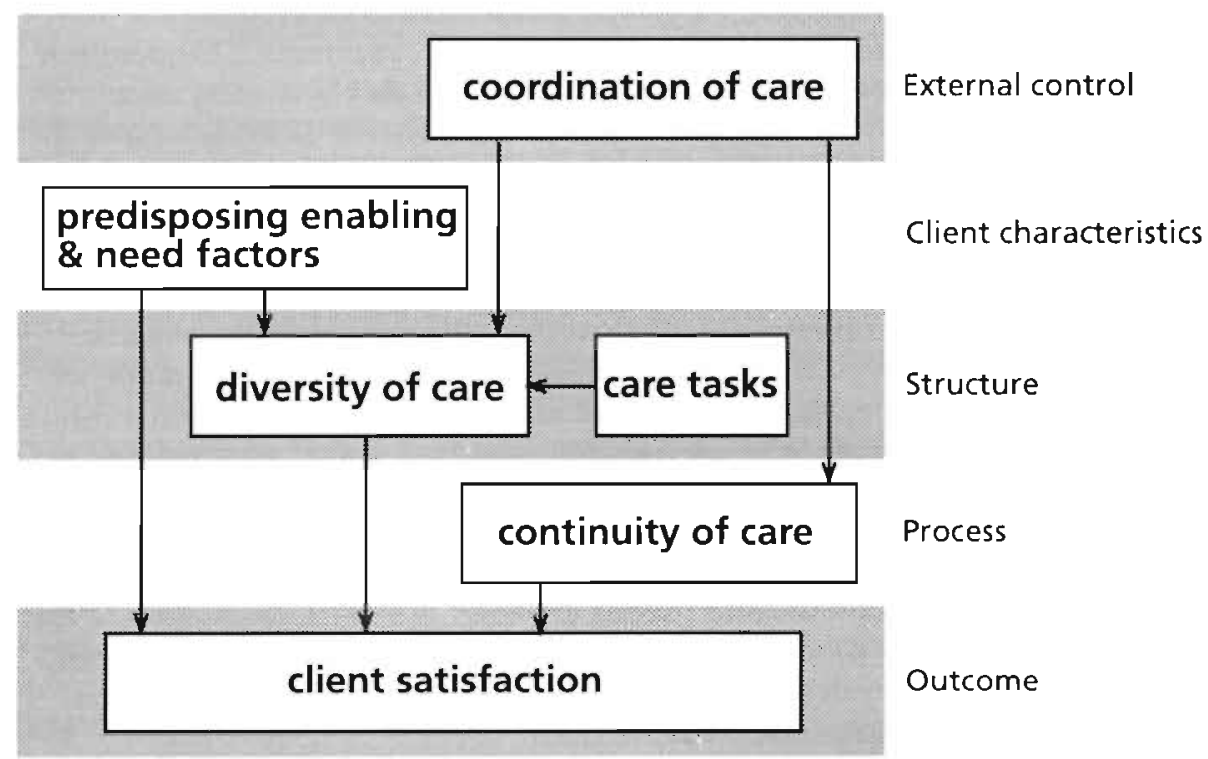

Research questions

Ia What problems occur during the implementation of coordination of care and how does coordinators' task performance relate to the original coordination of care model?

Ib In what way does the appointment of care-coordinators affect the interdisciplinary, interpersonal and informational continuity of care?

ic Does the appointment of care-coordinators affect clients' satisfaction with care?

Ila What is the diversity of professional and non-professional care used by care dependent persons in a general population?

$\mathrm{Ilb}$ Which predisposing, enabling and need factors and which care-tasks can be used to explain the total diversity of care?

Ik Which predisposing, enabling and need factors and which care-tasks can be used to explain the diversity of professional and non-professional care?

14 Ild How are professional and non-professional community care evaluated by clients in a population survey?

Ile Can predisposing factors, enabling factors, need factors, diversity of care and aspects of continuity of care be used to explain satisfaction with non-professional and professional community care?

Iff Can predisposing, enabling and need factors and can the diversity and continuity of care be used as predictors of deterioration or improvement in client satisfaction? 
services and providers. Both definitions refer to clients" evaluations of the care they receive. The basic difference between the two definitions is that where the one definition refers to 'positive evaluations', the other refers to evaluations in general (either positive or negative). Since negative evaluations can be as meaningful to the concept of client satisfaction as positive evaluations, our definition of client satisfaction was based on the second description. In the two studies that are presented here, client satisfaction refers to how clients evaluate professional and non-professional community care.

Various authors have addressed correlates of client satisfaction. In most of these studies however, client satisfaction refers to how clients evaluated professional, medical services. Furthermore, numerous operationalizations of the concept were used and results from longitudinal studies are not often reported. Among the potentially related factors with regard to client satisfaction that were identified in these studies are the client's sex (Ware, Davies-Avery \& Stewart 1978; Fox \& Storms 1981; Weiss 1988), age (Hull \& Hull 1984; Fox \& Storms 1981; Weiss 1988; Ware, Davies-Avery \& Stewart 1978), educational level (Fox \& Storms 1981; Zastowny, Roghmann \& Kafferata 1989; Fitzpatrick 1991; Ware, Davies-Avery \& Stewart 1978), health (Hall \& Feldstein 1990; Linn, Linn \& Stein 1982, Weiss 1988), quality of life (Roberts, Pascoe \& Attkisson 1983, Weiss 1988), diversity of care (Hull \& Hull 1984; Linn, Linn \& Stein 1982) and several aspects of continuity of care (Marquis, Davies \& Ware 1983; Weiss 1988; Pascoe 1983; Flynn 1985; Williams \& Calnan 1991; Gerace \& Sangster 1987; Fox \& Storms 1981).

\subsubsection{Use of care services / diversity of care}

In the original Andersen model (Andersen, Cravats \& Anderson 1975), the use of health services referred to the use of medical or dental care services. Over the years the model has been applied to practically every type of professional care. Here the 'use of health or care services' is extended even further, to include the use of non-professional services as well.

One can think of two possible approaches to determine the use of services. In the first approach one can simply count the numbers of persons that give care to a client within a certain period of time. The second approach is to count the number of care sources used, rather than counting the number of persons. According to the first approach, a client who receives care from a physician and a community nurse would have a "use of care services" that is similar to that of a client who receives care from two different community nurses. Following the second approach however, the first client (who receives care from both nurse and physician) would have a higher "use of care ser. vices". In general the second approach will do more justice to the reality of clients' use of care. Counting every person involved can to often be influenced by 'coincidence' such as shortage of staff or a temporary absence of care-givers. For this reason, the use of services was approached as the use of care sources. The term 'diversity of care' is therefore more accurate than 'use of health/care services' and will be used throughout the text. 
Need factors (health, impairment etc.) are often identified as the most important factors in the explanation of the use of health services (Coulton \& Frost 1982; Evashwick, Rowe, Diehr \& Branch 1984, Andersen 1995), while enabling and predisposing factors can also be relevant but have a more modest contribution to the explanation of the use of health services. In a Dutch study by Frederiks et al. (1992) functional status, household composition and the amount of informal care were the most important correlates of the use of professional home care services.

\subsubsection{Continuity of care}

When reading literature on 'continuity of care', one can easily become confused about the exact meaning of the concept. The term continuity in itself refers to: 1) logical sequence, cohesion or connection or 2) a continuous or connected whole (Collins 1986). The term 'continuity of care' seems be unclear with regard to the care involved and with regard to the precise aspects of that care. Continuity of care can for instance refer to continuity in a specific type of care such as the care or treatment provided by medical specialists, or to continuity in and between a much wider range of services such as community care in general. Furthermore, continuity can refer to specific aspects such as sameness of providers or locations (Ware, Snyder, Wright \& Davies 1984) or to activities that aim at providing tuned and well balanced care (Cox, Peeters-Niemantsverdriet, Philipsen, Neumann, Van Campen \& Huyer Abu-Saad 1994). Rogers and Curtis (1980) describe three types of continuity: 1) interdisciplinary continuity, the continuity in complex, multidisciplinary services; 2 ) interpersonal continuity, the quality and the endurance of relationships between clients and care providers and 3) informational continuity, the completeness of information available to and documented by caregivers. Whereas coordination of care is a care-giver strategy, continuity of care can be seen as a (outcome) criterion. Continuity of care refers to the degree to which professional and informal care is provided as a coordinated and uninterrupted sequence of activities in accordance with the experienced needs of the patient during the illness trajectory (Philipsen \& Stevens 1996). Continuity of care can be approached from both the client's and the caregiver's point of view. Both approaches were used; in study I care-givers supplied information on continuity of care, in study II the continuity of care was judged by clients.

\subsubsection{Coordination of care}

16 The concept of coordination of care is derived from the idea of 'case management' as it was first introduced in the USA (Intagliata 1982). This automatically restricts the scope of the concept to coordination in specific client situations. Actions that aim at improving the overall cooperation between care-givers (e.g. care-givers from different disciplines using similar assessment procedures) are therefore not within the scope of the concept. Coordination of care can be seen as a care-giver-strategy that aims at improving the continuity and quality of care (Philipsen \& Stevens 1996). 
Definitions of coordination of care usually refer to the provision of tailormade care for clients and/or the improvement of cooperation or fine tuning within the care network (Intagliata 1982; Austin \& O'Conner 1989; Weiss 1987; Alter \& Hage 1993). A Dutch study among experts showed that coordination is believed to serve many purposes such as consistent and tailor-made client care, more effective and efficient client care, promoting self care, and integrating formal and informal care (Scholte op Reimer 1993). Coordination of care is often implemented to serve one of two purposes. Several studies have aimed at increased efficiency and a reduction of costs in health care by means of coordination of care, some of them with success (Davies \& Challis 1986; Challis, Darton, Johnson, Stone \& Traske 1991; Koedoot, Hommel, Van der Horst \& Knipscheer 1992). Improving the quality of care is the second possible goal of coordination of care that was successfully met in some studie's (Carcagno, Wooldridge, Brown \& Kemper 1986; Rabiner 1992; Woissert, Matthews Cready \& Pawelak 1988; Surles, Blanch, Shern \& Donahue 1992). The intervention study that is described in chapters 2 and 3 aimed at improving client care, thus increasing client satisfaction (Van Achterberg \& Stevens 1994). It was hypothesized that client satisfaction might be increased by possible effects on the diversity of care and improvements in the continuity of care. Effects on diversity of care might result from the care-coordinators specific goal to provide tailor made care and to reduce the number of unmet needs. Improved continuity of care was thought to result from specific attention for the cooperation between care-givers and the tuning of care.

\subsubsection{Predisposing factors}

Andersen $(1975,1995)$ describes predisposing factors as factors that refer to the individuals predisposition to use (care) services. In other words, predisposing factors are factors that influence the client's likelihood to use care services. Andersen names demographic variables, social structure and health beliefs as the three types of predisposing factors. Demographic variables refer to operationalizations such as age and sex, that more or less represent biological imperatives. Social structure refers to status, the ability to cope with problems and commanding resources. Education, occupation and ethnic origin are examples of the social structure dimension. Finally, health beliefs stand for the person's knowledge of and values and attitudes towards health and health services. This third dimension of predisposing factors was not used in the studies presented here.

\subsubsection{Enabling factors}

Enabling factors refer to the ability to use services (Andersen. 1975, 1995). Enabling factors can either be personal or community resources. Enabling factors that can be seen as personal characteristics are income and type of health insurance. These client characteristics can account for the clients access to several types of professional care. Aspects of care services such as waiting and traveling times can be seen as community aspects that enable or disable the use of services. Where the given examples can be relevant to the 
ability to use professional services, they can hardly be expected to be important to the client's ability to use non-professional care. Whether or not clients have potential sources of non-professional care is a more relevant factor when extending the model to the use of non-professional care.

\subsubsection{Need factors}

Finally, need factors refer to conditions that determine the need for care. Need factors essentially refer to perceived need and not, for instance, to pathology. Andersen (1995) emphasizes that perceived need cannot be seen outside of its social context and that the client's social structure and health beliefs are relevant when interpreting the need for care. Health status, impairment and functioning are examples of factors that can affect the use of care services. Furthermore the client's worries about their health and whether or not clients think their health problems are important enough to seek help are factors that determine the need for care.

\subsubsection{Care-tasks}

The concept of 'care-tasks' was derived from the work of Litwak (1985). Litwak describes how different care-tasks can best be performed by different types of professional or non-professional care-givers. This 'task specifity' limits the possibility of sharing or dividing 'case loads'. The central argument in this perspective is that groups will most effectively handle those tasks that are consistent with their structure. Tasks that require a day to day contact or care-tasks that require a similar life style of care provider and care recipient can best be performed by spouses, family members who live nearby or neighbours. Tasks that require expert knowledge or supervision on the other hand, should be performed by professionals who received specific training. These insights imply that the type of care involved has consequences for the diversity of both professional and non-professional care. Therefore, the concept of 'care-tasks' was included in the study that looked at correlates of the diversity of care, that is described in chapter 4.

\subsubsection{Summary}

In this section the research model for the two studies that are presented in chapters 2 through 6 was described (figure 1.1). The Conceptual Framework for Studying Interorganizational Networks by Alter \& Hage (1993) was used as a framework for this model. The actual model within this framework was a combination of models or theoretical notions by Andersen (1995), Litwak

18 (1985) and Wall (1981). It was described how predisposing, enabling and need factors, diversity of care and continuity of care might affect client satisfaction. Furthermore, it was proposed that the diversity of care is influenced by the actual carr-tasks in a specific situation. Coordination of care, the intervention in the first study, was presented as an external control factor that might affect client satisfaction indirectly, through an effect on either the diversity or the continuity of care.

An overview of the two studies is given in sections 1.3 and 1.4. The operationalizations of the model's components are presented in figure 1.2. 


\section{Figure 1.2}

Operational model.

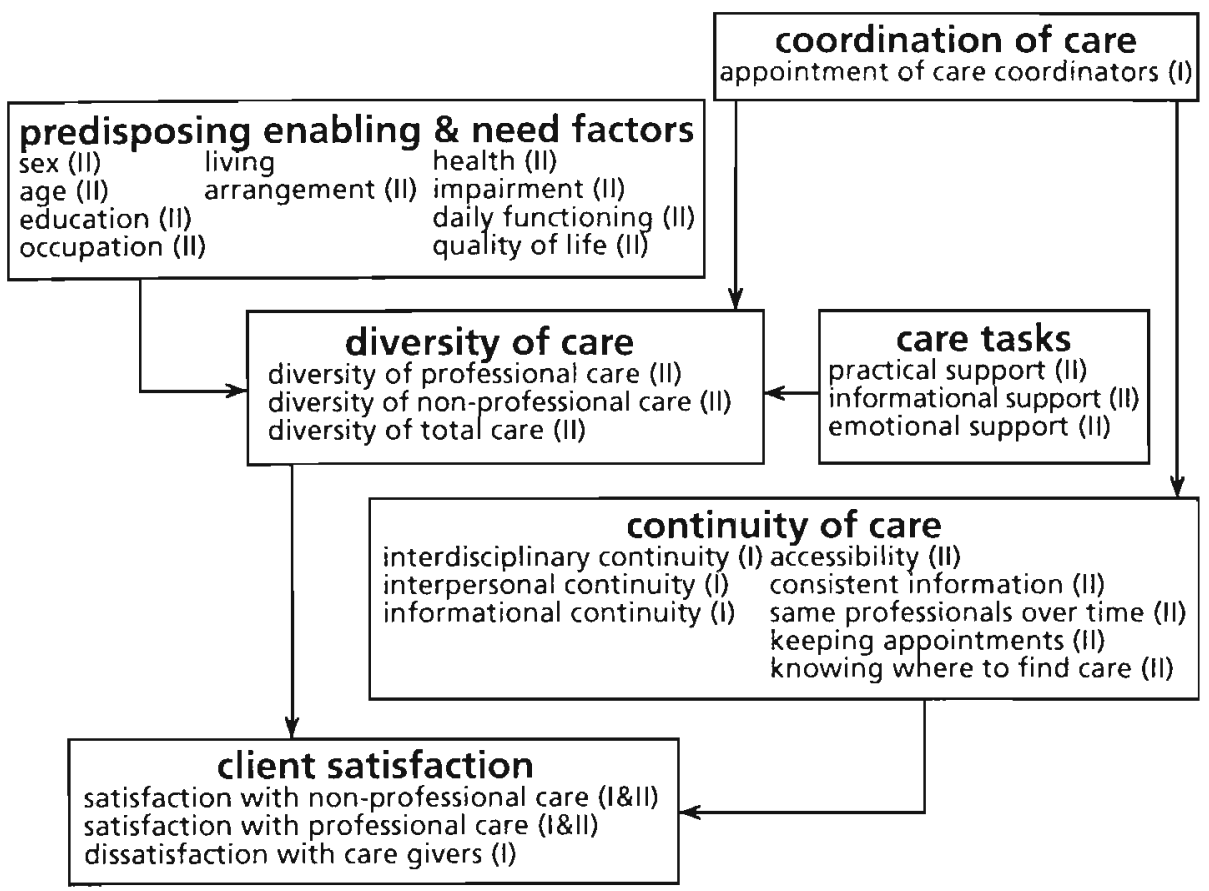

\subsection{Study I: Implementation and effects of coordination in community care}

Chapters 2 and 3 of this book describe the different phases of an intervention study that was performed from June 1990 until December 1993. The intervention study aimed at improving coordination of care in the community, by appointing community care-givers as coordinators for one or more clients. With this approach, one specific operationalization of coordination of care was chosen.

Interventions that aim at coordinating care can be ordered along several dimensions. First of all, interventions can either include the appointment of care-coordinators (case managers) or use other means to coordinate care. In those cases where no coordinator is appointed, introducing protocols or organizing regular consultations can be alternative ways of coordinating care (Fijn \& Velthausz 1992). These operationalizations of coordination of care were not within the scope of our study, since the concept of coordination of care was derived from the idea of case management. Coordination models that include the appointment of coordinators can be ordered along a second 
dimension. The appointment of coordinators can either refer to the introduction of a new task for existent care-givers (Van Achterberg \& Stevens 1994) or to the introduction of the care-coordinator as a new profession (PacandaBolier 1991, Van Amelsvoort, Dokter \& Willems 1992). Finally, a third dimension is that of coordination of care using client budgets (Davies \& Challis 1986, Koedoot, Hommel, Van der Horst \& Knipscheer 1991) versus coordination of care within the existing regulations of reimbursements for care services (Carcagno, Wooldridge, Brown \& Kemper 1986). Some effects of previous coordination of care studies are increased client satisfaction (Davies \& Challis 1986, Challis, Darton, Johnson, Stone \& Traske 1991), fewer unmet needs and more confidence in care-givers (Carcagno, Wooldridge, Brown \& Kemper 1986, Rabiner 1992, Weissert, Matthews Cready \& Pawelak 1988 , Surles, Blanch, Shern \& Donahue 1992), and substitution of institutional care by community care (Davies \& Challis 1986, Koedoot, Hommel, Van der Horst \& Knipscheer 1991).

The intervention in this study was less deviant from normal practice than other possible interventions. The intervention could be characterized as the creation or formalization of a (new) task for professional and non-professional community care-givers. One of the existing care providers was appointed as coordinator. The coordinator could not use additional budgets and had no formal authority .

It was expected that the intervention could affect clients' satisfaction with the care they received. This potential effect might indirectly result from improved continuity of care, since improving continuity in client care was one of the specific aims of the project. Furthermore, one might expect to find improved client satisfaction as a result of changes in the care they received.

\subsubsection{The intervention}

Care-givers who were already involved in the care for specific clients could be appointed as care-coordinators. Thus, the care-coordinator was never a new person to the clients. Potential coordinators could be both professional or non-professional community care-givers. Professionals who could be appointed as coordinators were family physicians, social workers, managers/intakers of the home-help agency and community nurses. Non-professionals who could function as coordinators were persons from the clients informal network such as partners, children, other relatives, neighbors and friends. All coordinators were instructed to perform five basic tasks. These tasks were derived from general principles of systematic working (Intagliata 1982, Moore 1990), and were very similar to those that were used in other coordination projects (Davies \& Challis 1986, Knapen \& Puts 1990) or even in individual disciplines such as nursing (Yura \& Walsh 1983). The tasks could be distinguished from those within separate disciplines however, by their focus on the total (professional or non-professional care) in specific client situations. The five coordinator tasks were (1) Introduction: coordinators were expected to make themselves known as the coordinator and to explain their 
new role and tasks to both the client and other care-givers; (2) Making a care-inventory: coordinators were supposed to make a list of all of the client's care demands and the care that was already available on a form that was devel-oped for this purpose; (3) Making a care-plan: a care-plan stating general goals and listing the contributions of individual care-givers had to be devel-oped along a care-plan form; (4) Execution of the care-plan and monitoring care: coordinators were expected to come to agreements with individual care-givers, while introducing a logbook that was a tool in monitoring the care that was actually received by clients; (5) Evaluation of the care-plan: coordinators were asked to compare the effects of the care that was provided to the care goals that were stated in the care-plan on a regular basis. Apart from the care-inventory form, the care-plan form and the logbook, coordinators were provided with coordinator guidelines in which the objectives of the project and the coordinators' tasks were introduced and explained.

Coordinators were instructed with regard to the tasks described and were provided with materials during instruction meetings, which were separately organized for professionals and non-professionals.

Instruction meetings were merely an introduction to and a clarification of the five coordinator tasks. No additional training with regard to potentially useful skills (developing goals, planning, negotiating) was provided. The logbook (introduced as a tool in monitoring care) was a somewhat pre-structured notebook. This book was placed in the client's house, while all care-givers were asked to record their visits to the patient and to give a summary of their findings or actions when potentially relevant to the work of others.

The professionals and non-professionals who functioned as coordinators were invited to attend follow-up meetings. During these meetings, experiences could be exchanged and potential problems could be discussed. Professionals had a greater need for follow-up meetings than non-professionals. Non-professionals attended 1 or 2 follow up meetings, whereas the number of followup meetings attended by professionals varied from 1 to 4 .

The choice for the relatively simple intervention (coordination of care within the already existing structures) was made for a number of reasons. Caregivers in the intervention regions indicated that a coordination model that would alter existing structures was not acceptable. Furthermore, the intervention was designed to include non-professionals (who have no formal position in community care) as potential care-coordinators. Finally, it was believed that the intervention should not add to the complexity of everyday care (e.g. by creating a new profession).

\subsubsection{Clients}

Eligible clients had to be 60 years of age or older, had to suffer from a chronic (somatic) disease, had to receive care from at least two professional or nonprofessional care-givers and had to live independently in the community. Clients were recruited in three rural-urban communities in the Dutch province of Limburg: Venray, Echt and Meerssen. Professional care-givers from the three communities were asked to select clients who met the selection cri- 
teria. This approach resulted in a list of 486 clients, all of whom received a short questionnaire by mail. This questionnaire was developed for the purpose of getting more insight into the selected client group and to provide a second check on whether or not the clients actually met the selection criteria. Only 234 persons (48\%) returned the questionnaire. A comparison of sex and age for those who did and those who did not return the questionnaire showed no differences in the mean age and the proportions of males and females in the two groups. Of the 234 clients who returned the questionnaire, $33 \mathrm{did}$ not want to participate in the rest of the study. In the secondary screening (using the same selection criteria) and after approaching the clients for participation in the project, another 93 clients dropped out of the project.

At the start of the intervention period, 108 clients participated in the first interview round. These clients were divided into two groups. A coordinator was appointed for clients in the first group $(n=65)$, while clients in the second group received only regular community care $(n=43)$. The two groups of clients were matched on age, sex and living arrangement. Clients were interviewed on three occasions: at the start of the project $(n=108)$, after six months $(n=87)$ and after twelve months of coordination of care $(n=72)$. Of the 72 clients who participated during the whole project, 44 had a coordinator (in 26 cases a professional, in 18 a non-professional), while no coordinator was appointed in the other 28 cases.

The group of 72 clients was used for the evaluation of the effects of the intervention.

The majority of the clients was female (71\%), while the mean age was 74 years of age. More than half of the clients lived alone $(56 \%)$. Among this group, the most common diseases were diseases of the heart (33\%), chronic back-pain $(28 \%)$, lung diseases $(21 \%)$, diabetes $(18 \%)$, rheumatic diseases $(18 \%)$ and hypertension (18\%). On average, 3.5 types of professional or nonprofessional care-givers were reported. Family physicians (83\%) and home helpers $(50 \%)$ were the most common professional care-givers, while family members (other than the partner) were the most commonly reported non-professional care-givers.

\subsubsection{Coordinators}

For the group of 65 clients, 22 non-professionals and 19 professionals were appointed as coordinators. Interviews with coordinators were held after 6 and after 12 months of coordination of care. At 6 months, 19 professionals and 19 non-professionals participated. The 3 non-professionals that were not inter-

22 viewed at 6 months, dropped out because their clients were no longer participating. After 12 months, 14 professionals and 15 informal care-givers were still participating. Of the 9 drop-outs after the first interview, 5 resulted from clients who no longer participated and 4 were a result of specific problems or circumstances of the coordinator (e.g. pregnancy or the death of a family member). The 19 professionals that were interviewed at 6 months were 7 managers of the home-help agency, 5 community nurses, 5 family physicians, and 2 social workers. The 19 non-professionals were 9 children (in 
law), 5 spouses, 3 neighbors or friends, and 2 relatives other than spouses or children.

\subsubsection{Sources of data}

Four different sources of data were used to study the implementation and the effects of coordination of care. Interviews with coordinators were used for both purposes. The coordinator interviews had an 'open' structure. Standard questions and answers were not used in these interviews. A selected number of topics were, however, always addressed in the interviews. These topics included contacts with clients and other care-givers, task performance, necessary knowledge and skills and positive or negative effects of the intervention. All coordinator interviews were tape-recorded, transcribed and read by three members of the research team. Content analyses (Krippendorff 1980) was performed, using the computer program 'Kwalitan' (Peters, Wester \& Ricardson 1989). During this procedure, the interviews were transformed into 302 'notes' that were classified along 19 categories. Examples of such categories are 'tasks, skills and conditions' (47 notes), 'effects' (44 notes), and 'relationships with clients, professional and non-professional care-givers' (42 notes).

Two sources of data were only used for the purpose of evaluating the implementation of coordination of care. Minutes from follow-up meetings with coordinators were kept by the project staff. One member of the research team analyzed all minutes in a way that resembled the analysis of coordinator interviews. The minutes were divided into 'notes' that were categorized under headings as 'problems', 'contacts with clients and care-givers', and 'effects'. The second source of data that was used for the evaluation of the implementation of coordination of care exclusively, were the logbooks and care-plans that were used by the coordinators. Not all logbooks and careplans were returned at the end of the project. The professional care-givers handed in 30 care-plans and logbooks $(71 \%)$, while a total of 18 plans and logbooks was returmed by non-professionals $(74 \%)$. Reasons for not returning the logbook were not always clear. It was suspected however, that the logbooks that were not handed in at the end of the project were those that were less used or maybe even lost, or those that contained information that either coordinators or their clients thought of as sensitive.

Care-plans and logbooks were analyzed by two members of the project's research staff. With regard to the care-plans it was checked if the plans had actually been used and whether or not the original plan had ever been adjusted. With regard to the logbooks, the length of usage, the numbers of notes and of persons making notes, and the types of persons who made notes were registered. Furthermore, content analysis was performed, categorizing the logbook notes under headings such as 'the client's condition', 'household activities', and 'medical treatment or the use of medication'. Finally, interviews with clients were used for the evaluation of the effects of the intervention. The prestructured client interviews addressed topics such as client satisfaction, the use of care services, health and health related charac- 
teristics and client characteristics such as age, sex, living arrangement and education. Only interviews with clients who participated at both the start and the end of the project were used for the purpose of evaluating the effects of coordination of care.

\subsubsection{The implementation of coordination of care}

The evaluation of the implementation of the appointment of care-coordinators focussed on problems that were encountered during the implementation process and on the task performance of coordinators as compared to the original task description.

Four problems often occurred during the implementation process. First of all, coordinators tended to conclude that their client's situation was not complex and more or less stable. Therefore, they sometimes felt that the appointment of a coordinator was an improvement, but not really necessary. These evaluations by coordinators were, however, somewhat contradicted by the result that appeared from the analysis of the clients' logbooks. The average numbers of different care-givers who made notes during the intervention period of one year was 16 , often due to the substitution of care-givers within the same discipline. It seemed that coordinators did not appraise the instability that could be caused by changes in care-givers, as long as the different disciplines involved remained basically the same.

A second problem was that most coordinators found it difficult to be recognized as the care-coordinator. Both clients and other care-givers primarily viewed the coordinators as care-givers (e.g. the nurse, the partner). The success of attempts to deal with this problem was limited. The problem recurred during follow-up meetings throughout the project.

A third topic that was often addressed by coordinators was a 'concern' rather than an actual problem. Coordinators felt that the clients' privacy needed extra attention in the process of coordination of care. The use of logbooks, the exchange of information with other care-givers and discussing client situations (anonymously!) during group meetings could result in more chances of violating privacy. The violation of privacy remained a potential problem. It was not a major problem in any of the cases.

The fourth problem that resulted from the intervention was a specific problem of the non-professionals who were appointed as coordinators. Some of the non-professionals had difficulties in combining the roles of care-giver, coordinator and parent to their own children.

24 This problem often existed before the start of the project, but became more problematic after the addition of the new role of coordinator. The task performance of coordinators was evaluated using the interviews with coordinators, minutes of follow-up meetings, and the used care-plans and logbooks. The results of this evaluation are summarized in table 1.1.

Both professionals and non-professionals did not always introduce themselves adequately. In fact, most of the problems with the introduction occurred between the two types of care-givers. Whereas professionals sometimes for- 


\section{Table 1.1}

Coordinators' task performance according to the five basic tasks.

NON-PROFESSIONALS

Introduction

Making a care-inventory

Making a care-plan

Execution and monitoring

Evaluation of the care-plan reasonable hesitant in contacting profs good

not always useful

not particularly useful tend to use implicit plans

PROFESSIONALS

reasonable tend to forget non-profs

useful exercise

good

reasonable

not particularly useful tend to use implicit plans

\begin{tabular}{|c|c|}
\hline $\begin{array}{r}\text { good } \\
\text { essence of coordination }\end{array}$ & $\begin{array}{r}\text { good } \\
\text { essence of coordination }\end{array}$ \\
\hline $\begin{array}{r}\text { poor } \\
\text { hardly any evaluation }\end{array}$ & $\begin{array}{r}\text { reasonable } \\
\text { some evaluation }\end{array}$ \\
\hline
\end{tabular}
(n) 
Therefore, it was concluded that non-professionals can certainly be seen as good candidates for the role of care-coordinator.

The intervention hardly affected client care. Only nine out of 38 coordinators thought that client care had improved as a result of the project. According to clients the diversity of care had not in- or decreased as a result of the study and only a short term effect on clients' satisfaction could be reported. More results were found with regard to continuity of care. Interpersonal continuity was especially affected by the appointment of coordinators. Therefore, it was concluded that the appointment of coordinators can be useful if one seeks to improve the continuity of care. If one aims at improving client satisfaction, other interventions can be more appropriate.

\subsection{Study II: Explaining diversity of care, client satisfaction and the course of client satisfaction in a population of care-dependent adults}

The second study was more basic in nature than its predecessor. In the first study, an intervention was based on a research model. In turn, the essence of this model was based on the ideas and perspectives of Andersen $(1975,1995)$ and Ware (1978). In the model, relationships between coordination of care, diversity of care, continuity of care and clicnt satisfaction were addressed. The intervention study showed that coordination of care had some effects on the continuity of care. However, none or hardly any effects could be reported with regard to the diversity of care and client's satisfaction with the care they received. Therefore, it was an obvious choice to pursue the questions of which factors -if not coordination of care- could be used to explain the diversity of care, client satisfaction and the course of satisfaction scores. These questions were addressed in a community survey among care-dependent adults. Potential correlates of diversity of care were derived from the original research model.

\subsubsection{Selection of care-dependent adults}

Care-dependent adults were selected by means of a telephone survey in the rural-urban community of Tegelen $(+19,000$ inhabitants), The Netherlands. A team of trained interviewers contacted 1932 randomly selected households. To enhance the response rates, the study was previously announced in two local newspapers and on two local radio stations. If the first attempt at reaching a household was not successful, new attempts were made until one of the members of the household was reached. New appointments were made with those respondents who were caught at an inconvenient moment. The survey was carried out between $9 \mathrm{a} . \mathrm{m}$. and 9 p.m. on 13 successive working days. A total of 1406 households (73\%) participated in the survey. Language problems occurred in $2 \%$ of the cases ( $n=36$ ), while the remaining $25 \%$ $(n=490)$ did not participate due to either a lack of time, or a lack of interest. 
Whenever the person on the phone was willing to participate, the interviewer asked if the person him- or herself or one of the other members of the household was care-dependent. If the care-dependent person was not the initial respondent, it was asked if this person could come to the phone. Care dependency was explained as not being able to function without care. Furthermore, it was illustrated that care dependency could result from both physical and mental health problems and that care could refer to both professional and non-professional care services.

A care-dependent person was part of the household in 190 cases (14\%). When adulthood (18 years of age or older) was used as a selection criteria, the number of cases was somewhat reduced to 177 (13\% of the households). After a period of eight months, all 177 care-dependent adults were approached for the second time. This second interview round was conducted to study the predictors of the course of clients' satisfaction scores (chapter 6). A total of 134 care-dependent adults (76\%) participated in both interview rounds. Of the remaining 43 clients, 10 were never reached, 10 moved to an institution, 5 were deceased, 5 were no longer care-dependent, 3 were unable to participate due to ill health and 10 refused any further cooperation.

The group of clients who were interviewed on the first occasion had a mean age of 64 years, about two thirds of the groups were female. Nearly half of the subjects lived alone. Half of the group had only attended primary school and $40 \%$ had a lower occupational level. The most commonly reported types of diseases were diseases of the eye, ear or organ of balance $(27 \%)$, cardiovascular diseases $(26 \%)$, bone or joint diseases $(25 \%)$, chronic back pain $(12 \%)$, lung diseases $(10 \%)$, diseases of the digestive system $(10 \%)$, psychiatric disorders $(9 \%)$ and trauma resulting from accidents $(6 \%)$. Practical support was received by $80 \%$ of the sample, $70 \%$ received emotional support and $70 \%$ reported informational support.

Respondents who dropped out after the first interview were older and had lower professional levels than those who participated in both interview rounds. No differences between the two groups were found with regard to the health or care related variables.

\subsubsection{Questionnaire}

An identical, prestructured questionnaire was used for both the interview at baseline and after eight months. Both interviews were telephone interviews. Topics that were addressed in the questionnaire could be categorized under the headings of predisposing, enabling and need variables, care-tasks, diversity of care, continuity of care and client satisfaction. Predisposing variables were the client's sex, age, educational level and occupational level. The client's living arrangement was the only enabling variable. It was thought that this factor was especially enabling with regard to the use of non-professional care services. Need variables were one-item measures for perceived health and impairment, a sixteen item scale for (Instrumental) Activities of Daily Living and a three-item scale for quality of life. 
'Care-tasks' was operationalized as receiving practical support, informational support, emotional support or any combination of the three. Diversity of care was estimated by counting the different types of professional and non-professional care-givers involved. The number of types of care-givers was estimated for professional, non-professional and total care. Continuity of care was addressed using five aspects of continuity: accessibility of care-givers, caregivers keeping appointments, same professionals over time, consistent information and knowing where to find care. The aspects of care-givers keeping appointments and accessibility were addressed for all care-givers. The aspect 'same professionals over time' was obviously addressed for professional caregivers only, while the aspects of consistent information and knowing where to find care were 'overall' items. Finally, client satisfaction was operationalized using a six-item scale, including the items: sincere interest, sufficient time, friendliness, health related information, care related information and the quality of care services. The six items were addressed for all professional and non-professional care-givers involved. From this, satisfaction scores with regard to specific care-givers, and satisfaction scores with regard to professional, non-professional and total care were derived. In all cases the results for client satisfaction were recoded as 0 (one or more complaints) or 1 (completely satisfied). This implies that four groups could be constructed for the analyses with regard to the course of client satisfaction scores: (1) stable positive scores, (2) stable negative scores, (3) improved satisfaction and (4) deterioration in satisfaction. Correlates of deteriorations or improvements in client satisfaction were identified by comparing these groups.

Relationships between the potential correlates are presented in the appendix.

\subsubsection{Diversity of care}

Only $6 \%$ of the sample did not receive any professional care, while only $4 \%$ did not receive non-professional care. This implies that almost all respondents received both professional and non-professional care. On average the respondents received care from 4.8 types of care-givers, 2.1 types of non-professionals and 2.7 types of professional care-givers. More than half of the care-dependent adults received care from family physicians (76\%), children $(66 \%)$ and medical specialists $(62 \%)$, while nearly half of the respondents reported care from neighbours or friends (48\%) and partners (46\%). Other care-givers that were often involved were home helpers $(35 \%)$, physiotherapists $(28 \%)$, privately hired cleaning ladies (20\%), community nurses $(16 \%)$, parents $(12 \%)$ and family members other than the above mentioned $(35 \%)$.

30 When interpreting the figures on care provided by parents and partners, one should note many respondents did not have parents that could provide care (mean age was 64) and that half of the clients lived alone. This implies that nearly all partners were in fact care-givers.

\subsubsection{Correlates of diversity of care}

$T$-tests, correlation coefficients and regression analyses were used to identify correlates of total, non-professional and professional care. In this summary of 
the results, the most important correlates (as identified by the use of a regression analysis) are reported. Factors related to the diversity of total, professional and non-professional care are summarized in table 1.3

A total of $21 \%$ of the variance in the diversity of total care could be explained by the (need) factors daily functioning and quality of life, and the care-tasks emotional support and informational support. The diversity of total care was higher when respondents were more impaired in their daily functioning. The effect for quality of life was somewhat deviant: diversity of care was higher when the client's quality of life was relatively high. Furthermore, diversity of care was higher for clients who received emotional support and for clients who received informational support.

Five factors explained $34 \%$ of the variance in the diversity of non-professional care. Age, living arrangement, quality of life, emotional support and the diversity of profes sional care were the most important correlates with regard to the diversity of non professional care. More diversity was found for respondents who were younger, who shared a household with others, who had a higher quality of life, who received emotional support and who reported a higher diversity of professional care.

\section{Table 1.3}

Correlates of the diversity of total, non-professional and professional care ( $n=177)$.

$\begin{array}{lll}\text { TOtAl CARE NON-PROF ProF } & \text { No }\end{array}$

Being older

Living alone

Daily functioning

Lower quality of life

Practical support

Emotional support

Informational support

Diversity of non-prof care

Diversity of prof care

$\begin{array}{lll} & - & - \\ - & - & - \\ - & - & + \\ + & + & + \\ + & & +\end{array}$

+/ - positive / negative relationship, $p \leq .05$

A higher diversity of professional care was found for respondents who shared a household with others, those with more impairments in daily functioning, respondents who received practical and informational support and those who reported a higher diversity of non-professional care. A total of $25 \%$ of the variance in the diversity of professional care could be explained using these factors. 


\subsubsection{Client satisfaction}

On the whole, clients tended to be satisfied with the professional and nonprofessional care they received. Satisfaction was somewhat higher for the care that was provided by non-professionals. A total of $59 \%$ of the clients had no complaints regarding non-professional care. The percentage of clients who were completely satisfied with the professional care they received was $47 \%$. For both professionals and non-professionals, the highest number of complaints was reported for the aspect 'quality of services'. Within the group of non-professionals, the care provided by neighbours, friends and more distant relatives was more positively evaluated than the care that was provided by closer relatives. When looking at differences between specific professionals, it was found that hardly any complaints were uttered with regard to the care provided by community nurses, while the number of complaints that referred to medical specialists was relatively high. Clients' satisfaction with professional care and clients' satisfaction with non-professional care were not interrelated. Clients' satisfaction scores were less stable than one might expect. A comparison of satisfied (no complaints) and dissatisfied (any number of complaints) care-dependent adults on both occasions showed that $65 \%$ of the clients was stable in their satisfaction with non-professionals and $56 \%$ showed stable scores for satisfaction with professional care. When looking at non-professional care, $30 \%$ of those who were dissatisfied at first were satisfied eight months later, while $34 \%$ of the clients who were satisfied at first became dissatisfied during the same period. For professional care, $48 \%$ of those who started out as dissatisfied ended up being satisfied, while $38 \%$ of those who were satisfied at first became dissatisfied.

\subsubsection{Correlates of client satisfaction}

Correlates of client satisfaction were addressed for professional and non-professional care on the whole, as well as for six specific care-givers. These were the six most commonly reported care-givers: partners, children, neighbours and friends, family physicians, home helpers and medical specialists. Chisquare tests, T-tests and logistic regression analyses were used to identify correlates of client satisfaction scores. The results of the final regression analyses are summarized in table 1.4. In general, aspects of continuity of care were the most relevant factors in the explanation of client satisfaction, but the relevance of the different aspects varied with the type of care-giver involved. Satisfaction with both professional and non-professional care was higher when care-givers kept their appointments, The satisfaction with professional care was higher if respondents reported that they knew 'where to find care'. Furthermore, the aspects 'knowing where to find care', accessibility' and 'care-givers keeping appointments' were relevant to the care provided by medical specialists, children and partners respectively.

With regard to the other factors, it should be noted that the clients' educational level was an important factor in the explanation of clients' satisfaction with non-professional care on the whole and the care provided by neighbours and friends in particular. As was found in several other studies, respondents 
with lower educational levels tended to be more satisfied (Fox \& Storms 1981; Zastowny, Roghmann \& Kafferata 1989; Fitzpatrick 1991).

\section{Table 1.4}

Correlates of clients' satisfaction with the care provided by partners, children neighbours and friends, family physicians, home helpers, medical specialists and professional and non-professional care on the whole $(n=177)$.

\begin{tabular}{|c|c|c|c|c|c|c|}
\hline & & $\mathrm{NEIGH-}$ & & & & \\
\hline RT- & & BOUR & FAM & HOME & MED & NON \\
\hline$N \in R$ & CHILD & FRIEND & PHYS & HELPER & SPEC & PROF \\
\hline
\end{tabular}

Female

Educational level

Perceived health

Perceived impairment

Quality of life

Diversity non-prof care

Diversity professional care

Accessibility

Keeping appointments

Same professionals over time

Knowing where to find care
(-)

$(+)$

(+)

$+$

$\begin{array}{rrr}+ & (+) & \\ +\quad(+) & (+) \\ & (+) \\ & (+)\end{array}$

$(-)$

$+$

(+)

(t)

$+1$

$+$

(t)
$+$

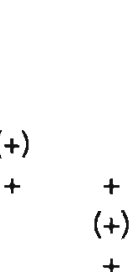

$+/$ - positive / negative relationship $p \leq .05 ;$ () trend $p \leq .10$

\subsubsection{Predictors of the course of client satisfaction}

Predictors of the course of clients' satisfaction scores were studied by a) comparing respondents whose satisfaction had deteriorated with respondents with stable positive scores, and by b) comparing respondents whose scores had improved with respondents with stable negative scores. This procedure was followed for the course of client satisfaction with both professional and non-professional care services. Differences between the groups of respondents were estimated using T-tests and Chi-square tests, dependent on the type of independent variable. The results of these comparisons are summarized in table 1.5. Changes in the diversity of care and changes related to several aspects of continuity of care appeared to be the best predictors of developments in client satisfaction. Of the other factors, only quality of life at base-line, impairment at base-line and the developments in impairment were relevant to the course of satisfaction scores. In general, an increase in the diversity of care occurred went along with more deterioration and less improvement in client satisfaction. Furthermore, positive developments in con- 
tinuity of care occurred along with less deterioration and more improvement in satisfaction scores.

\section{Table 1.5}

Predictors of the course of client satisfaction with professional and non-professional care.

\begin{tabular}{crrr}
\multicolumn{2}{c}{ DETERIORATION } & \multicolumn{2}{c}{ IMPROVEMENT } \\
SATISF & SATISF & SATISF & SATISF \\
NON-PROF & PROF, & NON-PROF & PROF
\end{tabular}

Impairment $\mathrm{t} 1$

Impairment t2-t1

Quality of life $\mathrm{t} 1$

Diversity of non-prof care $\mathrm{t} 2$ - $\mathrm{t} 1$

Diversity of prof care $\mathrm{t} 2 \mathrm{-t} 1$

Non-profs accessible t $2 / t 1$

Profs accessible $t 2 / \mathrm{t} 1$

Non-profs keep appointments t $2 / \mathrm{t} 1$

Same profs over time $\mathrm{t} 2 / \mathrm{t} 1$

Consistent information $\mathrm{t} 1$

Consistent information $\mathrm{t} 2 / \mathrm{t} 1$

Knowing where to find care $t 2 / t 1$

$(+)$

$(-)$

$+$

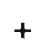

$+$

$+$

$+$

$(-)$

$+$

$(+)$

$+/$ - positive/negative relationship, $p \leq .05 ;()$ trend, $p \leq .10$

\subsubsection{Conclusions}

For the purpose of identifying correlates of the diversity of care, client satisfaction and the course of client satisfaction, a population survey was carried out in the Dutch community of Tegelen. Response rates for this survey were satisfactory $(73 \%)$. A care-dependent adult was identified within $13 \%$ of the household. This percentage seems to be in line with figures from other Dutch studies (De Boer, Hessing-Wagner, Mootz \& Schoemakers-Salkinoja 1994, Tjadens \& Woldringh 1989). After eight months, $76 \%$ of the sample was inter-

34 viewed for the second time. Respondents who dropped out during the eight months period were relatively old and had lower professional levels. There were, however, no differences with regard to client satisfaction, the diversity of care or any other potentially related factors.

Within the sample the diversity of professional and non-professional care was quite high. Clients received care from five types of care-givers on average and nearly all clients received both professional and non-professional care services. 
In general, clients were satisfied with the care they received. Nearly half of the clients was completely satisfied with the services from professional caregivers and more than half of the clients was satisfied with the non-pro-

fessional care they received. Nevertheless, the proportion of clients with complaints was not to be neglected and the fact that satisfaction with professional care was not related to satisfaction with non-professional care implied that clients did not give desirable answers without meaning.

The Andersen model was useful in the explanation of some variance in diversity of care. The clients' daily functioning and living arrangement could be used to explain some of the variance in the diversity of professional care. Age and iving arrangement could be used in the explanation of the diversity of professional care. The factors that were derived from litwak's task specifity model however, were at least as important as the factors that were derived form the Andersen model. While emotional support was relevant to the diversity in non-professional care, practical and informational support could be used to explain the variance in the diversity of professional care. These findings are supportive of Litwak's hypothesis that different groups are equipped to perform different tasks, rather than sharing case-loads. The idea that sufficient non-professional care might make professional care superfluous, was not supported. The diversities of professional and non-professional care were positively related, indicating that a high diversity of non-professional care occurred along with a high diversity of professional care, rather than the other way around.

The predisposing, enabling and need factors and the diversity of care, from Andersen's model, were of limited importance in the explanation of clients' satisfaction with professional and non-professional care. Although some of these factors (especially educational level) were identified as correlates of satisfaction, aspects of continuity of care were clearly the most relevant factors with regard to client satisfaction. In general, clients were more often satisfied when continuity of care was high. The continuity aspects that were the most relevant to client satisfaction varied with the type of care-giver involved. It appeared that satisfaction scores for specific care-givers, professionals and non-professionals had some correlates in common, but had some unique variation as well.

Results were somewhat different for the course of client satisfaction scores. Here, quality of life and impairment were related to the course of satisfaction scores. Furthermore, developments in the diversity and continuity of care were good predictors of the course of the client's satisfaction with care services. In general, less diversity and more continuity of care occurred along with less deterioration and more improvement in client satisfaction. 


\subsection{Discussion}

The studies that are described in chapters 2 through 6 , and that were summarized in this chapter, addressed some important aspects of community care The first study focussed on the implementation and the effects of coordination of care. The second study dealt with quite a number of topics. First of all diversity of care and the level of satisfaction in a general population were addressed. Furthermore, the study dealt with correlates of diversity of care, 'lient satisfaction and the course of clients' satisfaction scores. In this paragraph limitations of the studies will be addressed, conclusions with regard to the research model shall be drawn and implications of the studies will be discussed.

\subsubsection{Limitations}

An unintended selection of clients, non-professionals and family physicians was a problem in the first study. With regard to the clients no concrete evidence of selection was found, but the high numbers of clients who dropped out in several phases of the project imply that some selection bias probably took place. Furthermore, non-professionals and family physicians were quite likely a selection of those who were relatively more motivated. The first study was further hindered by the relatively small numbers of clients and coordinators who participated in the study. The strength of the study, however, was the use of four different sources of data. The coordinators' views on the implementation of coordination of care could be compared to the actual use of project. materials and effects according to clients and effects according to courdinators could be compared to some extent. The use of four different sources of information, the use of repeated measures and the use of both qualitative and quantitative methods offered a good deal of insight into the implementation and effects of coordination of care.

Selection bias and small numbers of clients were not a problem in the second study. The numbers of clients who agreed to participate in the study were certainly acceptable and the proportions of care-dependent adults were comparable to those in other studies. A major limitation of this study however, is that not all potentially relevant factors could be addressed. Potentially relevant factors such as clients' values and expectations (Linder-Pelz 1982) and relationships between clients and care providers (Weiss 1988) were not included in the study. This implies that conclusions with regard to the relevance of these factors as compared to the relevance of correlates that were

36 identified in this study cannot be drawn.

Limitations also result from the operationalization of diversity of care that was used in study II. The operationalization can be characterized as 'counting sourres uf cire'. Frequency of contacts and the number of care-givers within each 'source' (e.g. the number of neighbors) were not recurded. It is possible this operationalization of the concept has influenced the results. The potential prohlem of social desirability is a problem that was not clearly identified in cither of the studies. At the same time however, social desirability of answers 
could not be excluded completely. In the first study (implementation and effects of coordination of care) one might suspect that both coordinators and clients could have given desirable answers. The results that were derived from client interviews however, make the possibility of desirable answers less likely. Only a short term (and relatively small) effect on dissatisfaction with care-givers was found, whereas the general satisfaction with professional and non-professional care-givers was not affected. Clients' satisfaction scores were high at baseline and remained high throughout the project, a phenomenon that is often reported in other studies (Fox \& Storms 1981, Pascoe 1983). Therefore, it can be concluded that if clients gave desirable answers, these were direcled towards the care they received and not so much towards the effects of the intervention. An attempt was made to prevent the possibility of coordinators giving desirable answers. Interviews with coordinators had an open structure and questions were formulated as neutral as possible. The question of effects would be addressed as 'Do you feel that the intervention had any effects?', rather than 'Which effects did you experience?' or 'Did coordination of care improve the continuity of care?'. Nevertheless, it should be noted that conclusions with regard to the intervention's effects on the continuity of care were based on reports by coordinators themselves. Therefore, the possibility of information-bias can not be excluded.

In the second study - a population survey- high scores for client satisfaction were found as well. Nevertheless, two factors made the possibility of desirable answers less likely. First of all, the proportions of clients who had cornplaints about the care they received were not to be neglected, and showed some variation over specific care aspects and specific care-givers. Secondly, the fact that satisfaction scores for professional and non-professional care were not interrelated implied that clients did not give meaningless positive answers, regardiess of the cquestions asked.

\subsubsection{Conclusions}

Seven (causal) relationships were proposed in the research model for the two studies. Resuls for these relationships will be discussed below. A summary of the results is given in figure 1.3 .

Effects of coordination of care - It was presumed that systematic coordination of care might have two effects on client care. Coordination of care could affect he diversity of care as a result of coordinators attempts to provide tailor-made care for clients. Furthermore, coordination of care was aimed at. tuned and coherent care for clients or rather, improved continuity of care. The relationship between coordination of care and diversity of care was not

identified in study 1 . During the intervention year, the appointment of carecoordinators did not affect the diversity of care that was available to chents. It would go too far to conclude that coordination of care and diversity of care are not related. In lact, some studies indicated otherwise (Carcagno et al. 1986). Alhough we have lithe knowledge of the implementation of other coordination of care interventions, it was found that the implementation of the intervention in this study was not complete. Not all coordinator tasks 
were carried out to the same extent. Furthermore, the intervention itself was less deviant from standard commun-ity care than most other interventions. It cannot be excluded that the lack of effects on the diversity of care resulted from the nature of the intervention and the incompleteness of its implementation. Whether or not coordination of care affects diversity of care remains unclear. The other potential effect of coordination of care -improved continuity of care- was clearly identified. Results from interviews with care-coordinators showed that the intervention affected the continuity of care, particularly interpersonal continuity. It can be concluded that improving continuity of care is a realistic goal, even if coordination of care does not involve client budgets or formal authority of coordinators.

\section{Figure 1.3}

Summary of the findings.

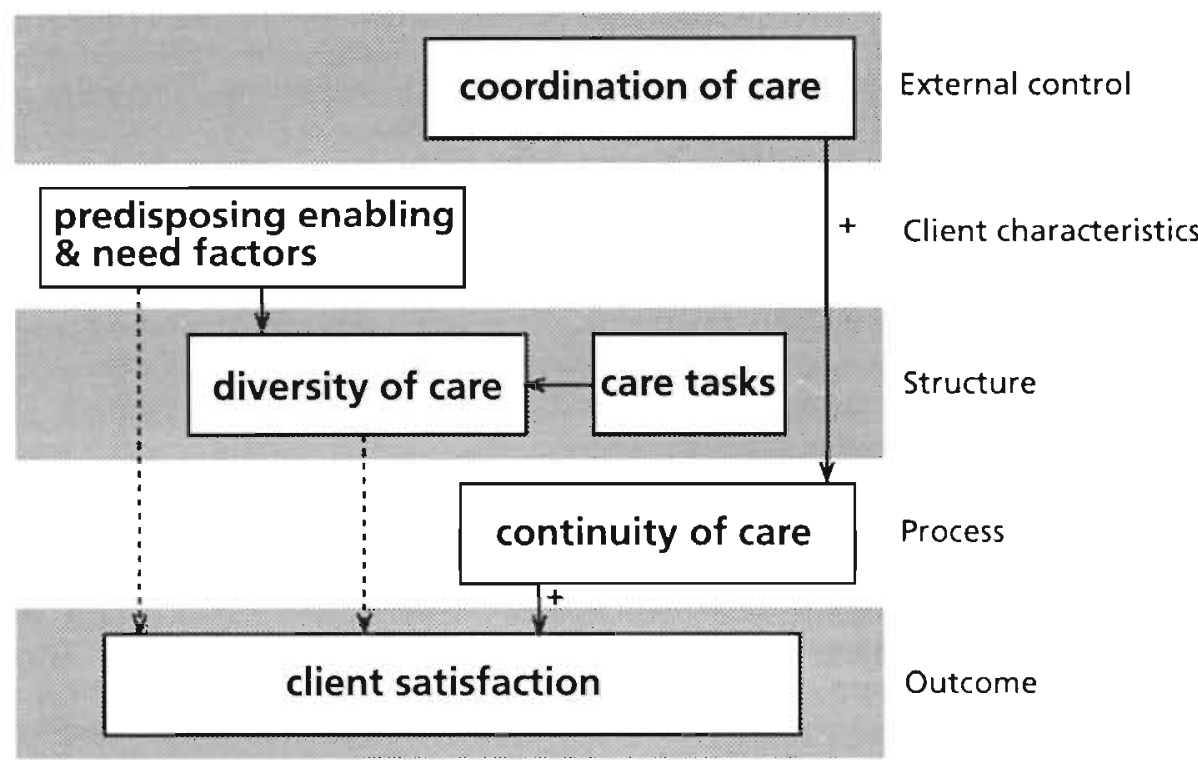

Care-tasks and diversity of care - The supposed relationship between caretasks and diversity of care was de-rived from Litwak's task specifity model (Litwak 1985). Following Litwak's ideas, one might expect to find aifferences in the diversity of care resulting from the care-tasks involved. Furthermore, one would expect to find that the diversity of professional care and the diversity of non-professional care were related to the presence of different caretasks. 
The operationalization of care-tasks was somewhat limited. Only 'general' care-tasks that could apply to all care-givers involved (practical support, emotional support and informational support) were addiressed. Tasks that are specific for the work of one or more care-givers (such as medical treatment or nursing interventions) were not addressed. Nevertheless, the relevance of care-tasks when explaining the diversity of care was indeed identified. The care-tasks 'emotional support' and 'informational support' could be used in the explanation of the diversity of total care. Furthermore, emotional support could be used to explain the diversity of non-professional care, whereas practical and informational support were valuable to the explanation of the diversity of professional care. It can be concluded that the hypothesis that different care-tasks require different types of care providers is probably true. Therefore, adding the type of care involved enriches a model that aims at explaining the diversity of community care.

Predisposing, enabling \& need factors and diversity of care - Other determinants of the diversity of care were derived from Andersen's Behavioral Model of Health Services $(1975,1995)$. Andersen proposes that predisposing, enabling and need factors will determine the use of health care services. The relationship between these three groups of factors and the diversity of care was indeed identified in the study that was presented here. Age, living arrangement and daily functioning were some of the factors that were relevant to the explanation of the diversity of total, professional and/or non-professional care. This implies that the Andersen model is valuable to the explanation of the diversity of care, even if the type of care involved is already taken into account.

Diversity of care and client satisfaction - A second relationship that was derived from the Andersen model is the relationship between diversity of care and client satisfaction. Andersen proposes that the use of (health) care services will eventually affect the client's satisfaction with the care provided. Only limited support for this hypothesis was found in the cross sectional study. Diversity of care was an important factor in the explanation of clients' satisfaction with the care provided by partners. Diversity of care was related to, but not important when explaining client satisfaction with regard to the care provided by neighbours and friends, home helps, and non-professionals in general. No relationship was found for client satisfaction with regard to professionals in general and children, family phys-icians and medical specialists in particular. In the longitudinal study however, improvement or deterioration in client satisfaction was significantly related to changes in the diversity of care. The results imply that the relationship between diversity of care and client satisfaction is very much dependent of the type of care involved. While the diversity of care is only weakly related to current diversity of care, changes in the diversity of care are significant predictors of changes in client satisfaction.

Predisposing, enabling \& need factors and client satisfaction - One relationship that is proposed in the research model was not part of the original model by Andersen. Whereas Andersen supposes that predisposing enabling 
and need factors can have an indirect effect on client satisfaction (through their effects on the diversity of care), it was expected that some of these factors could also directly be related to client satisfaction. This idea was based on the results of studies that reported relationships between client satisfaction and some of these factors such as age (e.g. Hull \& Hull 1984; Fox \& Storms 1981), education (e.g. Ware 1978; Fox \& Storms 1981) and health (e.g. Linn, Linn \& Stein 1982; Hall \& Feldstein 1990). Only one of these factors was really important in the explanation of client satisfaction. The clients' educational level was related to their satisfaction with the care provided by neighbours and frisends and to client satisfaction with professional and nonprofossional care. In general, clients with lower educational levels were more often satisfied with the care they received. The need factor perceived impairment was a significant factor in the explanation of clients' satisfaction with the care provided by medical specialists. Clients who reported more impairment were more often satisfied with the care they received. Other predisposing enabling and need factors were not or less important in the explanation of client satisfaction in the cross sectional study. In the longitudinal study, only two of the original need factors were related to changes in client satisfaction. Results for the need factor 'impairment' however, were inconsistent. The other factor, quality of life, should not be treated as a need factor. Results for diversity of care indicated that quality of life could rather be seen as an enabling factor, than as a need factor. A higher quality of life might enable clients to seek help and mobilize care-givers. Therefore one cannot state that predisposing, enabling and need factors are relevant to the explanation of client satisfaction. This appears to be true only for the client's educational level and to a lesser extent for perceived impairment. In should be noted, however, that the modest results for need factor might be due to the homogeneity of the research group in study II. All clients in this group were selected on 'care dependency'. This implies that the population was restricted to clients with more serious health problems. Need factors might be more relevant when studying a population with more variation in need factors.

Continuity of care and client satisfaction - Finally, it was expected that more continuity of care would have positive effects on client satisfaction. From the results of study II, it became clear that continuity and client satisfaction were related as expected. A positive relation between the two concepts was found. Although the relevance of different aspects of continuity of care could vary with the type of care involved, conti-nuity of care was important to both the current levels of client satisfaction and the course of clients'

40 satisfaction scores. Furthermore, continuity aspects were the most important correlates of both the actual level of client satisfaction and developments in client satisfaction over time.

\subsubsection{Implications}

Several implications for community care practice follow from the results of this study. First of all, the implementation of coordination of care in study I was not successful in all respects. Since other studies hardly describe the 
process of implementing coordination of care, it is not possible to compare these results to those of others. The coordinators who were selected for the intervention study were to some extent a selection of those who were relatively more motivated. Therefore, it is likely that the problems in the implementation of coordination of care would at least equally apply to community care-givers in general. This means that implementing coordination of care requires a good deal of attention for the principles of systematic working in general, and the coordinator tasks of introduction, planning and evaluating in particular. Furthermore, training non-professionals (with conflicting roles) as coordinators should focus on assertiveness and strategies for mobilizing other care-givers. In conclusion, both professionals and non-professionals seem to lack a number of skills and although professionals were somewhat better working systematically, differences between professionals and nonprofessionals who functioned as coordinators were very small. Therefore, both professionals and non-professionals can be candidates for the role of coordinator in future interventions.

The intervention in study $I$ indicated that even a relatively simple intervention can have positive effects on the continuity of client care. This implies that increasing the continuity of care does not necessarily call for formal arrangements or organizational changes. On the contrary, every community care-giver who takes upon him the role of care-coordinator can establish these positive effects. Therefore, community care-givers should more often take the initiative of coordinating care for individual clients, especially in those cases where formal procedures for coordination of care are lacking. The appointment of coordinators did not result in changes in the diversity of care and only a minor effect on client satisfaction was identified. Deriving implications of these findings is hindered by the fact that one cannot be sure that the effects would have been similar if coordinators had paid more attention to some of the coordinator tasks. Nevertheless, interventions of a more drastic nature might have more impact on client care. If improving client care is one of the goals of coordination of care, interventions that involve case managers (coordinators without care-giver tasks) and client budgets might be more effective.

One important implication of study II is that substitution of professional community care by non-professional care is not a realistic option. First of ali, Litwak's hypothesis that different care-tasks call for different care-givers was supported. Furthermore, nearly all care-dependent adults received both professional and non-professional community care, and the diversity of the two types of care were positively related. Therefore, policy makers in health care should focus on matching care-givers to the types of care required and efficient use of care resources, rather than on the substitution of professional care. The result for the diversity of care also indicate that some groups might be at risk for receiving insufficient care. Care-dependent adults who were older, living alone, who were more impaired in their daily functioning or had a lower quality of life reported less diversity of care, where one might expect to find the contrary. This suggests that these clients might experience more 
difficulties in building care networks and mobilizing care-givers. Community care providers should pay more attention to potential care deficits in these clients.

Aspects of continuity of care were important correlates of client satisfaction and the course of satisfaction scores. The continuity aspect 'care-givers keeping appointments' appeared to be the most relevant aspect with regard to client satisfaction. This finding makes attention for the coordination of care all the more relevant. As was found in study I, the continuity of care can indeed be increased by coordination of care.

Satisfaction scores for professional and non-professional care were not interrelated and neither were some of the scores for specific care-givers. Clients actually had the ability to discriminate between the activities of specific caregivers and to judge the quality of services accordingly. This implies that clients' satisfaction scores are meaningful and that it is an illusion to think that being satisfied or uttering complaints is a client characteristic, rather than the result of the care clients receive. Furthermore, satisfaction scores were related to the continuity of care as hypothesized. These results imply that appraising client satisfaction is a significant and valid approach of addressing quality of care. Therefore, the use of client satisfaction scores can be meaningful to both research and quality assurance in community care. Finally, changes in the diversity of care were important with regard to the course of client satisfaction. Increased diversity of care occurred along with more deteriorations or less improvements in client satisfaction, even though satisfaction scores were corrected for the diversity of care. From this, it might be concluded that the quality of care is more at stake in those cases where the diversity of professional and non-professional care is high. Care-givers should pay more attention to potential problems in these situations. 


\section{References}

Achterberg, Th. van \& Stevens, F.C.J. (1994) Coördinatie van zorg in de eerste lijn: Verslag van het onderzoek bij cliënten en zorgcoördinatoren. Utrecht, The Netherlands: Nederlands Instituut voor Zorg en Welzijn (NIZW).

Alter, C. \& Hage, J. (1993) Organizations working together. Newbury park, CA: SAGE.

Amelsvoort, F. van, Dokter, H. \& Willems, A. (1992) Tussen zes komma viji en acht komma vier: Evaluatie-onderzoek naar de functie van zorgcoürdinator ouderen in de gemeente Aalten. Utrecht, The Netherlands: Nederlands Instituut voor Zorg en Welzijn (NIZW).

Andersen, R. (1995) Revisiting the behavioral model and access to medical care: Does it matter? Journal of Health and Social Behavior 36: 1-10.

Andersen, R., Kravits, J, \& Anderson, O.W. (1975) Equity in health services: Emperical analyses in social policy. Cambridge: Ballinger Publishing Company.

Austin, C.D. \& O'Conner, K. (1989) Case management: Components and program contexts. In: Petersen, M.D. \& White, D.L. (Eds.) Care of the elderly: An information source book ( $\mathrm{pp}$ 167-205). Newbury Park, CA: SAGE.

Baldock, J. \& Evers, A. (1992) Innovations and care for the elderly: The cutting edge of change for social welfare systems. Examples from Sweden, The Netherlands and The United Kingdom. Aging \& Society 12: 289-312. Boer, A.H. de, Hessing-Wagner, J.C., Mootz, M. \& Schoemakers-Salkinoja, I.S. (1994) Informele zorg: Een verkenning van huidige en toekomstige ontwikkelingen. Rijswijk, The Netherlands: Sociaal en Cultureel Planbureau.

Carcagno, G.J., Wooldridge, J., Brown, R.S. \& Kemper, P. (1986) The evaluation of the national long term care demonstration: Final report. Princetown: Mathematica Policy Research.

Challis, D., Darton, A., Johnson, L., Stone, M. \& Traske, K. (1991) An evaluation of an alternative to long-stay hospital care for frail elderly patients II: Costs and effectiveness. Age and Ageing 20: 245-254.

Coulton, C. \& Frost, A.K. (1982) Use of social and health services by the elderly. Journal of Health and Social Behavior 23: 330-339.

Cox, K., Peeters-Niemantsverdriet, S., Philipsen, H., Neumann, M., Van Campen, C., Huyer-Abu Saad, H. (1994) Onderzoekprogramma kwaliteit van zorg 3: Overzichtstudie Discontinuïteiten in de thuiszorg, aantasting van de kwaliteit van zorg? Den Haag. The Netherlands: Nederlandse Organisatie voor Wetenschappelijk Onderzoek.

Davies, B. \& Challis, D. (1986) Matching resources to needs in community care. Aldershot, England: Gower Publishing Company.

Evashwich, C., Rowe, G., Diehr, P. \& Branch (1984) Factors explaining the use of health care services by the elderly. Health Services Research 19: 357-382. 
Fijn, J.M.G. \& Velthausz, M.D. (1992) Een betere overdracht?: Onderzoek naar de effecten van de invoering van een zorgdossier in Capelle aan den IJssel. Capelle aan den Ijssel, The Netherlands: De Capelse Kruisvereniging.

Fitzpatrick, R. (1991) Surveys of patient satisfaction I: Important general considerations. British Medical Journal 302: 887-889.

Flynn, S.P. (1985) Continuity of care during pregnancy: The effect of provider continuity on outcome. Journal of Family Practice 21: 375-380.

Fox, J.G. \& Storms, D.M. (1981) A different approach to sociodemographic predictors of satisfaction with health care. Social Science \& Medicine 15a: 557-564.

Frederiks, C.M.A., Te Wierik, M.J.M., Van Rossum, H.J.L., Visser, A. Ph., Volovics, A. \& Sturmans, F. (1992) Why do elderly people seek professional home care?: Methodologies compared. Journal of Community Health 17: 131-141.

Gerace, T.M. \& Sangster, J.F. (1987) Factors determining patients' satisfaction in a family residence teaching centre. Journal of Medical Education 62: 485-490.

Hall, J.A. \& Feldstein, M. (1990) Older patients' health status and satisfaction with medical care in an HMO population. Medical Care 28: 261-270.

Intagliata, J. (1982) Improving the quality of community care for the chronically mentally diabled: The role of case management. Schizophrenia Bulletin 8: 655-674

Hull, F.M. \& Hull, F.S. (1984) Time and the general practitioner: The patient's view. Journal of the Royal College of General Practitioners 34: 71 75.

Knapen, M. \& Puts, P. (1990) Coördinatie van zorg in de steigers: Een inventarisatie van cliëntgerichte coördinatie in dertig vernieuwende initiatieven. Utrecht, The Netherlands: Nederlands Instituut voor Zorg en Welzijn (NIZW).

Koedoot, C.G., Hommel, A.A.C., Van der Horst, E.J. \& Knipscheer, C.P.M. (1992) De ouderen in het project individuele zorgsubsidie Rotterdam: Longitudinaal onderzoek naar de effecten van zorgbemiddeling en zorgsubsidie. Amsterdam: Vrije Universiteit.

Krippendorff, K. (1980) Content analysis: An introduction to its methodology. Beverly Hills, CA: SAGE.

Linder-Pelz, S.L. (1982) Toward a theory of patient satisfaction. Social 44 Science \& Medicine 16:577-582.

Linder-Pelz, S. \& Streuning, E.L. (1985) The multidimensionality of patient satisfaction with a clinic visit. Journal of Community Health 10: 42-54.

Linn, M.W., Linn, B.S. \& Stein, S.R. (1982) Satisfaction with ambulatory care and compliance in elderly patients. Medical Care 20: 606-614.

Litwak, E. (1985) Helping the elderly: The complementary roles of informal networks and formal systems. New York: Guilford Press. 
Marquis, M.S., Davies, A.R. \& Ware, J.E. (1983) Patient satisfaction and change in medical care provider. Medical Care 21: 821-829.

Moore, S.T. (1990) A social work practice model of case management: The case management grid. Journal of the National Association of social Workers 35: 444-448.Pascoe, G.C. (1983) Patient satisfaction in primary health care: A literature review and analysis. Evaluation and program planning 6: 185-210.

Peters, V., Wester, F. \& Ricardson, R. (1989) Kwalitatieve analyse in de praktijk en handleiding bij Kwalitan. Nijmegen, The Netherlands: Instituut voor Toegepaste Sociale Wetenschappen.

Philipsen, H. \& Stevens, F.C.J. (1996) Modernization, rationality and continuity of care: Theoretical concepts and empirical findings. Sociological Focus: in press.

Rabiner, D.J. (1992) The relationship between program participation, use of formal in-home care and satisfaction with care in an elderly population. The Gerontologist 32: 805-812.

Roberts, R.E., Pascoe, G.C. \& Attkisson, C.C. (1983) Relationship of service satisfaction to life satisfaction and perceived well-being. Evaluation and Program Planning 6: 373-383.

Rogers, J. \& Curtis, P. (1980) the concept and measurement of continuity in primary care. American Journal of Public Health 70: 122-126.

Scott, R.W. (1975) Organizational structure. Annual Review of Sociology 35: 1-20.

Scholte op Reimer, W.J.M. (1993) Coördinatie van zorg in de eerste lijn: Met behulp van een delphi-methode op zoek naar een profiel van de zorgcoördinator. Maastricht, The Netherlands: Doctoraalscriptie Rijksuniversiteit Limburg.

Stanfield, G.S. (1976) Technology and organization structure as theoretical categories. Administrative Science Quarterly 21: 489-492.

Surles, R.C., Blanch, A.K., Shern, D.L. \& Donahue, S.A. (1992) Case management as a strategy for systems change. Health Affairs 11: 151-163.

Tjadens, F.L.J. \& Woldringh, C.L. (1989) Informele zorg in Nederland:

Zelfzorgproblemen, behoefte aan hulp en praktisch instrumentele onderlinge hulp. Nijmegen, The Netherlands: Instituut voor Toegepaste Sociale Wetenschappen.

Wall, E.M. (1981) Continuity of care and family medicine: Definition, determinants and relationship to outcome. The Jounal of Family Practice 13: $655-664$.

Ware, J.E. \& Davies, A.R. (1988) Patients' perspectives on the quality of medical care. The Journal of Family Practice 26: 489-490.

Ware, J.E., Davies-Avery, A. \& Stewart, A.L. (1978) The measurement and meaning of patient satisfaction. Health and Medical Care Services Review 1: $1-15$.

Weiss, L.J. (1987) Care coordination: An integration mechanism. In: Evashwick, C.J. \& Weiss, L.J. (Eds.) Managing the continuum of care (pp 271-291). Rockville, MD: Aspen Publishers. 
Weiss, G.L. (1988) Patient satisfaction with primary medical care: Evaluation of sociodemographic and predispositional factors. Medical Care 26: 383392.

Weissert, W.G., Matthews Cready, C. \& Pawelak, J.E. (1988) The past and future of home and community based long-term care. The Millbank Quarterly 66: 309-387.

Williams, S.J. \& Calnan, M. (1991) Key determinants of consumer satisfaction with general practice. Family Practice 8: 237-242.

Yura, H. \& Walsh, M.B. (1983) The Nursing Process: Assessing, planning, implementing, evaluating. Norwalk, CT: Appleton-Century-Crofts.

Zastowny, T.R., Roghmann, K.J. \& Kafferata, G.L. (1989) Patient satisfaction and the use of health services. Medical Care 27: 705-723. 


\section{2}

IMPLEMENTING

COORDINATION

OF CARE:

TASK PERFORMANCE AND

PROBLEMS ENCOUNTERED

Theo van Achterberg,

Fred C.J. Stevens,

Marion J.H.Hekkink,

Harry F.J.M. Crebolder, \& Hans Philipsen.

Scandinavian Journal of Caring Sciences

(1995) 9: 209-217. 


\section{Abstract}

In recent years effects of interventions in the field of coordination of care have been well reported. However implementing coordination of care is hardly addiressed. This article focusses on the implementation of coordination of care for the elderly in three community settings in the Netherlands. A group of 38i professional and non-professional care-givers functioned as coordinators during the period of one year. Open interviews with coordinators, minutes from group meetings and forms and logbooks were used as sources of data.

Major problems during implementation involved conflicting roles, guarding the client's privacy, lack of recognition and the perception that coordination was not always necessary. Coordinators had no difficulties in making a careinventory and organizing care. On the other hand, introducing oneself as a coordinator, and planning and evaluating care are tasks that need more attention in future interventions.

Key words

Coordination of care, community care, elderly, program implementation. 


\subsection{Introduction}

This article describes the implementation of. community based coordination of care, as it was performed in the province of Limburg. The Netherlands. Health care in the Netherlands is characterized by a strong emphasis on community care. In practice, general practitioners function as 'gate-keepers' for other community or institutional services. Dutch community care is highly accessible. All services are covered by national, compulsory or private insurance or require only limited contributions. Coordination of care for chronically ill elderly clients has become increasingly important in the Netherlands as well as in the USA and in other European countries. In these areas, the number of elderly clients who need care from several professional and nonprofessional care-givers and who live independently in the community has increased considerably over the years. Whereas communication between care-givers seems simple and logical in theory, in practice it is not. Caregivers who are required to care for the same client are not always aware of each other's involvement and if they are, communication is not always the obvious result. Overlaps, unnecessary duplications and discontinuity in services occur (Zawadski 1984). Moreover, the growing complexity in health care threatens the comprehensiveness and continuity of care and increases the need for coordination (Weiss 1987). Where some problems -such as sicknessare officially the domain of professionals (Abbott 1988), this is not the case: with coordination of care. Depending on objectives, the coordination of tasks can alternately be ascribed to different care providers.

In both the USA and Europe many projects have focussed on coordination of care -often referred to as case management-and the evaluation of its effects. Probably the most well-known of these projects are the long term care demonstrations, that experimented with several models of coordination of care and cost control (Zawadski 1984), and the Kent Community Care Project which experimented with client budgets, controlled by social workers who acted as care-coordinators (Davies \& Challis 1986). Recent projects dealing with coordination of care for elderly clients have been used for a wide variety of desired outcomes. These include improving mental health outcomes and reducing unmet needs (Surles et al. 1992), linking hospital care with community care (Warrick et al. 1992), improving community care after discharge from hospital (Edelstei \& Lang 1991), preventing institutionalization (Shugart 1992; Koedoot et al. 1992), preventing discrimination against old age (Hugman 1994) and, of course, improving coordination of care (Challis et al. $1991 \mathrm{a} ; 199 \mathrm{~b})$. An inventory of experiments in community care since 1960 was drawn up by Weissert et al. (1988). They identified 27 studies that included both intervention and control groups with at least 50 clients in each group. Irom these 27 studies 15 included case management or similar models. Analysis of the findings from all the studies showed that the interventions did not affect health care costs, accomplished only a small reduction in the use of nursing homes, had very little effect on clients' performance of Activities of Daily Living (ADL), but improved the clients' social participation and quality of life and reduced the number of unmet needs. 
Although the results of studies undertaken in recent years are often well reported, there seems to be a paucity of reports on what it is that care-coordinators or case managers actually do (Radol Raiff \& Shore 1993). Miost authors present their ideal model of coordination of care or case management and go on to presenting and interpreting results from there. As a consequence, there is little insight into coordinators' task performance. Furthermore little is known about the usual types of problems that are encountered in the implementation of coordination of care. In an attempt to deal with this lack of knowledge, this article discusses the experiences of both professionals and non-professionals who functioned as care-coordinators, using the following research question:

What problems occur during the implementation of coordination of care and how does coordinators' task performance relate to the original coordination of care model?

Apart from studying encountered problems, task performance will be described for the purpose of estimating the 'degree of implementation' (to what extent is the implementation actually successful?; Shreier \& Lantos Rezmovic 1983). The degree of implementation can be estimated by looking at examining completeness and fidelity. Whereas completeness refers to carrying out all aspects of the intervention, fidelity focuses on whether the different aspects were performed as was intended (Smith et al. 1993; Hall \& Loucks 1977). In the discussion section the results will be discussed in relation to both aspects.

\subsection{The project 'Coordination of care in the community'}

The aim of the research project 'Coordination of care in the community' was to improve the quality of care and the communication between care-givers. The project focussed on elderly, somatic and chronically ill clients. Coordination of care was defined as (1) to fit the capabilities of a person and the care needed by that person to the care provided by care-givers and (2) to link up the efforts of several care-givers. The project can be distinguished from other projects in the field of coordination of care (or case management) by two basic characteristics.

First, the coordinatorship did not necessarily have to be performed only by those who were professionally trained in one of the disciplines in community care. Professional care-givers that could function as coordinators were the community nurse, the family physician, the social worker and the manager/intaker from the home-help agency. Non professional care-givers who could also be appointed as coordinators were the spouse, one of the children, a relative, a neighbor or a friend of the client. In the philosophy of this project, informal care-givers thought to be capable of coordinating just as efficiently as professionals. According to Twigg (1989) informal care-givers 
can be seen as resources, co-workers or co-clients. In this study they were approached as co-workers and therefore could be seen as experts in their own right.

A second feature that distinguishes this intervention from others, is that coordination of care was operationalized as an integral part of everyday caregiving. An intervention in which the coordinatorship is operationalized as a separate function would have implied considerably more practical and formal arrangements and could be expected to be less acceptable to care-givers (RIGG Noord en Midden-Limburg 1992). Apart from these practical considerations it was believed that community care should not be so complex that it would make the introduction of a new profession necessary. Furthermore, the introduction of a new professional might be seen as a complication in itself, since clients would have to deal with yet another extra person.

The tasks of coordinators were derived from general principles of systematic working practice (Intagliata 1982; Moore 1990). These are very similar to those that have been developed for individual professions such as nursing (Yura \& Walsh 1983) and for other intervention studies such as Engström's patient information study (1988). Coordinators' tasks can be differentiated from those of care-givers, however, by their focus on the total care of a client. The original coordination of care model included five basic tasks for all coordinators:

Introduction - Coordinators were asked to introduce themselves as the carecoordinator to the clients, the clients network and all care-givers that wore involved with the client.

Making a care-inventory - Coordinators were expected to make a list of all care demands and all care activities in the client's situation. For this purpose a care-inventory form was drawn up.

Making a care-plan - After completing the care-inventory, the coordinator was expected to make a care-plan, on a form that was developed for this purpose. This plan should contain general goals and the contributions of all care-givers.

Executing the care-plan and monitoring care - Executing the care-plan involved the consultation of other care-givers and redching a mutual agreement on the care needed. At this stage decisions were made on the exact care activities, their goals, their frequency and ways of evaluating them. The logbook -a notebook for all care-givers that was placed in the client's house- was a tool in monitoring care.

Evaluating the operationalization of the care-plan - Coordinators were expected to compare the effects of the care that was actually given to the client with the goals that were stated in the care-plan. 


\subsection{Methods}

\subsubsection{Clients}

Coordination of care was implemented in three communities in the Dutch province of Limburg. These communities varied in size from 18.000 to 34.000 inhabitants. Professional care-givers were asked to select clients of at least 60 years of age, who suffered from a chronic disease, were receiving care from at least two professional or non-professional care-givers and who lived independently within one of the three communities (a detailed description of the selection of clients is provided by Van Achterberg \& Stevens 1994). The 108 clients who participated at the start of the project were divided over three groups. The first group had a professional as coordinator $(n=42)$, the second group had a non-professional care-giver as coordinator $(n=23)$ and the clients in the third group did not have a coordinator $(n=43)$. This last group

\section{Table I}

Selected client characteristics ( $n=72)$.

Gender

male

female

MEAN

N

$\%$

21

$29 \%$

51

$71 \%$

Age

74

Living arrangement

living alone

40

$56 \%$

living with someone

32

$44 \%$

Number of conditions

3.0

Non-professionals

spouse

family members

friends/neighbors

52 Professionals

general practitioners

home helps

community nurses

physiotherapists

social workers

others 
served as a comparison group for the study among clients that is not reported in this article. Since the appointment of a coordinator depended on the presence of (informal) care-givers and the preferences of clients, randomization was not an option for this study. Therefore clients for the non-professional group were selected first and participants in the other two groups were matched with this group, on age, gender and living situation (whether or not they were living alone). After one year of coordination 72 clients were still in the project ( 26 in the professional group, 18 in the non-professional and 28 in the comparison group). Of the 36 clients that no longer participated in the project, 12 refused further cooperation and 24 others no longer participated because they had died, had moved to a nursing home or a hospital or because they developed Alzheimer's disease.

Most of the 72 clients who participated during the whole project were female (table I). The average age for this group was 74 and 40 of these clients (56\%) lived alone. The average client reported three chronic conditions. Informal care-givers included spouses $(32 \%)$, family members (64\%) and neighbors/friends $(37 \%)$. Professional care-givers included general practitioners $(83 \%)$, home helps $(50 \%)$, community nurses $(29 \%)$, physiotherapists $(24 \%)$, social workers $(8 \%)$ and others $(24 \%)$.

\subsubsection{Coordinators}

A total of 19 professional and 22 informal care-givers were instructed as coordinators for one or more clients. The coordinators were interviewed at 6 and 12 months after the start of the project. Only those who had coordinated for more than 3 or 9 months respectively were included in these interview rounds. Therefore interviews were held with 19 professionals and 19 informal care-givers at 6 months and with 14 professionals and 15 informal care-givers after 12 months. The three coordinators who dropped out before the interview at 6 months were all due to clients who no longer participated in the project. Of the nine coordinators who dropped out after the first interview, five were a result of clients that could no longer participate and four were a result of problems or circumstances surrounding the coordinator (such as pregnancy and the death of a spouse). The distributions of sex and (professional) background for the 38 coordinators that were interviewed after 6 months are presented in table II. Most of both informal care-givers and professionals who became coordinators were female. Those that were not interviewed after 12 months were two community nurses and three managers from the home-help agency (all women) for the professional group and four children (three male and one female) for the non-professional group.

\subsubsection{Implementation}

The coordinators were instructed at the beginning of the project. During instruction meetings the objectives and methods of the project were clarified, and the five coordinator tasks were explained and illustrated. The coordinators received a care-inventory form, a carc-plan form, a logbook and the coordinator's guide. During the year that followed the instructions, several fol- 


\section{Table II}

Distribution of sex and (professional) background for coordinators interviewed after 6 months $(n=38)$.

\section{Professionals}

Male female total

Social worker

General practitioner

Managers home-help

Community nurses

Non-professionals

Partner/spouse

Children (in-law)

Other relatives

Neighbors/friends

Total

2

3

1

1

14
1

5

1

-
3

5

9

2

3

38

low-up meetings were organized seperately for professional and informal care-givers.

Professional care-givers expressed a greater need for follow up meetings. The average informal care-giver was present at one or two follow up meetings, whereas the number of meetings that professionals attended varied from one to four. The authors were involved in the instruction and follow up meetings, but were not part of the intervention.

\subsubsection{Sources of data}

Three sources of data were used to answer the research question. Interviews with coordinators were a first source of data. Both of the interviews with coordinators were open interviews, dealing with a selection of topics, such as contacts with the client and with other care-givers, task performance and necessary knowledge and skills. All interviews were tape-recorded, tran-

54 scribed and then read by three members of the research team. Content analysis was used to order and analyze the data (Krippendorff 1980). This resulted in 302 different 'notes' that were classified into 19 categories. The most important categories were 'tasks, skills and conditions' (47 notes), 'effects' (44 notes), 'relationships with clients, professional and informal care-givers' (42 notes) and 'tools' (37 notes).

Secondly, the minutes from meetings with coordinators were systematically taken by the project staff. One of the members of the research team analyzed 
the minutes. Statements were derived from the minutes and were divided over 15 categories such as 'effects', 'contacts' and 'problems'.

Logbooks and care-plans were a third source of data. For the professionals' group 30 care-plans and logbooks were returned $(71 \%)$, for the informal carers' group 18 plans and logbooks were collected $(74 \%)$. Despite of repeated requests, the reasons for not returning the logbooks were never clarified. The logbooks and plans that were not returned were probably those that were less used, lost, or that contained information that the coordinator or the client did not want to reveal for reasons of privacy. Two members of the research team read and analyzed all the plans and logbooks.

\subsection{Results}

\subsubsection{Problems encountered during implementation}

Several problems were encountered during the implementation of the project. Four problems that often recurred will be discussed here.

Perception of no Need - Coordinators all too willingly concluded that the situation of their client(s) was stable and showed little complexity. From this they often deduced that coordination of care was rather a welcome addition, but not really a necessary one. Eight non-professionals and six professionals expressed that they dealt with stable situations exclusively.

From this, the coordinators concluded that the selection criteria for clients made it possible for relatively simple cases to enter the project. This would mean that being chronically ill, 60 years of age or older and receiving care from at least two care-givers does not automatically imply a need for coordination of care. However, the finding is contradicted by what is found in the logbooks. For the 47 logbooks that were returned, the average number of care-givers who made notes in the logbook was 16 . In most cases, this large number of care-givers was due to substitution of care-givers within disciplines. Especially striking were the large numbers of community nurses and home helpers. The average client saw four different community nurses and three different home helpers over the year (clients who did not receive community nursing or home helping services were included when these averages were computed). The most extreme example is a case in which the client saw 35 different community nurses over the year.

Lack of Recognition - Almost all coordinators reflected and agreed upon the fact that it was difficult to be recognized as the care-coordinator. Other caise-

givers and especially clients continued to see the coordinator primarily in the role of care-giver (e.g. the nurse, the daughter). During follow-up meetings the problem of lack of recognition was one of the recurring topics. In an attempt to deal with the problem, coordinators were provided with stickers giving their name, function and telephone number and which could be placed on all relevant client documents. Furthermore, more publicity was given to the project by distributing newsletters with current information on 
the project in each of the three communities. These activities only slightly improved the situation, however.

Privacy - Coordinators were afraid that extra consultations, the use of a logbook and discussing clients (anonymously) during group meetings, might result in a violation of the clients' privacy. In most cases violation of privacy remained a potential problem. A way of dealing with the problem could not be offered, since exchange of information was one of the essential characteristics of the intervention. Coordinators were advised to exchange only relevant information, not to reveal matters that were addressed as confidential and to rely upon good manners and decency.

Conflicting Roles - A fourth problem was specific for the non-professional group. In some instances coordinators who were non-professionals reported having conflicting roles. Non-professionals who had young children found it difficult to combine care giving, coordinating, and having a family. This was not so much a question of time, as of unpredictability and psychological pressure. The problem was also mentioned during follow-up meetings.

Two potential problems that were often mentioned by care-givers before the implementation phase were extra time investment and lack of acceptance by others. However, both professional and non-professional care-givers reported that the extra time investment was not problematic and whereas being recognix d as a courdinator was a major problem, being accepted as such was not.

\subsubsection{Task performance}

The coordinators' task performance was evaluated along the five coordinator tasks.

Introduction - Not all coordinators had introduced themselves in this capacity to the clients and their care-givers at the start of the project. Although the importance of this first task was stressed during instructions, coordinators only introduced themselves to a limited group. Problems occurred especially between professionals and non-professionals. Non-professionals seemed to lack the courage to approach professionals for no other reason than to introduce themselves. Professionals, on the other hand, sometimes forgot to inform non-professionals because for them being termed 'care-givers' was synonymous with being 'professionals'

Making a care-inventory - On the whole, the drafting of a care-inventory was performed very adequately. A total of 35 out of 38 coordinators filled out the care-inventory form. According to coordinators, the care-inventory func-

56 tioned as an 'eye opener'. The inventory was helpful in gaining insight into the clients situation as well as the network of care-givers. However, this does not imply that coordinators made this their guideline in the process of coordination. Some of the coordinators seemed to complete the form as if it were a goal in itself.

A comparison of the two groups of coordinators shows that all non-professionals and 16 out of 19 professionals used the care-inventory form (table III). At the start of the project professionals were often unaware of care given 
by non-professionals or by professionals from other disciplines. Non-professionals already had a better insight in these matters prior to the intervention. Only four non-professionals regarded making a care-inventory as being really useful, compared with ten professionals (table III).

\section{Table III}

Use and usefulness of the care inventory form for professionals and non-professionals $(n=38)$.

$\begin{array}{ccc}\text { NON-PROFS } & \text { PROF5 } & \text { TOTAL } \\ (N=19) & (N=19) & (N=38)\end{array}$

$\begin{array}{lccc}\text { Used } & 19 & 16 & 35 \\ \text { Not used } & 0 & 2 & 2 \\ \text { Unclear } & 0 & 1 & 1 \\ & & & \\ \text { Useful } & 4 & 10 & 14 \\ \text { Not useful } & 6 & 1 & 7 \\ \text { Unclear } & 9 & 8 & 17\end{array}$

Making a care-plan - Compared to the care-inventory form, the use of the care-plan was somewhat disappointing. According to the coordinators the care-plan was often not used when the care-inventory failed to reveal any new information or insights. Some of the clients had received the same kind of care over a long period of time and had found it satisfactory. In these cases the care-plan did not have an additional function. Other reasons submitted by the coordinators for not using the care-plan were, overlap with plans they were already using and the fact that they 'had the plan in their heads'. Eight non-professionals and nine professionals actually used the form (Table IV). Only 2 out of 19 non-professionals and 6 out of 19 professionals regarded the care-plan as useful. Analyses of the care-plans indicated that of the 47 careplan forms that were returned after the project, 28 had not been used.

Professionals sometimes made adjustments to the care-plan (one modification on average), whereas non-professionals did not.

Executing the care-plan and monitoring care - Coordinators focused most of their attention on the execution of the care-plan, whether they had actually used the care-plan form or not. Those who had omitted to fill out the careplan form did not pay less attention to this task, but appeared to carry out a plan that was not made explicit. In the eyes of most coordinators, coordination of care was all about 'regulating' and 'making arrangements'. By this they meant negotiating with other care-givers, applying for facilities or services and taking care of the client's findmial affairs. 
Guiding and tuning care was also mentioned with regard to this task.

One difference between the two groups in this respect, was that professionals felt responsible for the process of coordination, whereas non-professionals felt responsible towards their 'client'. Therefore professionals thought of themselves as process and care managers, whereas non-professionals saw coordination of care as client advocacy.

\section{Table IV}

Use and usefulness of the care-plan for professionals and non-professionals $(n=38)$.

$\begin{array}{ccc}\text { NON-PROFS } & \text { PROFS } & \text { TOTAL } \\ (N=19) & (N=19) & (N=38)\end{array}$

$\begin{array}{lccc}\text { Used } & 8 & 9 & 17 \\ \text { Not used } & 8 & 8 & 16 \\ \text { Unclear } & 3 & 2 & 5 \\ \text { Useful } & & & \\ \text { Not useful } & 2 & 6 & 8 \\ \text { Unclear } & 9 & 3 & 12 \\ & 8 & 10 & 18\end{array}$

Eighteen professionals and an equal number of non-professionals used the logbook that was developed as a tool for this task (table V). A small group of seven coordinators (six non-professionals and one professional) thought the logbook was not particularly useful. In their opinion, the stability of the client's situation resulted in few relevant or often repetitious notes. Those who thought the logbook was useful stated that it gave them more insight into the network of care-givers and that it improved communications between care-givers. All 47 logbooks that were returned after the project ended were used. On analysis it was revealed that the average logbook was used over a period of 267 days and contained 182 notes by 16 different caregivers. Logbooks in the professionals group were used over a longer period (about a 100 days longer) and contained notes by a greater number of persons (about 14 more) than those in the non-professional group. These differ-

58 ences turned out to be statistically significant in a T-test procedure (table VI). Other significant differences were found for the numbers of partners, general practitioners and home helpers. In the non-professional group the number of partners who made notes was greater than that in the professional group. The number of general practitioners and home helpers who made notes in the logbook was greater for the professional group. Content analysis showed that the most usual kinds of notes were those that referred to: one of the caregivers being present $(n=36$, meaning the'se notes were found in 36 out of 47 
logbooks); medical treatment or the use of medication $(n=35)$; personal care $(\mathrm{n}=31)$; household activities $(\mathrm{n}=31)$; the client's condition $(\mathrm{n}=30)$ and social activities $(n=26)$.

The fact that professionals used the logbooks more intensively and over a longer period of time can partially be explained by the differences between the two groups. In those instances where a professional functioned as coordinator the client's network consisted of relatively more professionals and of relatively fewer non-professionals than in those instances where a non-professional was coordinator.

According to the coordinators non-professionals had relatively more contacts with both the client and other care-givers, which made the logbook less of a necessity.

\section{Table V}

Use and usefulness of the logbook for professionals and non-professionals ( $n=38$ ).

$\begin{array}{ccc}\text { NON-PROFS } & \text { PROFS } & \text { TOTAL } \\ (\mathrm{N}=19) & (\mathrm{N}=19) & (\mathrm{N}=38)\end{array}$

$\begin{array}{lccc}\text { Used } & 18 & 18 & 36 \\ \text { Not used } & 1 & 0 & 1 \\ \text { Unclear } & 0 & 1 & 1 \\ \text { Useful } & 11 & 12 & 23 \\ \text { Not useful } & 6 & 1 & 7 \\ \text { Unclear } & 2 & 6 & 8\end{array}$

Evaluating the operationalisation of the care-plan - The fifth and last coordinator task received little attention. In interviews with coordinators, the evaluation of care was minimal. Coordinators probably performed some evaluation, but this was not made explicit in a vast majority of the cases.

Coordinators seldom looked back on the care goals as stated in the care-plan. In only one-third of the cases in the professional group and in none of the cases in the non-professional group were evaluative remarks found in the logbook. Professionals seemed to give relatively more attention to evaluation, or at least were more adept at expressing themselves in the matter. But even here the exception proved the rule. The coordinator who seemed to handle evaluation in the most systematic and careful manner was a non-professional. This coordinator had a weekly meeting with the client, during which both the logbook and the client's diary were used for the purpose of evaluating all care received in the past week. 


\section{Table VI}

Use and contents of logbook for professionals and non-professionals ( $n=47)$.

Means

\# Days used*

$\begin{array}{ccc}\text { MEAN } & \text { MEAN } & \text { MEAN } \\ \text { PROFS } & \text { NON-PROFS } & \text { TOTAL } \\ (N=30) & (N=17) & (N=47)\end{array}$

\# Notes

\# Persons

303,6

202,3

267,0

196,8

156,1

182,0

21,1

6,9

16,0

Relationship:

partner*

0,1

0,4

0,2

children

1,3

1,4

1,3

other relatives

1,9

0,6

neighb./friends

4,4

1,0

3,2

physician*

1,1

0,6

0,9

comm. nurse

5,4

1,6

4,1

4,1

2.9

physiotherapist

0,5

0,8

0,4

med. specialist

client

0,2

0,3

0,1

0,1

0,0

others

2,0

0,1

0,1

1,6

1,8

* prof. vs. non-prof significant at $p \leq 0.05$

\subsection{Discussion}

The project 'Coordination of Care in the Community' is unique in its focus on both professional and non-professional care-givers as potential coordinators. Although the group of coordinators was not a large one, there was sufficient variance in professional and non-professional backgrounds. Interviews with these coordinators formed an extensive source of information for the project. This information gained value since it could be compared with group meeting minutes, care-plans and logbooks.

\subsubsection{Problems encountered}

It goes without saying that many minor problems had to be dealt with during the implementation phase. There were, however, four major problems that recurred in coordinator interviews and group meetings.

1. Non-professionals who functioned as care-coordinators had to deal with the difficult combination of being a care-coordinator, having a job and having a family life of their own. Since a majority of the non-professional group was 
female, this finding might be an indication of problems similar to those of 'women in the middle' (Brody 1981). Developments such as increased lifeexpectancy, decreased fertility and the growing number of women with jobs outside the house, contribute to the risk of being sandwiched between conflicting responsibilities (Rosenthal et al. 1989; Potting 1994). For some carecoordinators, it was difficult to make the distinction between being a caregiver, family member and coordinator. Feelings of loyalty and commitment might cause a non-professional to try and solve all potential problems by doeing everything oneself.

2. Coordinators often jumped to the conclusion that their clients' situations were stable and not complex. They seemed to forget that the shifting of caregivers within disciplines could account for considerable instability within the client's network. Analysis of logbooks revealed that clients' situations were often less stable than might be supposed from coordinator interviews. The potential danger here is that coordinators might hold back in situations that could well be in need of improvement and might give way to misconceptions. 3. Both clients and other care-givers continued to see the new coordinator primarily in the old care-giver role. Attempts to further clarify the role and the existence of the coordinator did not solve this problem. On examining task performance it was clear that coordinators could have introduced themselves more appropriately. A better introduction might have prevented or at least reduced the problem.

4. The coordinators saw deliberations and the use of a logbook as a threat to the client's privacy. A solution to this problem cannot be offered. The exchange of information is an essential characteristic of coordination of care. Even so, the problem is of course not unique to care coordination. Discussing a client within one's own discipline could also threaten the client's privacy.

\subsubsection{Completeness}

Not all five of the coordinator tasks were carried out to the same extent. Whereas some tasks received a great deal of attention, others were (almost) omitted. Making a care-inventory and the execution of the care-plan were tasks that were carried out by most or almost all the coordinators. Tasks that were omitted by a relatively large group of coordinators were the introduction and the devising of a care-plan. Task number 5, evaluating the operationalization of the care-plan, was undertaken by only a small group of coordinators. The results for completeness indicated very little differences between the professional and the non-professional group. Evaluation of the care-plan was found somewhat more often for the professional group, but no differences were observed in the performance of the other tasks. Although coordinators performed some of the tasks adequately, it is obvious that the implementation was not a complete one. Instructions and follow-up meetings are no guarantee that all tasks will be performed.

\subsubsection{Fidelity}

As with completeness, the degree of fidelity (are different aspects performed as intended?) varied between the coordinator tasks. Some tasks were carried 
out (almost) exactly as intended, while the performance of other tasks only narrowly resembled the original task description. Fidelity was highest for the drafting of a care-inventory. High fidelity was also found for executing the care-plan and monitoring care. Although not all of the coordinators made their care-plans explicit, they performed the appropriate actions in executing and monitoring care. As expected, they used the logbook for this purpose. Fidelity was low for the three remaining tasks. Coordinators who introduced themselves as such, often did so only to a selection of those care-givers present. In those cases where d care-plan form was used it was often filled out according to the instructions. However, coordinators were also expected to use it during the course of their coordinatorship. Instead, coordinators often filled out the form and started working from a plan 'in their head', without further reference to the form and without registrating adjustments. This effect was somewhat stronger for the non-professional group. Finally, evaluation was hardly ever made explicit. Coordinators seemed unable to give explicit attention to the evaluation of care on a regular basis.

\subsubsection{Implications}

On the whole it can be concluded that coordinators displayed sufficient effort, but had prohlems in using a systematic style of working. As described hy Abbott (1988), professionals might be expected to be more familiar with a methodical working style than non-professionals. This seemed to be true for this study, but differences between professionals and non-professionals were much smaller than one might suppose. This indicates that coordination of care should not necessarily be the domain of professionals. Therefore, a first implication of this study is that non-professionals should be taken seriously as potential coordinators. It became clear that in the training of future coordinators some aspects need specific attention. Non-professionals who are to function as coordinators should be aware of the fact that being responsible as a coordinator is not synonymous with doing all the work oneself. Non-professionals should receive additional training in mobilizing other care-givers. Furthermore, in training coordinators it should be pointed out even more explicitly that stability does not simply mean receiving the same type and amount of care, but that it should also mean receiving it from the same person. With regard to completeness and fidelity it can be concluded that methodical aspects are not sufficiently addressed in the training of coordinators. Although these aspects are explicitly dealt with, it is necessary to give more attention to methodical issues such as planning, evaluating and contacting

62 others. Since these are essential aspects of the work of a coordinator, potential coordinators should receive more counseling with regard to these tasks. Finally, professionals do not always perceive non-professionals as important care-givers and non-professionals are somewhat hesitant in contacting professionals. Since contacts between professionals and non-professionals are of vital importance to successful coordination, this issue should be addressed in future studies. In training coordinators, non-professionals probably should be offered assertiveness training. Professionals on the other hand, should be encouraged to broaden their scope on care networks. 


\section{References}

Abbott, A. 1988. The system of professions: An essay on the division of expert labor. The University of Chicago Press, Chicago.

Achterberg, Th. van and Stevens, F.C.J. 1994. Coördinatie van zorg in de eerste lijn: Verslag van hel onderzoek bij cliënten en zorgcoördinatoren. NIZW, Utrecht, The Netherlands.

Brody, E.M. 1981. "Women in the Middle" and family help to older people. Gerontologist, 21, 471-480.

Challis, D., Darton, A., Johnson, L., Stone, M. and Traske, K. 1991a. An evaluation of an alternative to long-stay hospital care for frail elderly patients: I. The model of care. Age and Ageing, 20, 236-244.

Challis, D., Darton, A., Johnson, L., Stone, M. and Traske, K. 1991b. An evaluation of an alternative to long-stay hospital care for frail elderly patients: II. Costs and effectiveness. Age and Ageing, 20, 245-254.

Davies, B. \& Challis, D. 1986. Matching resources to needs in community care. Gower Publishing Company, Aldershot, England.

Edelstei, H. and Lang, A. 1991. Posthospital care for older people: A collaborative solution. The Gerontologist, 31, 267-270.

Engström, B. 1988. Solving patients' information problems by the nursing process and by collaboration between the medical and the nursing staff. Scandinavian Journal of Caring Sciences, 2, 3-10.

Hall, G.E. and Loucks, S.F. 1977. A developmental model for determining whether the treatment is actually implemented. American Educational Research Journal, 14, 263-276.

Hugman, G. 1994. Social work and case management in the UK: Models of professionalism and elderly people. Ageing and Society, 14, 237-253.

Intagliata, J. 1982. Improving the quality of community care for the chronically mentally disabled: The role of case management.

Schizophrenia Bulletin, 8, 655-674.

Koedoot, C.G., Hommel, A.A.C., Horst, E.J. van der and Knipscheer, C.P.M. 1992. De ouderen in het project individuele zorgsubsidie Rotterdam: Longitudinaal onderzoek naar de effecten van zorgbemiddeling en zorgsubsidie. Vrije Universiteit, Amsterdam, The Netherlands.

Moore, S.T. 1990. A social work practice model of case management: The case management grid. Journal of the National Association of Social Workers, 35, 444-448.

Potting, M. 1994. Sekse, ouderdom en wetenschap: De rol van sekse in de sociale gerontologie. Rijksuniversiteit Limburg, Maastricht, The Netherlands.

Radol Raiff, N. and Shore, B.K. 1993. Advanced case management: New strategies for the nineties. SAGE Publications, Newbury Park, California.

RIGG Noord en Midden-Limburg 1992. Eerstelijns en geestelijke gezondheidszorg voor ouderen. RIGG, Venlo, The Netherlands.

Rosenthal, C.J., Matthews, S.H. and Marshall, V.W. 1.989. Is parent care normative? The experiences of a sample of middle aged women. Research on Ageing, 11, 244-260 
Shreier, M.A. and Lantos Rezmovic, E. 1983. Measuring the degree of program implementation: A methodological review. Evalualion Review, 7 , 599-633.

Shugart, E.B. 1992. Using volunteer visitors in home care. Journal of Nursing Administration, 22, 42-45.

Smith, D.W., McCormick, L.K., Steckler, A.B. and McLeroy K.R. 1993.

Teachers' use of health curricula: Implementation of Growing Healthy, Project SMART, and Teenage Health teaching modules. Journal of School Health, 63, 349-354

Surles, R.C., Blanch, A.K., Shern, D.L. and Donahue, S.A. 1992. Case management as a strategy for systems change. Health Affairs, 11, 151163.

Twigg, J. 1989. Models of carers: How do social care agencies conceptualize their relationship with informal carers? Journal of Social Policy, 18, 53-66.

Warrick, L.H., Netting, E., Christianson, J.B. and Williams,F.G. 1992.

Hospital-based case management: Results from a demonstration. Gerontologist, 32, 781-788.

Weiss, L.J. 1987. Care coordination: An integration mechanism.

In: Evashwick, C.J. and Weiss, L.J. (eds.). Managing the continuum of care. Aspen publishers, Rockville, Maryland.

Weissert, W.G., Matthews Cready, C. and Pawelak, J.E. 1988. The past and future of home and community based long-term care. The Millbank Quarterly, 66, 309-387.

Yura, H. and Walsh, M.B. 1983. The nursing process: Assessing, planning, implementing, evaluating. Appleton-Century-Crofts/Norwalk, Connecticut.

Zawadski, R.T. (ed.) 1984. Community-based systems of long term care. The Haworth Press, New York. 


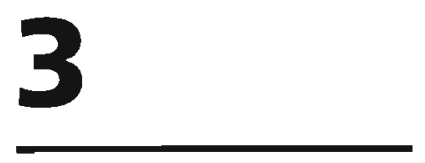

COORDINATION

OF CARE: EFFECTS

ON THE CONTINUITY

AND QUALITY

OF CARE

\author{
Theo van Achterberg \\ Fred C.J. Stevens \\ Harry F.J.M. Crebolder \\ Luc P. de Witte \\ and Hans Philipsen.
}

International Journal of Nursing Studies:

Accepted for publication. 


\section{Abstract}

Chronically ill elderly clients in three communities in the Netherlands were provided with the services of care-coordinators. Two studies were performed to evaluate the effects of this intervention. A study among 38 coordinators addressed the effects on the continuity of care. A second study among 72 elderly clients addressed the effects on client satisfaction.

While the study among coordinators clearly revealed effects on continuity (especially for interpersonal continuity), hardly any effects on satisfaction with care were reported by clients. Therefore, the appointment of care-coordinators seems valuable when aimed at increasing continuity, but other interventions can be more appropriate for the improvement of client care.

Key words:

Coordination of Care, Elderly, Community Care, Case Management 


\subsection{Introduction}

This paper examines the coordination of care in three communities in the Netherlands, as provided by professional and non-professional care-givers. Community care in the Netherlands is highly accessible and the fees are either covered by public insurance, compulsory insurance, private insurance, or only small fees are asked (Van Doorslaer et al., 1993). Although the standard of Dutch community care is high, a regular facility for the coordination of care is not available.

Definitions of coordination of care often refer to (1) the provision of tailormade care for clients, (2) the improvement of cooperation and fine-tuning within the care network, or (3) both elements (e.g. Austin \& O'Conner, 1989; Intagliata, 1982; Weiss, 1987; Alter \& Hage, 1993). Several projects that experimented with the coordination of care (or case management) reported effects on aspects of the quality of care. The Channeling Demonstrations in the U.S.A. for instance, showed that appointing case managers can result in fewer unmet needs and more confidence in care and care-givers (Carcagno et al., 1986; Rabiner 1992). Several other studies in the U.S.A. showed similar results (Weissert et al., 1988; Surles et al., 1992). Case management projects in the U.K reported increased client satisfaction as one of their outcomes (Davies \& Challis, 1986; Challis et al., 1991). In the Netherlands, the number of projects that focus on the conrdination of care is still limited and evaluation is sometimes insufficient. A Dutch study in the city of Rotterdam clearly showed effects of case management on several aspects of client satisfaction (Koedoot et al., 1991). Two other studies could only report indications for a possible effect on the quality of care (Van Amelsvoort et al., 1992).

Characteristic of most coordination projects is their emphasis on formalized care. A new professional, the coordinator or case manager, is introduced into the existing care network. This study had a different approach in that: a) professionals could only be coordinators when they were already involved in the care for a specific client, and b) informal care providers could also function as coordinators. According to Twigg (1989) informal care-givers can be seen as resources, co-workers or co-clients. In this study they were approached as coworkers. Informal care-givers might have less insight into community care and the available facilities, but they have expert knowledge of the client's history, private life and background. Their high frequency of contact with the client gives them optimal opportunity to monitor care. Furthermore, restricting coordination of care to professionals might bring along a process of medicalization (creating a monopoly of knowledge and increasing dependency) as described by Bond (1992). The choice for an intervention in which coordination of care was operationalized as a part of everyday care was based on both practical and ideological considerations. An intervention in which the coordinatorship was operationalized as a separate function would have necessitated more formal arrangements and was less acceptable to caregivers in the intervention setting (RIGG Noord en Midden-Limburg, 1992). Furthermore, it was believed that community care should not be so complex that it would necessitate a new profession. 
The intervention aimed at improving three elements of the continuity of care as described by Rogers and Curtis (Rogers \& Curtis, 1980; Hennen, 1975; Wall, 1981): interdisciplinary, interpersonal and informational continuity of care.

Interdisciplinary continuity can be seen as continuity in complex, multidisciplinary services. Appropriate referrals and coordination of services are examples of interdisciplinary continuity. Interpersonal continuity involves the quality and the endurance of relationships between clients and care providers. Finally informational continuity refers to the completeness of information available to and documented by care-givers, thus preventing unnecessary or duplicate care or treatment. It was expected that appointing coordinators for chronically ill elderly clients, would affect the cooperation and fine-tuning of services between care-givers (interdisciplinary continuity) and that coordinators would focus their attention on selected clients and would develop care-plans in cooperation with these clients (interpersonal continuity). Moreover, the appointment of coordinators was expected to increase both the amount and the avallability of relevant information (informational continuity). Apart from possible effects on the continuity of care, positive effects on client satisfaction might result from changes in client care. Client satisfaction -one essential aspect of the quality of care (Eustis \& Fisher, 1991)-refers to how well the individual feels that his needs have been met (Raaitkainen, 1991). Effects on client satisfaction might occur since coordinators were asked to make a care-inventory and care-plan. By doing this, problems in client care might be encountered and resolved.

Two studies were conducted to evaluate the effects on continuity and client satisfaction. A study among coordinators addressed the first research question.

1 In what way does the appointment of care-coordinators affect the interdisciplinary, interpersonal and informational continuity of care?

The second question -effects on client satisfaction- was evaluated in a client study.

2 Does the appointment of care-coordinators affect clients' satisfaction with care?

Although effects on client satisfaction were already found in quite a number 68 of studies, the question remains relevant for this study. While most projects include either additional budgets or formal arrangements regarding authorities and competencies, coordinators in this project could only rely on personal qualities and a limited number of tools. Therefore effects on client satisfaction for this approach could not automatically be assumed. 


\subsection{Methods}

\subsubsection{Intervention}

Professional care-givers that could function as coordinators were the community nurse, the family physician, the social worker and the manager/intaker from the home-help agency. Non-professional care-givers that could be appointed as coordinators were the spouse, one of the children, a relative, a neighbor or a friend of the client. Coordinators' tasks were derived from general principles of systematic working (Intagliata, 1982; Moore, 1990). These are very similar to those that have been developed for individual professions such as nursing (Yura \& Walsh, 1983).

The tasks can be differentiated from those of care-givers, however, by a focus on the total care for a client. All coordinators, whether they were professionals or not, were instructed to perform the following five basic tasks: (1) Introduction: Coordinators were asked to introduce themselves as the carecoordinator to the clients, the client's network and all care-givers that were involved with the client. (2) Making a care-inventory: Coordinators were supposed to make a list of all of the client's care demands, and care that was already available to the client. For this purpose a care-inventory form was developed. (3) Making a care-plan: After completing the care-inventory, the coordinator was expected to make a care-plan on a form that was developird for this purpose. This plan should contain general goals and the contributiuns of all care-givers. (4) Execution of the care-plan and monitoring care: Th:" execution of the care-plan involved consulting other car' givers and reaching a mutual agreement on the care needed. At this stage decisions were to be made on the exact nature of care activities, their gucls, their fle. quency and possible ways of evaluating them. As a tool in monitoring (art? the logbook was introduced. This logbook was a notebook for all care yivers that was located at the client's house. (5) Evaluation of the care-plan: Coordinators were asked to compare effects of the care that was actually received by the client to the goals that were stated in the care-plan.

All coordinators were instructed at the start of the project. During instruction meetings the objectives and methods of the project were clarified, and the five coordinator tasks were explained and illustrated. Coordinators were provided with a coordinators' guide and the above mentioned forms. During the intervention period, follow-up meetings were organized seperately for professional and informal care-givers. At these meetings experiences were exchanged and (potential) problems could be discussed. Professionals expressed a greater need for follow up meetings. Informal care-givers visited one or two follow up meetings, whereas the number of meetings that professionals attended varied from one to four.

\subsubsection{Selection of clients}

The intervention was implemented in three rural-urban communities in the province of Limburg (The Netherlands). Professional care-givers from the three communities were asked to select clients a) who were 60 years of age or 
older, b) who suffered from a chronic disease, c) who received care from at least two professional or non-professional care-givers and d) who lived independently in one of the three communities. This procedure resulted in a list of 486 clients. All of them were mailed a short questionnaire, that was developed for the purpose of getting more insight into the selected client group and used as a tool in a secondary screening of clients. Of the 234 persons that returned the questionnaire, 33 indicated that they did not want to participate. A comparison of age and sex did not show any significant differences for those who did and those who did not return the questionnaire. In the sicundary screening (by an independent general practitioner and an independent community nurse, using the same selection criteria) and in approaching clients for participation in the project, another 93 clients dropped out.

Eventually 108 clients participated at the start of the project. Clients were divided over two groups. The first group had a professional or a non-professional care-giver as their coordinator $(n=65)$. Clients in the second, smaller group did not have a coordinator $(n=43)$. The two groups of clients were matched, using a procedure that aimed at an equal distribution of clients up to and above 75 years of age, of males and females, and of those who were or were not living alone. Clients were interviewed at three stages in the project: at the start of the intervention ( $n=108)$, after six months $(n=87)$ and after twelve months $(n=72)$. For the purpose of this study, the results of the 72 clients that participated during the whole project were used. Analysis for the group of 87 clients that participated after 6 months did not reveal different results than those reported for the group of 72 clients.

\subsubsection{Coordinators}

At the start of the intervention, 22 non-professionals and 19 professionals were appointed as care-coordinators. Most non-professionals coordinated for one client, only one person coordinated for two clients (a couple) at the same time. For professionals, the number of clients ranged between one and four. Interviews were held with 19 professionals and 19 informal care-givers after 6 months and with 14 professionals and 15 informal care-givers after 12 months. Three of the informal care-givers dropped out before the interview at 6 months, due to the fact that their clients no longer participated in the project. Of the 9 drop-outs after the first interview, 5 were a result of clients that could no longer participate and four were a result of problems or circumstances of the coordinator (such as pregnancy or death of a spouse). At 6

70 months, the group of 19 professionals consisted of 2 social workers, 5 general practitioners, 7 managers of the home-help agency and 5 community nurses. The group of 19 non-professionals consisted of 5 spouses, 9 children (in law), 2 other relatives and 3 neighbors or friends. In both groups of coordinators, 12 persons were female and 7 were male. 


\section{Table 1}

Items and groups of items used in client interviews.

TOPICS

NUMBER OF ITEMS

$\alpha$

REFERENCES

\section{Client characteristics}

Sex

Age

Living arrangement

Education \& (former) profession

Disorders

Perceived health

Physical functioning

ADL impairments

IADL impairments

Mood

Psychosomatic complaints

Living arrangement

Income

Diversity of care

Diversity of total care

Client satisfaction

Dissatisfaction with care-givers

Satisfaction with informal care

Satisfaction with formal care

Quality of life

Perceived quality of life
.84

.84

Frederiks et al. 1991, Van Rossum 1989

Frederiks et al. 1991, Van Rossum 1989

.80

Arts et al. 1989

Arts et al. 1989

\subsubsection{Sources of data}

Interviews with clients and coordinators were used to assess the effects of the intervention. The two sources of data were, however, used for different purposes. Interviews with coordinators were used to answer the first research question, which concerned interdisciplinary, interpersonal and informational continuity. An open structure was used for these interviews. Coordinators were asked to reflect on such topics as communication, coordinator tasks and perceived effects of the intervention. All interviews were tape-recorded, transcribed and analyzed by two members of the research team. The computer program 'Kwalitan' (Peters et al., 1989) was used during the analyses. All interviows were divided into passages that were provided with topic: codes. Pre-structured client interviews were used to estimate the effect of conrdination on client satisfaction. The interviews addressed topics such as health, Activities of Daily Living (ADL), Instrumental Activities of Daily living 
(IADL), diversity of care, client satisfaction and quality of life. Table 1 gives an overview of interview topics, Chronbach's alphas for scales and references to the operationalizations used. The seven items on dissatisfaction with caregivers were used to calculate the number of complaints. To reduce the number of variables, perceived health, physical functioning, mood and psychosomatic complaints were combined in one new variable 'perceived health' (scores from 0 to 5). Factor analyses for these variables showed a one-factor structure. Cronbach's alpha for the new scale was .72 .

\section{Table 2}

Client characteristics, diversity of care, client satisfaction and quality of life ( $n=72)$.

$\begin{array}{llll}\text { RANGE } & \text { MEAN } & \text { SD } & N\end{array}$

\section{Client Characteristics}

Sex-female

Age

Living arrangement-alone

8.0

51

72

Education-only primary school

40

52

56

Profession

blue collar

39

white collar

housewife

Number of disorders

Perceived health

ADL impairments

IADL impairments

Diversity of care

Diversity of care

Client satisfaction

Dissatisfaction with care-givers

Satisfaction with informal care

Satisfaction with formal care

Quality of life

Perceived quality of life

\subsubsection{Description of the client group}

Of the 72 clients that participated during the whole year, 44 clients had a coordinator (in 26 cases a professional and in 18 cases a non-professional) and in 28 cases no coordinator was appointed. Characteristics of the total group can be found in tables 2 and 3 . The majority of the clients were female $(71 \%)$ and lived alone ( $56 \%$ ). Most of the clients belonged to the lower status 
classes as is shown by data on profession and education. Clients' mean age was 74, and clients reported three disorders on average. On the item 'impairment as a result of reported disorders', the average score was 2 (quite some impairment). Diseases that were reported most frequently were heart-diseases $(33 \%)$, chronic back pain $(28 \%)$, lung diseases $(21 \%)$, diabetes $(18 \%)$, rheumatic diseases (18\%) and hypertension (15\%). Clients perceived their health as "moderate". Clients reported an average number of 3.5 types of formal and informal care-givers. As could be expected, general practitioners and home helpers had the largest contribution in the formal network, whereas family members (other than the partner) had the largest contribution in the informal network (table 3 ).

\section{Table 3}

Clients receiving formal and informal care $(n=72)$.

$\begin{array}{lrrlll}\text { FORMAL } & \text { N } & (\%) & \text { INFORMAL } & \text { N } & (\%) \\ & & & & & \\ \text { general practitioner } & 60 & (83) & \text { partner/spouse } & 23 & (32) \\ \text { home help } & 36 & (50) & \text { family members } & 46 & (64) \\ \text { community nurse } & 21 & (29) & \text { neighbors/friends } & 27 & (37) \\ \text { physiotherapist } & 17 & (24) & & & \\ \text { social worker } & 6 & (8) & & & \\ \text { others } & 17 & (24) & & & \end{array}$

\subsection{Results}

1 In what way does the appointment of care-coordinators affect the interdisciplinary, interpersonal and informational continuity of care?

In order to study the results for interdisciplinary, interpersonal and informational continuity of care, all passages on effects were selected from the coordinator interviews, using the Kwalitan computer program. The effects were categorized according to 17 different subjects (table 4). A first result is that -regardless of the subject- professionals seemed to experience more effects than non-professionals. Furthermore, the 7 coordinators that reported no effects at all were all non-professionals. It follows that 12 non-professionals and all 19 professionals experienced one or more effects as a result of the intervention. 


\subsubsection{Interdisciplinary continuity}

Five categories of effects were grouped as effects on interdisciplinary continuity. The most important effect was the increased recognition that was reported by 14 coordinators. This effect not only referred to status. The increased recognition and authority basically implied that other care-givers approached coordinators with questions and kept the coordinator informed, thus creating better possibilities for interdisciplinary continuity. Nine coordinators reported more or improved contacts with other care-givers, and 7 coordinators experienced improved fine-tuning or cooperation. Furthermore, 4 coordinators claimed that they had used a broader perspective after they became coordinators. Improved fine-tuning or cooperation and working with a broader perspective were only reported by professionals. The formalization of an already existing coordinatorship was named by only 1 coordinator, a non-professional. Of the total group of 19 professionals, only 5 professionals reported no effect on interdisciplinary continuity. For the non-professional group just the opposite was found. A majority of 14 persons reported no effects on interdisciplinary continuity.

\subsubsection{Interpersonal continuity}

Coordinators addressed five topics that could be seen as effects on interpersonal continuity. Two of these effects are obviously related. Whereas 5 of the 38 coordinators thought that their appointment had resulted in decreased client dependency, 1 coordinator claimed just the opposite. The most important effect with regard to interpersonal continuity was that -according to 14 coordinators-clients received more attention and support. For this finding, the difference between professionals and non-professionals was relatively small. A group of 11 coordinators reported that the intervention had resulted in more or improved contacts with clients, and 7 coordinators had contacts with their clients more frequently or saw that the contacts with their clients improved. These two subjects were more often addressed by professionals. Effects on interpersonal continuity were mentioned more frequently than effects on interdisciplinary or informational continuity. A clear minority of 14 coordinators reported no effects on interpersonal continuity. Professionals reported more effects on interpersonal continuity than non-professionals.

\subsubsection{Informational continuity}

Only two subjects were grouped under informational continuity. A group of 14 coordinators claimed that they gained more insight and perceived more

74 clarity with regard to the client's situation, and 11 coordinators reported that they received more information as a result of the project. While the effect on informational continuity implied that coordinators received more or new information, the effect on insight and clarity meant an improvement in the accessibility and the organization of existing information.

Again, the effect was much stronger for professionals. Whereas a majority of 13 professionals experienced one or both effects on informational continuity, a minority of only 5 non-professionals did. 


\section{Table 4}

Effects according to coordinators $(n=38)$.

$\begin{array}{lrcc}\text { EFFEC } & \begin{array}{c}\text { TOTAL } \\ (\mathrm{N}=38)\end{array} & \begin{array}{c}\text { PROFS } \\ (\mathrm{N}=19)\end{array} & \begin{array}{c}\text { NON-PROFS } \\ (\mathrm{N}=19)\end{array} \\ \begin{array}{l}\text { Interdisciplinary } \\ \text { More recognition or authority }\end{array} & 14 & 10 & 4 \\ \text { More or improved contacts with care-givers } & 9 & 6 & 3 \\ \text { Improved fine-tuning or cooperation } & 7 & 7 & 0 \\ \text { Broader perspective } & 4 & 4 & 0 \\ \text { Formalization of existing coordinatorship } & 1 & 0 & 1 \\ \text { No effect on interdisciplinary continuity } & 19 & 5 & 14 \\ \text { Interpersonal } & 14 & & \\ \text { More attention and support for clients } & 11 & 9 & 6 \\ \text { More involved or responsible } & 7 & 6 & 2 \\ \text { More or improved contacts with clients } & 5 & 1 & 1 \\ \text { Decreased client dependency } & 1 & 0 & 4 \\ \text { Increased client dependency } & 14 & 2 & 1 \\ \text { No effect on interpersonal continuity } & & & 12 \\ \text { Informational } & 14 & 11 & 3 \\ \text { More insight and clarity } & 11 & 7 & 4 \\ \text { More information } & 20 & 6 & 14 \\ \text { No effect on informational continuity } & & & \\ \text { Other } & 9 & 7 & 2 \\ \text { More conscious or methodical working style } & 9 & 5 & 4 \\ \text { Improved client care } & 3 & 3 & 0 \\ \text { Increased (coordinator) satisfaction } & 2 & 2 & 0 \\ \text { Coordination in other situations } & 2 & 0 & 2 \\ \text { Instructive for coordinators } & 7 & 0 & 7 \\ \text { No effect } & & & \end{array}$

\subsubsection{Client satisfaction}

Effects on client satisfaction were addressed in the second research question:

2 Does the appointment of care-coordinators affect clients' satisfaction with care?

Table 5 shows the differences between clients with and clients without coordinators at the three measurement times, using $T$-tests. Sex, age, living arrangement, profession, education and income are not included in the table. For these characteristics, no differences between the two groups were found at baseline. Furthermore, these characteristics obviously showed no or very little variation over time. 
Significant differences between the two groups were found, however, for IADL impairments and diversity of care. At the start of the intervention, clients who were provided with coordinators reported more IADL impairments and received care from more types of care-givers than clients without coordinators. When looking at the effects of the intervention, group differences after 6 and after 12 months of coordination of care are important. Differences in client satisfaction were only found for clients' dissatisfaction with care-givers at the second interview. After six months of coordination of care, clients in the intervention group reported fewer complaints about caregivers than clients in the comparison group. After 12 months, the two groups were back at the same level. A multivariate analysis for the three repeated measurements showed an interaction effect of time and group $(F=3.55 \mathrm{df}=2$ $\mathrm{p}=.03$ ), meaning that the development of scores for dissatisfaction with caregivers was significantly different for the two groups. When IADL impairments and diversity of care at baseline were used as covariates in the MANOVA procedure, the effect remained equally strong. Comparison of the two experimental sub-groups (professionals as coordinators and non-professionals as coordinators) showed that the effect occurred for both groups.

\section{Table 5}

Differences between clients with (Intv, $n=44$ ) and clients without (Comp, $n=28$ ) coordination of care at 0, 6 and 12 months (tested with T-tests).

$\begin{array}{ccc}\text { O MONTHS } & 6 \text { MONTHS } & 12 \text { MONTHS } \\ \text { INTV COMP } & \text { INTV COMP } & \text { INTV COMP }\end{array}$

\section{Client characteristics}

Number of disorders

Perceived health

ADL impairments

IADL impairments

Diversity of care

Types of care-givers

Client satisfaction

Dissatisfaction with care-givers

$\begin{array}{ll}2.8 & 2.8\end{array}$

$3.2 \quad 3.5$

11.110 .0

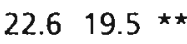

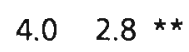

$\begin{array}{ll}0.8 & 0.9\end{array}$

$4.2 \quad 4.1$

$4.2 \quad 4.1$

$3.5 \quad 3.8$
3.03 .0

3.23 .6 *

$10.8 \quad 9.8$

22.320 .3

3.92 .8 *

$0.71 .0^{\star *}$

4.34 .1

$4.0 \quad 4.1$

3.64 .0 *
$3.2 \quad 2.8$

3.23 .7 *

11.510 .5

23.220 .9

$3.82 .8 \star \star$

$0.8 \quad 0.8$

$4.3 \quad 4.1$

4.14 .1

Quality of life

Perceived quality of life

* significant difference, $p \leq .10$

* significant difference, $p \leq .05$ 


\subsubsection{Other effects}

Both the interviews with coordinators and the interviews with clients revealed a number of effects that were not covered by the two research questions. Four 'other' effects were mentioned by relatively small groups of coordinators (table 4). Nine coordinators reported using a more methodical working style or being more conscious of one's personal working style. This effect was mentioned by 7 professionals and 2 non-professionals. Two effects were mentioned by professionals exclusively. Three professionals reported increased satisfaction with their own work, and 2 professionals reported applying coordination of care in situations outside the scope of the project. Two non-professionals mentioned that participating in the project had been a personal learning experience for them.

Interviews with clients revealed differences between those with and those without coordinators for perceived health after 6 and 12 months, for diversity of care at 0,6 and 12 months and for quality of life after 6 and 12 months (table 5). When tested with MANOVA however, no interaction effects of time and group were found for perceived health $(F=0.08 \mathrm{df}=2 \mathrm{p}=.92)$, diversity of care $(F=0.37 \mathrm{df}=2 \mathrm{p}=.69)$ or quality of life $(F=0.61 \mathrm{df}=2 \mathrm{p}=.54)$. This implies that differences in health, quality of life and diversity of care could not be contributed to the intervention, but resulted from differences between clients with and without coordinators at baseline or from developments over time that were more or less similar for both groups.

\subsection{Discussion}

The project 'Coordination of Care in the Community' focussed on one specific operationalization of coordination of care. The intervention in this project showed little deviation from normal practice in community care. Coordinators were appointed for specific clients. Only those that were already involved as care-givers could function as coordinators. Furthermore, coordinators were equipped with tools and guidelines, but did not receive budgets, special privileges or authorizations. This probably had positive effects on the feasibility of the intervention, but limited possible effects.

The strength of the design is that it offers insight into the coordination of care from both the client's and the coordinator's perspective, using repeated measures and using both qualitative and quantitative methods. However, some critical comments with regard to the methods should be madle. First of all, the number of clients and coordinators was relatively small. The low response rates for clients imply that it is unlikely that the group of 72 clients; is an exact representation of all clients who fit the selection criteria. The participation of coordinators partially depended on the willingness of potential coordinators. This was never a problem with community nurses, managers from the home-help agency and social workers, but some selection took: place: 
for non-professionals and general practitioners. In the study, these two groups are a selection of those who were relatively more motivated.

With regard to the interviews with both coordinators and clients, the question of the social desirability of the answers might be raised. It seems unlikely that clients gave the answers researchers would want to hear, since hardly any effects on client satisfaction were reported. On the other hand, it is possible that effects were not found because clients gave desirable answers at baseline and continued to do so after 6 and 12 months. The fact that clients scored very positively on the client satisfaction measures might be seen as an indication of this problem. Therefore it might be concluded that potential desirable answers of clients would be directed towards care-givers ('gratefulness') and not so much towards researchers.

It is unlikely that coordinators adapted their answers to what the interviewers might want to hear, since open questions were used in the interviews with coordinators. This means that coordinators chose their own topics in reaction to general questions such as "What do you think of the intervention?".

Interviews with coordinators showed that effects could be found for the three aspects of continuity of care. In all cases effects were stronger for pro-

fessionals than for non-professionals. For non-professionals effects were only reported by minorities. For the total group this meant that half of the coordinators experienced effects on interdisciplinary and informational continuity and that a majority of the coordinators mentioned effects on interpersonal continuity. Two conclusions can be drawn from this. First of all, the intervention clearly affected the continuity of care in the experience of professionals and showed relatively little effect for non-professionals. One explanation for this can be that non-professionals have somewhat more difficulty in expressing themselves on care issues. According to non-professionals themselves, the relative absence of effects was due to the fact that coordinator activities were not all that new to them. While professionals expressed that they were more focussed on specific clients and were more aware of the involvement and activities of other care-givers, non-professionals claimed that their client had been the focus of their attention for a long time and that they had already been aware of the presence and activities of other care-givers.

Secondly, one might conclude that the intervention affected all three aspects of continuity, but that the effect on interpersonal continuity was most considerable. This means that the appointment of coordinators especially affected care-giver-client relationships. Effects with regard to interpersonal continuity

78 might be summarized as follows: more attention, more support and less dependency for clients, and more involvement, responsibility and client contacts for coordinators. Obviously coordinators were (even) more deliberately focussed on and aware of their client's situation. According to coordinators, the use of care inventories, care-plans and logbooks largely contributed to this awareness. The potential problem of increasing dependency through coordination of care occurred only once, implying that this should not be considered a major potential problem in future studies. 
Interviews with clients showed hardly any effect on client satisfaction. Only a short-term effect on dissatisfaction with care-givers was found. Furthermore, only 9 out of 38 coordinators thought that client care had improved as a result of the intervention. The fact that clients were quite satisfied with the care at baseline can be one explanation for the lack off effects. Another explanation might be that coordinators lacked the power and authority to really affect care. In this study, coordinators could only rely on a number of tools to structure information and planning and to facilitate communication with other care-givers. An intervention that formalizes the position of coordinators and provides them with more authority (Challis et al., 1991; Koedoot et al., 1991) might have more effect on client care and the client satisfaction.

About one quarter of the group of coordinators (mostly professionals) reported using a more conscious or more methodical working style. This effect is hardly surprising since coordination of care is partially about methodical working and being more conscious of both the situation and the personal working style. Indeed one might expect this effect to be mentioned more often. However it is possible that this effect was not mentioned by some coordinators because it was too obvious to mention.

It can be concluded that coordination of care as operationalized in this project does not -or hardly-affect client satisfaction, but results in more continuity of care. Especially the care-giver-client relationship (interpersonal continuity) was affected as a result of a relatively simple intervention. Therefore, the intervention can be valuable if one aims at increasing continuity. However, if one focusses on improving care, other interventions might be more appropriate.

\section{Acknowledgement}

The project was financed by and carried out in cooperation with the Netherlands' Institute for Care and Welfare (NIZW). 


\section{References}

Alter, C. \& Hage, J. (1993). Organizations Working Together. SAGE, Newbury Park, CA.

Amelsvoort, F. van, Dokter, H. \& Willems, D. (1992). Tussen zes komma vijf en achtkomma vier: Evaluatie onderzoek naar de functie zorgcoördinator ouderen in de gemeente Aalten. NIZW, Utrecht, The Netherlands.

Andrews, F.M. \& Whitey, S.B. (1976). Social Indicators of Well-being: Americans'Perception of Life Quality. Plenum Press, New York.

Arts, C.H., Hommel, A.A.C., Felling, A.J.A. \& Knipscheer, C.P.M. (1989) Ouderen geprofileerd: Meetinstrumenten ten behoeve van het gemeentelijk ouderenbeleid. Vrije Universiteit, Amsterdam, The Netherlands.

Austin, C.D. \& O'Conner, K. (1989). Case Management: Components and Program Contexts. In M.D. Petersen \& D.L. White (Eds.), Care of the Elderly: An Information Source Book, pp. 167-205. SAGE, Newbury Park, CA.

Bond, J. (1992). The Politics of Caregiving: The Professionalisation of Informal Care. Ageing and Society, 12, 5-21.

Carcagno, G.J., Wooldridge, J., Brown, R.S. \& Kemper, P. (1986). The Evaluation of the National Long term Care Demonstration: Final Report. Mathematica Policy Research, Princetown, UK.

Challis, D., Chessum, R., Chesterman, J., Luckett, R. \& Woods, B. (1987). Community Care for the Frail Elderly: An Urban Experiment. British Journal of Social Work, 18, 13-42.

Challis, D., Darton, R, Johnson, L., Stone, M. \& Traske, K. (1991). An Evaluation of an Alternative to Long-stay Hospital Care for Frail Elderly Patients: II Costs and Effectiveness. Age and Ageing, 20, 245-254.

Davies, B. \& Challis, D. (1986). Matching Resources to Needs in Community Care. Gower, Hampshire, UK.

Doorsliter, E. van, Wagstaff, A. \& Janssen, R. (1993). Equity in the Finance and Delivery of Health Care. Oxford University Press, Oxford, UK.

Eustis, N.N. \& Fischer, L.R. (1991). Relationships between Home Care Clients and Their Workers: Implications for Quality of Care. The Gerontologist, 31, 447-456.

Frederiks, C.M.A., Te Wierik, M.J.M., Visser, A.Ph. \& Sturmans, F. (1991) A Scale for Functional Status of the Elderly Living at Home. Joumal of Advancid Nursing, 16, 187-292.

Hennen, B.K. (1975) Continuity of Care in the Family Practice: Dimensions of Continuity. Journal of Family Practice, 2, 373-374.

Intagliata, J. (1982). Impruving the Quality of Community (are for the Chronically mentally Disabled: The Role of Case Management.

Schizophrenia Bulletin, 8, 655-674.

Koedoot, ('.H., Hommel, A.A.C., Horst, E.J. van der \& Knipscheer, C.P.M.

(1991). De ouderen in het project Individuele Zorgsubsidie Rolterdam, Deel II: Longitudinaal onderzoeh naar de effecten van zorgbemiddeling en zorgsubsidie. Vrije Universiteit, Amsterdam, The Netherlands. 
Moore, S.T. (1990). A Social Work Practice Model of Case Management: The Case Management Grid. Journal of the National Association of Social Workers, 35, 444-448.

Peters, V., Wester, F. \& Ricardson, R. (1989). Kwalitatieve analyse in de praktijk en handleiding bij Kwalitan. Instituut voor Toegepaste Sociale Wetenschappen, Nijmegen, The Netherlands.

Raaitkainen, R. (1991). Dissatisfaction and Insecurity of Patients in

Domiciliary Care. Journal of Advanced Nursing, 16, 154-164.

Rabiner, D.J. (1992). The Relationship Between Program Participation, Use of

Formal In-home Care and Satisfaction with Care in an Elderly Population.

The Gerontologist, 32, 805-812.

RIGG Noord en Midden-Limurg (1992). Eerstelijns en Geestelijke

Gezondheidszorg voor Ouderen. RIGG Noord en Midden-Limburg, Horn,

The Netherlands.

Rogers, J. \& Curtis, P. (1980). The Concept and measurement of Continuity

in Primary Care. American Journal of Public Health, 70, 122.

Rossum, H.J.L. van (1989). Thuiswonende ouderen in de gemeenten Weert,

Nederweert en Stramproy: een verslag van een postenquête naar de

zelfredzaamheid, gezondheidsbeleving en het gebruik van hulp.

Rijsuniversiteit Limburg/ Provinciaal Samenwerkingsverband Limburgs

Groene Kruis, Maastricht, The Netherlands.

Surles, R.C., Blanch, A.K., Shern, D.L. \& Donahue, S.A. (1992). Case

Management as a Strategy for Systems Change. Health Aitairs, 11, 151163.

Twigg, J. (1989). Models of Carers: How Do Social Care Agencies

Conceptualize their Relationship with Informal Carers? Journal of Social

Policy, 18, 53-66.

Wall, E. (1981). Continuity of Care and Family Medicine: Definitiun,

Determinants, and Relationship to Outcome. The Journul of Family

Practice, 13, 655-664.

Weiss, L.J. (1987). Care Coordination: An Integration Mechanism. In C.J.

Evaschwick \& L.J. Weiss (Eds.), Managing the Continuum of Care (pp.

271-291). Aspen Publishers Inc, Rockville, MD.

Weissert, W.G., Matthews Cready, C. \& Pawelak, J.E. (1988). The Past and

Future of Home and Community Based Long-term care. The Millbank

Quarterly, 66, 309-387.

Yura, H. \& Walsh, M.B. (1983). The Nursing Process: Assessing, Planning, Implementing, Evaluating. Appleton-Century-Crofts, Norwalk, CT. 


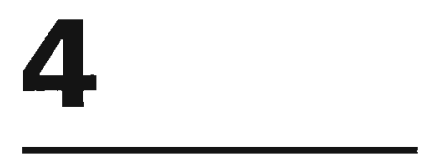

PREDICTORS OF

PROFESSIONAL AND

NON-PROFESSIONAL

COMMUNITY CARE FOR

CARE-DEPENDENT ADULTS

Theo van Achterberg,

Fred C.J. Stevens,

Harry F.J.M. Crebolder

\& Hans Philipsen.

Health Policy (1996) 36: 83-98. 


\section{Abstract}

The increasing number of elderly people in most industrialized countries makes reforms in health care necessary. However, knowledge of factors that determine the use of care is scarce. The study described in this article focusses on correlates of the diversity of professional and non-professional care used by care-dependent adults who live in the community. A group of 177 care-dependent adults was identified by means of a large scale telephone survey in the Dutch community of Tegelen. Potential correlates of the diversity of professional and non-professional care were derived from Andersen's Behavioral Model of Health Services [4,5] and Litwak's Task Specifity Model [12]. Both models proved to be valuable to the explanation of variance in the diversity of care. Potential correlates derived from the two models, could account for $21 \%$ of the variance for total care, $25 \%$ of the variance for professional care, and $34 \%$ of the variance for non-professional care.

Key words:

Community care, Informal care, Diversity of care 


\subsection{Introduction}

In the Netherlands, as in many other European countries, the number of people who are dependent on the care of others is increasing. The number of people over 85 -currently approximately half of all people who are caredependent- has been predicted to increase with $76 \%$ until the year 2010 [1]. Until now, institutional and community care in the Netherlands have been known to be highly accessible. Nearly all Dutchmen are either compulsory or privately insured for costs of care or medical treatment. This implies that most services are free of charge or require only minor fees [2]. However, the increasing number of care-dependent people has a vast influence on the costs of health care. For this and other reasons, substitution of institutional care by cheaper community care, higher financial contributions by clients and stimulating non-professional care are issues in Dutch health care today. Recently, the Dutch government has been promoting projects that aim at reforming community care [3]. Knowledge of the actual use of professional and non-professional community care and knowledge of possible related factors thus becomes relevant to policy in health care.

One of the models that was frequently used to predict the use of health services is the Andersen Behavioral Model of Health Services [4,5]. Andersen describes three groups of factors that can explain the use of services: predisposing, enabling and need factors. Predisposing factors refer to the individual's predisposition to use services. Age, sex and education are examples of predisposing factors. Enabling factors refer to the ability to use services. Examples of enabling factors are household composition, insurance and availability of services. The third group of factors, need factors, refer to conditions that determine the need for care, such as health status and functioning. Although the model was originally developed to explain the use of medical care and dental care services [4], it has been used with regard to many other types of care. The model has, for instance, been used to explain the use of medical, mental, personal and recreational care [6], the use of institutional and non-institutional care [7] and the use of community nursing and home helpers [8]. Most studies identified need factors as the most relevant factors in the explanation of the use of care. Some studies identified several enabling and predisposing factors as important correlates of the use of care as well. In Dutch studies, gender, marital status, age, severity of the disease, income and functioning with regard to Instrumental Activities of Daily Living (IADL), were identified as factors that influence the use of professional and/or non-professional care $[8,9,10,11]$. However, no clear and consistent pattem of relevant predisposing, enabling and need factors was identified as yet.

The first purpose of this study was to test the Andersen model's relevance to the diversity of non-professional and the total care (professional+non-professional). The Andersen model was used to find correlates of the use of both professional and non-professional community care. Professional community care was seen as all medical and non-medical care that was provided by 
persons who were trained, organized and/or paid for, and that was used by clients who lived independently in the community. Non-professional community care included all informal care by persons from the client's own network. The use of care was estimated by studying the diversity of care (number of different types of care-givers), rather than the actual numbers of care-givers. Whereas the model has been used for the explanation of the use of several professional services, it is unknown if predisposing, enabling and need factors can also be used in the explanation of non-professional and total care. The second purpose of this study was to see if the Andersen model could be extended with a fourth group of factors. According to Litwak's task-specifity model [12] the use of professional or non-professional care is a result of specific tasks to be carried out. Litwak hypothesizes for instance, that emotional support is a specific task for non-professionals from the personal lay-network. This implies that the relationship between professional and non-professional care is one of complementarity, rather than substitution. For this reason, a fourth factor called Care-tasks was included, to represent the type of care involved (e.g. emotional or practical support).

Ultimately, three research questions will be addressed. First, a description of the diversity of professional and non-professional care used in a general population will be given. From there, the relationship between predisposing, enabling and need factors and care-tasks on the one hand, and the diversity of the tutal, non-professional and the professional care on the other hand, will be discussed.

The three research questions were formulated as follows:

1 What is the diversity of professional and non-professional care used by care-dependent persons in a general population survey?

2 Which predisposing, enabling and need factors and which care-tasks can be used to explain the total diversity of care?

3 Which predisposing, enabling and need factors and which care-tasks can be used to explain the diversity of professional and non-professional care?

\subsection{Methods}

\subsubsection{Sample}

86 A telephone survey was carried out in the Dutch community of Tegelen $(+19,000$ inhabitants). The community of Tegelen can be described as a somewhat urbanized rural community in the south of the Netherlands. The population of this community is not different from the Dutch population as a whole with regard to basic demographics such as age distribution, percentages of males and females and population growth $[13,14]$. A total number of 1932 randomly selected households were contacted by a team of trained interviewers. The survey had been announced in two local newspapers and 
on two local radio stations. If the first attempt at contacting the household was fruitless, new attempts were made until a member of the household was reached. In those cases where potential respondents were caught at an inconvenient moment, an appointment was made for a more appropriate time. The survey was carried out during mornings, aftemoons and evenings of 13 successive working days. About $73 \%$ of the households ( $n=1406$ ) participated in the study. A total of 490 persons refused to participate due to lack of time or interest (25\%). In 36 cases ( $2 \%$ ) language problems occurred. Respondents were asked if there was a person within their own household who was dependent on the care of others. Being dependent on the care of others was defined as not being able to function without care. Furthermore, it was explained that the dependency had to be related to reasons of mental or physical health and that care could involve both professional and non-professional care. If a care-dependent person was part of the household, the interviewer asked if this person could come to the phone. In 190 cases (14\%) the household contained a care-dependent person. For the analysis in this article only data from dependent adults -18 years of age or older-were used. This reduced the number of cases to 177 (13\% of 1406$)$.

\subsubsection{Questionnaire}

The questionnaire used in the survey addressed predisposing factors, need factors, care characteristics and diversity of care. Items or groups of items that were addressed in the survey are shown in table 1 . The operational research model is shown in figure 1.

Predisposing factors - Four predisposing factors were included in the study. For this purpose the respondents' age, sex, educational level and profession (occupational level) were registered. Educational level was measured as only primary school or any additional education. The respondents' occupational level was classified in nine categories, using the Dutch standard classification of occupations [15]. In this classification the minimum score of 1 represents the so called 'elementary occupations' (mostly manual work, no education required), whereas a score of 9 represents the 'scientific-administrative occupations'. For the analyses in this study, occupational level was recoded as either 'low' (scores 1 to 3 ) or 'middle or high' (scores 4 to 9). It was expected that women and relatively older respondents would score higher on diversity of professional care [8]. One might expect that this would also be the case for non-professional and total care. With regard to educational and occupational level it was expected that respondents with higher educational and occupational levels would have fewer difficulties in mobilizing professional and non-professional care-givers, and there-fore would report higher diversity of care. were less relevant in this study since clients were all from the same community and next to all Dutchman are insured for the costs of health care. It was expected that those who lived alone would report a lower diversity of non-professional care $[9,11]$, which might result in a higher diversity of professional care. 


\section{Figure 1}

Research model: Correlates of the diversity of care.

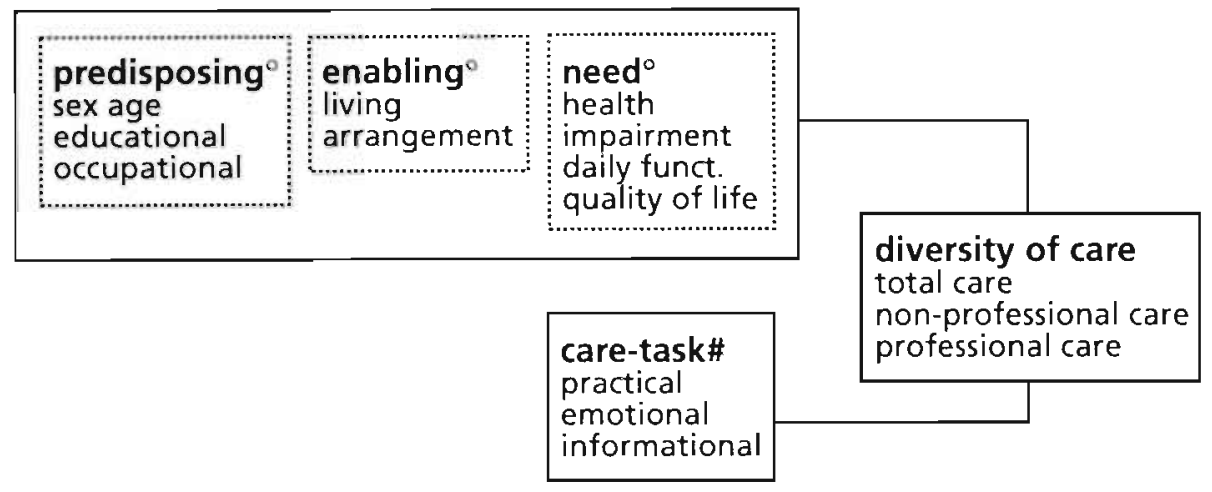

- derived from Andersen (1975, 1995)

\# derived from Litwak (1985)

Enabling factors - Only one enabling factor was included in the study. The respondents' living arrangement (living alone or sharing a household) was seen as enabling, especially for the diversity of non-professional care. Other enabling factors, such as available health services and health insurance, Need factors - Need factors in the study were perceived health, perceived impairment, daily functioning and perceived quality of life. Functioning with regard to Activities of Daily Living (ADL) and Instrumental Activities of Daily Living (IADL) was estimated using a 16-item list including the topics: getting infout of bed, washing, dressing, going to the bathroom, eating and drinking, walking around the house, walking stairs, making beds, doing the laundry, cleaning windows, shopping, cooking, washing dishes, vacuum cleaning, administrative activities and visiting others [16]. Factor analysis showed that ADL and IADL items could be combined in a one-factor scale (Eigenvalue 5.44), which is in line with results reported by Frederiks et al. [16]. In this study Cronbach's alpha for the daily functioning scale was 0.86 . Perceived quality of life was measured using a three item list, derived from the work of

88 Andrews and Whitey [17]. Items included happiness, satisfaction and a global estimation of one's own life in terms of good and bad. Cronbach's alpha for this three item scale was 0.78. A factor analysis for the quality of life scale revealed a clear one factor structure (Eigenvalue 2.22). Apart from the four health-related need variables, the type of disease was also registered.

However, this variable is not listed in tables 1 and further, since it was only included for the purpose of describing the research group and was not part of the actual model. Naturally, it was expected that respondents with a higher 
need (e.g. less healthy, more impaired in daily functioning) would report higher levels of diversity of care.

Care-tasks - Three care-tasks were registered. Respondents could indicate whether they received practical support, emotional support, informational support, or any combination of the three. Practical support was operationalized as help or support with regard to personal care, household activities, personal finances, transport or other tasks such as shopping or taking care of children. Emotional support was clarified as help or support with regard to personal problems, problems in relations with others, or problems in coping with disease or handicap. Finally, informational support was operationalized as all support conceming health or care related questions. Following Litwak's line of thinking [12], it was expected that emotional support would indicate more diversity of non-professional care, that informational support might indicate more diversity of professional care, and that practical support might indicate higher diversity in both types of care.

\section{Table 1}

Items and groups of items used in client interviews.

TOPICS

NUMBER OF ITEMS

RANGE

$\alpha$

\section{Predisposing}

Sex

Age

Educational level

Occupational level

Enabling

Living alone

Need

Perceived health

Perceived impairment

Daily functioning

Perceived quality of life

\section{Care-type}

Practical support

Emotional support

Informational support

Diversity of care

Diversity of non-professional care

Diversity of professional care

Diversity of total care $\mathrm{m} / \mathrm{f}$

18 .

prim/sec

low/mid-high

yes/no

$1-4$

$0-16$

$1-5$

.86

.78

yes/no

yes/no

yes/no 
Diversity of care - The diversity of professional care was measured by counting the number of different professional services involved. A maximum of eleven different professionals could be indicated. Respondents could indicate whether they used services from private cleaning ladies, family physicians, community nurses, home helpers, social workers, physiotherapists, medical specialists, day-care centers and a maximum of three others (such as dieticians and psychiatrists). For non-professional care a maximum of five types of non-professional carers could be mentioned: partners, children (in law), parents, other family members and neighbors, friends or acquaintances. In computing the diversity, the number of different sources was counted instead of the number of persons. Children (in law), for instance, could be a source of non-professional care. If a respondent received care from three children, this would be scored as 1 (non-professional) source. The scores for the diversity of professional and non-professional care thus represent the number of types of care-givers and not the actual number of persons. The diversity of total care was computed as the sum of the diversity of professional and non-professional care. Thus, a maximum of 16 different types of care-givers could be indicated. Two of the 'outcome measures' were also used as factors in the explanation of one of the other measures. Since it is often hypothesized that the diversity of non-professional care influences professional care [18], the diversity of non-professional care was included as a potential correlate of professional care only. In order to be able to examine the opposite mechanism The diversity of professional care as a factor in the explanation of the diversity of non-professional care - The diversity of professional care was included in the analysis for non-professional care. In line with the Andersen model and current discussions on substitution, the diversity of either professional or non-professional care might be seen as a need factor in relation to the other type of care. In this line of thought a deficit in one type of care will lead to an increased need for the other care type.

\subsubsection{Analyses}

Simple frequencies were used with regard to the first research question (an inventory of the diversity of professional and non-professional care). More complicated analyses were used for research questions 2 and 3 (identifying correlates of total, professional and non-professional care. First of all, T-tests were performed to determine the bivariate relationships between potentially related factors with two possible scores (e.g. male/female) and the three outcome measures. For the other variables, correlation coefficients were com-

90 puted. For the purpose of identifying trends, relationships that did not meet the .05 significance level, but were above a significance level of .10 were also reported. In a second step, all potentially relevant factors were used in a backward regression procedure. In this procedure a significance level of .05 was used. 


\section{Table 2}

Scores on predisposing factors, enabling factors, need factors, care-type and diversity of care $(n=177)$.

$\begin{array}{lll}\text { MEAN } & \text { SD } & \text { N }\end{array}$

\section{Predisposing factors}

Female

Age

63.6

Only primary school

17.5

Low occupational level

Enabling factors

Living alone

\section{Need factors}

Perceived health

$\begin{array}{rr}3.1 & 0.9 \\ 3.0 & 0.9 \\ 11.3 & 3.9 \\ 3.7 & 0.8\end{array}$

Perceived impairment

Daily functioning

Perceived quality of life

\section{Care-type}

Practical support

Emotional support

Informational support

\section{Diversity of care}

Diversity of non-professional care

2.1

1.6

Diversity of professional care

2.7

1.5

Diversity of total care

4.8

2.1

\subsection{Results}

\subsubsection{Background characteristics}

The mean age of the 177 respondents was 64 years of age, $67 \%$ of the caredependent adults were females. Among the most commonly reported diseases were diseases of the eye, ear or organ of balance $(27 \%)$, cardiovascular diseases $(26 \%)$, bone or joint diseases $(25 \%)$, chronic back-pain $(12 \%)$, lung diseases $(10 \%)$, diseases of the digestive system $(10 \%)$, psychiatric disorders $(9 \%)$ and trauma resulting from accidents $(6 \%)$. Other disorders were reported by less than $5 \%$ of the respondents. More than one disorder could b. reported. However, $64 \%$ reported only one disease, $28 \%$ reported two and $8 \%$ reported three diseases or disorders. Some characteristics of the total sample are shown in table 2 . The educational level of the total group was quite low, about half of the group had only attended primary school. Accordingly, $40 \%$ 
of the sample had a lower professional level. Almost $50 \%$ of the respondents lived alone. Respondents perceived their health as 'moderate' (3.1) and perceived their quality of life as 'moderate' to 'good' (3.7). The average respondent was independent on 11 out of 16 aspects of daily functioning. Practical support was received by $80 \%$ of the respondents, $70 \%$ received emotional support and $70 \%$ reported receiving informational support. Results with regard to the diversity of care and relationships with predisposing factors, need factors and care characteristics will be discussed as part of the three research questions.

\subsubsection{Diversity of professional and non-professional care}

Nearly all respondents received both professional and non-professional care. Ten respondents $(6 \%)$ did not receive any professional care, while eight respondents $(4 \%)$ received only professional care. As shown in table 2 , the respondents received care from 2.1 types of non-professionals and 2.7 types of professionals on average. More detail on professional and non-professional care is given in table 3 . Non-professional care was most frequently provided by the respondents' children; $66 \%$ of the respondents received care from one or more of their children. Partners and neighbors or friends were equally important as sources of non-professional care. Neighbors or friends were care-givers for $48 \%$ of the sample and in $46 \%$ of the cases the partner of the care-dependent adult contributed to the non-professional care. When the fact that $49 \%$ of the sample lived alone is taken into account, this means that more than $90 \%$ of the partners contributed to non-professional care. About one third of the sample (also) received care from family members other than the partner, parents or children. Relatively few respondents $(12 \%)$ received care from their parents. Given the mean age of 64 , this is hardly surprising. A large majority of the sample received care from the family physician. A total of 135 clients $(76 \%)$ had visited -or had been visited by- their family physician in the last three months. During the same period, one or more

\section{Table 3}

Use of different types of professional and non-professional care ( $n=177)$.

NON-PROFESSIONALS

N $\%$

Professionals

N

92

$\begin{array}{lrr}\text { Children } & 117 & 66 \\ \text { Neighbors/friends } & 85 & 48 \\ \text { Partner } & 82 & 46 \\ \text { Parents } & 21 & 12 \\ \text { Other family members } & 62 & 35\end{array}$

Family physician

13576

Medical specialist

Home helper

$62 \quad 35$

Physiotherapist

$50 \quad 28$

Private cleaning lady $\quad 35 \quad 20$

Community nurse

28

Other

43 
medical specialists were visited by $62 \%$ of the respondents. About one third of the care-dependent adults received care from home helpers, $20 \%$ had a private cleaning lady at their disposal. Physiotherapists were part of the professional network in $28 \%$ of the cases. A group of 28 clients (16\%) received care from community nurses. Finally, other care-givers were mentioned by $24 \%$ of the respondents. These include, for instance, dieticians, day care centers and psychologists.

\subsubsection{Correlates of diversity of total care}

As is shown in table 4, seven factors were related to the diversity of total care. The diversity of care was negatively related to age. Those who were older reported fewer care-givers. One other predisposing factor was related to diversity. Respondents who had attended only primary school reported fewer types of care-givers than those who had received additional education. The enabling factor 'living arrangement' was also relevant to the diversity of total care. Clients who lived alone received care from fewer sources than those who shared a household with others. Of the five need factors included in the model, only two were related to the diversity of total care. Respondents who reported more impairment, scored higher on diversity. Furthermore, the diversity of total care was related to quality of life. Respondents with a lower quality of life received care that was less diverse. Surprisingly enough, other need factors were not related to the diversity of total care. Diversity did not increase with poor health, or more impairment in daily functioning. Two of the three care-tasks were strongly related to care diversity. Respondents who received emotional support reported 5.3 types of care-givers, while clients without emotional support reported only 3.9 on average. A similar result was found for informational support. Respondents with informational support received care from an average of 5.2 types of care-givers. The number of types of care-givers was 4.1 for those without informational support. Whether or not respondents received practical support did not affect the scores for the diversity of total care. A regression analyses was performed to further investigate the relationship between potentially relevant factors and the diversity of total care received. As shown in table 5, four factors explained $21 \%$ of the variance in the diversity of total care. Especially emotional support and informational support added to the explanation of variance (together $17 \%$ ). Quality of life, and daily functioning (although not a relevant factor when using a T-test) were significantly related but had relatively modest contributions to the variance explained (together $4 \%$ ).

\subsubsection{Correlates of diversity of professional and non-professional care}

A difference in potentially related factors for professional and non-professional care was found for the predisposing factors (table 4). While the diversity of professional care was related to the respondents' sex and occupational level, the diversity of non-professional care was related to age and educational level. Women and respondents with a higher occupational level reported more professional care-givers than men and those with lower occupational levels. Those who were relatively older and had attended primary 


\section{Table 4}

Factors related to the diversity of total, non-professional and professional care $(n=177)$.

$\begin{array}{clc}\text { TOTAL CARE } & \text { NON-PROF CARE } & \text { PROF CARE } \\ \text { RELATION T CORR } & \text { RELATION T CORR } & \text { RELATION T CORR }\end{array}$

\section{Predisposing factors}

Female

Being older

Only primary school

Low occupational level

Enabling factors

Living alone

Need factors

More impairment

Daily functioning Lower quality of life

Care characteristics

Emotional support

Informational support

Diversity of care

Diversity of non-prof careo

Diversity of prof care\#

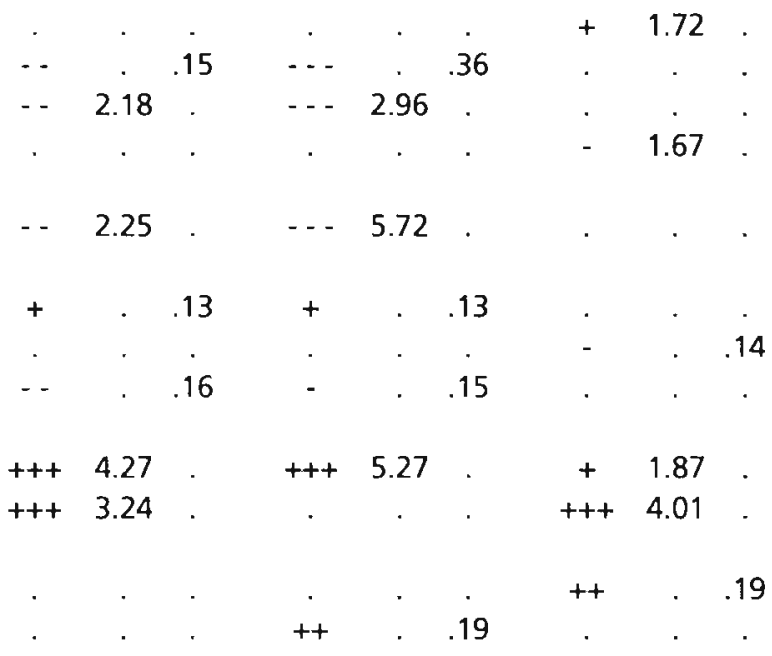

+ positive/negative relationship $p \leq .10++/$ - positive/negative relationship $p \leq .05$

+++1 - - positive/negative relationship $p \leq .01$

- not included in the analyses for the diversity of non-professional and total care

\# not included in the analyses for the diversity of professional and total care

school only, reported less non-professional care. The enabling factor 'living arrangement' was only relevant to the diversity of non-professional care. Those who lived alone received less non-professional care. Again, no overlap between professional and non-professional care was found for related need

94 factors. While the diversity of professional care was higher for those with more impairments in daily functioning, the diversity of non-professional care was higher for respondents with more perceived impairment and for respondents with a higher quality of life. Perceived health was neither related to the diversity of professional care, nor to the diversity of non-professional care. With regard to care-tasks, both professional and non-professional care were related to whether or not emotional support was involved in the care provided. Where emotional support was reported, both the diversity of pro- 
fessional and the diversity of non-professional care were higher. Informational support however, was only related to the diversity of professional support. Respondents with informational support reported more professional caregivers than others.

Finally, the diversity of professional and non-professional care were significantly interrelated. Respondents who scored higher on professional care also reported higher scores on non-professional care and vice versa.

A linear regression analysis identified five factors that could be used for the explanation of scores on the diversity of non-professional care (table 5). Here, living alone (11\%) and receiving emotional support (15\%) were the two most important factors in the explanation of variance. Age, quality of life, and the

\section{Table 5}

Regression analyses for the diversity of total, non-professional and professional care ( $n=177)$.

$\begin{array}{rlr}\text { TOTAL CARE } & \text { NON-PROF } & \text { PROF } \\ \text { Beta* } \% \text { var } & \text { Beta* \%var } & \text { Beta* } \% \text { var }\end{array}$

\section{Predisposing}

Being older

Only primary school

Lower profession

Enabling

Living alone

Need

Daily functioning

Lower quality of life

\section{Care-types}

Practical support

Emotional support

Informational support

Diversity of care

Diversity of non-prof careo

Diversity of prof care\#

R2 (adjusted)

$\mathrm{F}$

$-.22 \quad 3$

$-.28 \quad 11$

$-.26 \quad 4$

$-.16 \quad 2$

$-.30 \quad 4$

$-.17 \quad 2$

$-.15 \quad 2$

$33 \quad 12$

$.20 \quad 5$

.18

3

$.26 \quad 15$

$.29 \quad 10$

.30

4

$.18 \quad 3$

$.34(.32)$

$25(22)$

15.83

9.96

* correlation coefficients and T-tests in table 4; all potentially relevant factors were used in the regression analyses

- not included in the analyses for the diversity of non-professional and total care

\# not included in the analyses for the diversity of professional and total care 
diversity of professional care each added 2 or $3 \%$ to the total variance explained. A total of $34 \%$ of variance in the diversity of non-professional care was explained. The explanation of scores on the diversity of professional care was somewhat less successful. A total of $25 \%$ of the variance in scores could be explained using the factors living arrangement, daily functioning, practical support, informational support and diversity of non-professional care. Here, informational support was obviously the most important factor $(10 \%)$. Living arrangement, daily functioning, practical support and diversity of non-professional care each added another 3 or $4 \%$ to the variance explained.

Somewhat surprising is the fact that living arrangement and receiving practical support were identified as two significant factors. When using T-tests, no difference in the diversity of professional care were found for these variables (table 4). However, after correction for the other variables in the regression procedure, significant effects for these variables could be reported.

\subsection{Discussion}

In an attempt to identify factors relevant to the the diversity of professional and non-professional care received by care-dependent adults, a telephone survey was carried out in the Dutch community of Tegelen. The community of Tegelen was not very deviant from the Dutch population in general with regard to basic demographics. In this community $13 \%$ of the households contained an adult who was dependent on the care of others. Few Dutch studies aimed at identifying the number of care-dependent adults. De Boer et al. [9] identified $17 \%$ of Dutch households as containing someone who was 'impaired' and 'using care'. Tjadens and Woldringh [11] studied individuals rather than households. They found that $8 \%$ of those who lived independently needed care from others. The percentage of $13 \%$ of all households, as it was found for this study, seems somewhat in line with these results. However, one might question the comparability of these figures as a result of differences in operationalizations. Nevertheless, there are no indications that the findings for community of Tegelen are very deviant from what one might expect to find in other communities in the Netherlands.

Diversity of care was operationalized as the number of different types of caregivers involved. Although this approach proved to be valuable, it resulted in limitations with regard to the results of the study. In computing the number of types of care-givers, more qualitative information with regard to the actual content of the care was omitted. An approach that would focus on diversity of care as a quality, rather than a quantity, might result in more or even somewhat different results. With regard to the group of respondents it must be stressed that a conscious choice was made to select only care-dependent adults. This implies that results for this study are only valid for the diversity of care within groups of adults who actually use care. Conclusions from this study should be used with caution when actually comparing persons who receive pro- 
fessional or non-professional care with those who do not. Correlates of the diversity of care as identified here, might not apply to whether or not people receive professional or non-professional care to begin with.

The first purpose of this study was to describe the extent to which persons who were dependent of the care of others used both professional and non professional care. With regard to this purpose, some conclusions can be drawn. First of all, the use of care was extensive. On average, respondents received care from approximately five types of professional and non-professional care-givers. Children, family physicians and medical specialists were the three most commonly reported care-givers. However, others such as partners, neighbors and friends, home helpers and physiotherapists were involved in more than $25 \%$ of the cases. A large group of clients that used either only professional or only non-professional care could not be identified. About $90 \%$ of the sample received both types of care. Obviously, professional and non professional care cannot be seen as alternatives, but rather as complementary to one another.

In an attempt to explain the variance in scores on total care and the diversity of both professional and non-professional care, the relationships with several groups of possible correlates were studied. Three groups of factors -predisosing, enabling and need factors- were derived from the Andersen model. Litwak's task specifity model was used to generate a fourth group of factors, that of care-tasks. The validity of two of the operationalizations of need factors should be questioned as a result of this study. Although it might seem plausible that a low quality of life could result in more care needs (e.g. emotional support), the results for this sample indicated otherwise. Scores for quality of life were significantly related to both the diversity of total care and the diversity of non-professional care. Furthermore, scores for quality of life had a small but significant contribution to the explạnation of variance in both factors. However, lower scores for quality of life correlated with lower scores for total and non-professional care. Two possible explanations can account for this effect. A first explanation could be that those who receive more care, are happier, more satisfied and perceive their lives as of better quality as a result. In other words, care has a positive effect on one's quality of life. An alternative explanation for this effect is that persons with a higher quality of life are better at generating non-professional care. Thus, quality of life could either be seen the effect of care, or as a factor that enables care. Either way, the original idea that quality of life might be treated as a need factor is not supported.

A somewhat similar problem occurs for the diversity of non-professional (ar'. While it is often claimed that those who receive less non-professional care have a greater need for professional care, this could not be confirmed for this study. In fact, respondents who received more non-professional care, received more professional care as well. Thus, if the diversity of non-professional care is seen as an indicator of the need for professional care, one should not expect that the presence of non-professionals reduces the need for 
professional care. One should rather see a higher diversity of non-professional care as an indication of a higher need for professional care.

Regression analyses was performed to identify factors that could contribute to the explanation of the diversity of total, professional and non-professional care. The diversity of total care could at best be explained using daily functioning, quality of life, emotional support and informational support.

Respondents who received emotional and informational support, had a higher quality of life and who had more impairments in daily functioning, reported more diversity of care than others. Predisposing and enabling factors were obviously not important in the explanation of scores on the diversity of total care. Care-task -especially receiving emotional support-, however, appeared to be the most important variable in the explanation of the diversity of total care. The need for care (daily functioning) had a small but significant contribution.

To explain the variance in the diversity of non-professional care, a function of age, living arrangement, quality of life, emotional support and the diversity of professional care provided the best fit. A somewhat obvious result could be reported for living arrangement. Those who lived alone experienced less non-professional care. Furthermore, older respondents received less non-professional care. Apparently, older respondents had more problems in generating networks of non-professional care-givers. These findings are in line with results that are commonly found in social network studies. The fact that the size of the social network decreases for the elderly $[12,19]$, implies that the elderly have fewer potential care-givers. Finally, respondents received more non-professional care if they received emotional support, received more professional care and had a higher quality of life. Causality can be questioned with regard to the effect for emotional support. The fact that emotional support is required might result in higher diversity of non-professional care. On the other hand, more diversity of non-professional care can imply that clients have more chances of receiving emotional support.

Living arrangement, daily functioning, practical support, informational support and the diversity of non-professional care could be used in the explanation of scores on the diversity of professional care. As with non-professional care, the diversity of professional care was lower for those who lived alone. As was already explained, the diversity of professional care increased with the diversity of non-professional care. Furthermore professional care was higher for respondents who received informational and practical support, and for those who shared a household with others.

It can be concluded that the Andersen model is useful in explaining at least some of the variance in the diversity of both professional and non-protessional care. While the need factor daily functioning seemed useful in the explanation of professional care, the predisposing factor age was relevant to the explanation of the diversity in non-professional care. The enabling factor 'living arrangement' contributed to the explanation of diversity in both types of care. Extending the Andersen model with the factor 'care-tasks' as derived 
from Litwak's task specifity model proved to be valuable. While Chappel and Blandford [18] concluded that professionals and non-professionals divide case-loads rather than care-tasks, the findings in our study can be seen as supportive of Litwak's model. The fact that emotional support could contribute to the explanation of the diversity of non-professional care while informational and practical support indicated more professional care, supports Litwak's hypothesis that the diversity of professional and non-professional care is related to the tasks to be fulfilled. The results of this study might indicate that substitution of professional by non-professional care is not a realistic option. Nearly all clients who received non-professional care also used professional health or care services. At the same time, the diversity of nonprofessional care was not a very important factor in the explanation of the diversity of professional care. Furthermore, it becomes clear from the results for care-tasks that professional and non-professional care can serve different purposes. However, substitution might still be an option for specific tasks. Future research might indicate whether substitution is possible for the less specialized or non-medical professional tasks.

\section{Acknowledgements}

Cooperation with the Noord-Limburg Foundation for Community Care, and a grant from the Province of Limburg made this study possible. The authors would like to thank care-givers and citizens of the community of Tegelen, and mrs. Marion Hekkink for their efforts and participation in this study. 


\section{References}

1 Baldock, J. and Evers, A., Innovations and Care for the Elderly: The Cutting Edge of Change for Social Welfare Systems. Examples from Sweden, The Netherlands and the United Kingdom, Ageing \& Society, 12 (1992) 289-312.

2 Doorslaer, E. van, Wagstaff, A. and Rutten, F., Equity in the Finance and Delivery of Health Care: An International Perspective, Oxford University Press, Oxford, UK, 1993.

3 Mur-Veerman, I., Van Raak, A. and Maarse, H., Dutch Home care: Towards a New Organization?, Health Policy, 27 (1994) 141-156.

4 Andersen, R., Kravits, J. and Anderson, O.W., Equity in Health Services: Empirical Analyses in Social Policy, Ballinger Publishing Company, Cambridge, 1975.

5 Andersen, R., Revisiting the Behavioral Model and Access to Medical Care: Does it Matter?, Journal of Health and Social Behavior, 36 (1995) 110.

6 Coulton, C. and Frost, A.K., Use of Social and Health Services by the Elderly, Journal of Health and Social Behavior, 23 (1982) 330-339.

7 Evashwick, C., Rowe, G. and Branch, L., Factors Explaining the Use of Health Care Services by the Elderly, Health Services Research, 19 (1984) 357-382.

8 Frederiks, C.M.A., te Wierik, M.J.M., van Rossum, H.J.L., Visser, A. Ph., Volovics, A. and Sturmans, F., Why Do Elderly People Seek Professional Home Care? Methodologies Compared, Journal of Community Health, 17 (1992) 131-141.

9 Boer, A.H. de, Hessing-Wagner, J.C., Mootz, M. and SchoemakersSalkinoja, I.S., Informele zorg: Een verkenning van huidige en toekomstige ontwikkelingen (Informal Care: A Study of Current and Future Developments), Sociaal en Cultureel Planbureau, Rijswijk, The Netherlands, 1994.

10 Frederiks, C.M.A., Zorgbehoefte van en zorgverlening aan ouderen (Caredemands of and Care Provided for the Elderly). Thesis, University of Limburg, Maastricht, The Netherlands, 1990.

11 Tjadens, F.L.J. and Woldringh, C.L., Informele zorg in Nederland: Zelfzorgproblemen, behoefte aan hulp en praktisch instrumentele onderlinge hulp (Informal Care in the Netherlands: Self-care Deficits, Care-demands and Mutual Practical Support), Instituut voor Toegepaste Sociale Wetenschappen, Nijmegen, The Netherlands, 1989.

12 Litwak, E., Helping the Elderly: The Complementary Roles of Informal Networks and Formal Systems, The Guilford Press, New York, 1985.

13 Centraal Bureau voor de Statistiek, Bevolking der gemeenten van Nederland op 1 januari 1994 (Population of the Municipalities in the Netherlands on January 1st 1994), SDU/CBS, 's Gravenhage, The Netherlands, 1994. 
14 Centraal Bureau voor de Statistiek, Maandstatistiek der bevolking, oktober 1994 (Monthly Population Statistics, October 1994), SDU/CBS, 's Gravenhage, The Netherlands, 1994.

15 Centraal Bureau voor de Statistiek, Standaard beroepenclassificatie 1992 (Standard Classification of Occupations 1992), SDU/CBS, 's Gravenhage, The Netherlands, 1993.

16 Frederiks, C.M.A., te Wierik, M.J.M., Visser, A.Ph. and Sturmans, F., A Scale for the Functional Status of the Elderly Living at Home, Journal of Advanced Nursing, 16 (1991) 287-292.

17 Andrews, F.M. and Whitey, S.B., Social Indicators of Well-being: Americans' Perception of Life Quality, Plenum Press, New York, 1976.

18 Chappell, N. \& Blandford, A., Informal and Formal Care: Exploring Complementarity, Ageing and Society, 11 (1991) 299-317.

19 Knipscheer, C.P.M., Oude mensen en hun sociale omgeving: een studie van het primaire sociale netwerk (The Elderly and Their Social Environment: A Study of the Social Network), VUGA, 's Gravenhage, The Netherlands, 1980. 


\section{5}

EXPLAINING

CLIENT SATISFACTION

IN CARE-DEPENDENT

ADULTS

Theo van Achterberg,

Fred C.J. Stevens,

Harry F.J.M. Crebolder, and Hans Philipsen.

Submitted for publication. 


\section{Abstract}

Client satisfaction is one impartant aspect of quality of care. Few studies, however, have addressed clients' satisfaction with non-medical services. The study described in this article focusses on the level of client satisfaction and factors that can explain clients' satisfaction with both professional (medical and non-medical) and non-professional community care.

A group of 177 care-dependent adults was identified by means of a large scale telephone survey in the Dutch community of Tegelen. Potential correlates of client satisfaction were derived from Andersen's Behavioral Model of Health Services (Andersen 1995) and Wall's work on continuity of care (Wall 1981). Although the level of client satisfaction was high, the proportions of clients with complaints were substantial. Clients with lower educational levels were more often satisfied with the care they received. Other factors that were derived from the Andersen model were relatively unimportant in explaining client satisfaction. Aspects of continuity of care were identified as the most important correlates of client satisfaction. More continuity of care was positively related to higher levels of satisfaction. The importance of different continuity aspects, however, varied with the type of care involved.

Keywords:

client satisfaction, community care, informal care, continuity of care 


\subsection{Introduction}

Client satisfaction is one aspect of quality of care that has received a great deal of attention over the years. However, most of the literature on client satisfaction deals with satisfaction with medical care. Studies that identify factors related of satisfaction with total professional care and with non-professional care in particular are still lacking. A major feature that distinguishes this study from others is that satisfaction is not limited to medical or professional care. Instead, satisfaction was addressed for both professional and non-professional community care. Furthermore, the study examined the exact relationship between the client's perception of continuity of care and the client's satisfaction with care.

Basically, the study served two purposes. A first purpose of the study was to describe the level of clients' satisfaction with professional and non-professional community care. A second purpose of the study was to identify factors that could be used in the explanation of clients' satisfaction with both types of care. Professional community care included all medical and non-medical care that was provided by persons who were trained, organized and/or paid for, and that was available to clients who lived independently in the community. Non-professional community care included all informal care by persons from the client's own social/informal network.

Five groups of potentially related factors were evaluated in this study. Four of these groups were derived from the Andersen model (Andersen 1995). Andersen describes several groups of factors that -either directly or indirectly-influence client satisfaction. The factors that were derived from this model are the predisposing, enabling and need factors and the diversity of care. According to Andersen, predisposing factors refer to the individual's predisposition to use services, enabling factors refer to the ability to use services, and need factors refer to conditions that determine the need for care. In this study, diversity of care refers to the variety of care-givers involved. A fifth group of potential correlates was derived from Wall's work on continuity of care (Wall 1981). The factor continuity of care refers to continuity of care as perceived by clients. Several aspects of continuity were taken into account in this study. An overview of the five groups of potentially related factors and their operationalizations is given in table 1 .

The literature was reviewed with regard to the five groups of potentially related factors that were derived from the works of Andersen (1995) and Wall (1981). Many authors have focussed on identifying the determinants of client satisfaction (or consumer satisfaction). Especially the influence of sociodemographic factors -or predisposing and enabling factors according to the Andersen terminology- has been studied frequently (Weiss 1988). However, a consistent pattern of relevant factors still has to be found. With regard to the client's sex, for instance, it is very unlikely that men would be more satisfied in general. Some studies report higher levels of satisfaction for women (Ware 
1978, Fox \& Storms 1981, Weiss 1988), whereas others find no differences between men and women (Hull \& Hull 1984, Zastowny, Roghmann \& Kafferata, 1989, Hall. \& Feldstein 1990, Hall \& Dornan 1990). Similar inconsistencies are found with regard to age. While some authors found that elderly clients are more satisfied in general (Hull \& Hull 1984, Fox \& Storms 1981, Weiss 1988, Ware 1978), others concluded that age is irrelevant to client satisfaction (Zastowny, Roghmann \& Kafferata 1989, Hall \& Doman 1990). Results are rather consistent when it comes to whether or not clients live alone. Hardly any evidence is found that living alone, or sharing a household with others affects the level of satisfaction (Hall \& Feldstein 1990, Fox \& Storms 1981, Linn, Linn \& Stein 1982, Zastowny, Roghmann \& Kafferata 1989, Hall \& Dornan 1990, Ware 1978). The same appears to be true for occupational level; it seems safe to conclude that the occupational level of clients is not related to their satisfaction with health services (Hall \& Feldstein 1990, Fox \& Storms 1981, Linn, Linn \& Stein 1982, Weiss 1988, Hall \& Dornan 1990). Finally, it is unclear whether education affects client satisfaction. While some authors report higher levels of satisfaction for those with a lower educational level (Fox \& Storms 1981, Zastowny, Roghmann \& Kafferata 1989, Fitzpatrick 1991, Ware 1978), others find no relationship (Hall \& Feldstein 1987, Linn, Linn \& Stein 1982, Weiss 1988).

A number of studies addressed the relationship between need factors and client satisfaction. Findings, however, are inconclusive. Weiss (1988) describes two possible relationships between health and satisfaction with health services: (1) those who are less healthy tend to be more grateful and therefore more satisfied, or (2) those who are less healthy can be more demanding and therefore less satisfied. From the literature it becomes clear that the second explanation is the most plausible. It has been reported that clients who are less healthy are less satisfied with health services (Hall \& Feldstein 1990, Linn, Linn \& Stein 1982, Weiss 1988). Others find no relationship between health and satisfaction (Fox \& Storms 1981, Zastowny, Roghmann \& Kafferata 1989). Not much is known about the effect of quality of life on satisfaction with health services. However, from the studies that have been performed, one might conclude that those with a better quality of life report higher levels of satisfaction (Roberts, Pascoe \& Attkisson 1983, Weiss 1988). According to the Andersen model, one might expect to find at least a modest relationship between the diversity of care and client satisfaction. However, the relationship between the diversity of care and satisfaction remains unclear (Zastowny, Roghmann \& Kafferata 1989). While some studies indicate that more care results in more satisfaction (Hull \& Hull 1984) others indicate just the opposite (Linn, Linn \& Stein 1982). Fox \& Storms (1981) conclude that satisfaction might be highest when the number of services is neither high nor low.

Finally, some aspects of continuity of care were found to be related to client satisfaction. These include continuity in care providers (Marquis Davies \& Ware 1983, Weiss 1988, Pascoe 1983), accessibility (Flynn 1985, Williams \& Calnan 1991, Pascoe 1983), availability (Williams \& Calnan 1991a, Gerace \& 
Sangster 1987, Pascoe 1983) and continuity in location and geographical distance (Fox \& Storms 1981). In a study by Van der Waal et al. provider continuity was identified as one of the aspects of care that clients themselves prefer in relation to quality of care (Van der Waal, Casparie \& Lako 1996).

The studies that focussed on the explanation of client satisfaction used a wide variety of approaches. Differences in client groups, indicators of client satisfaction and operationalizations of related factors make many of these studies incomparable. As was stated before, the studies only refer to professional care or medical care in particular. Therefore, even factors that were consistently irrelevant in earlier studies (such as whether or not clients live alone) were still included in this study.

The following research questions were addressed:

1 How are non-professional and professional community care evaluated by clients in a population survey?

2 Can predisposing factors, enabling factors, need factors, diversity of care and aspects of continuity of care be used to explain satisfaction with nonprofessional and professional community care?

\subsection{Methods}

\subsubsection{Sample}

A telephone survey was carried out in the Dutch community of Tegelen, a community of approximately 19,000 inhabitants (Centraal Bureau voor de Statistiek, 1994]. The survey was announced in two local newspapers and on two local radio stations. A total number of 1932 randomly selected households were contacted by a team of trained interviewers. If the first attempt at contacting the household was fruitless, new attempts were made until a member of the household was reached. In those cases in which potential respondents were reached at an inconvenient time, an appointment was made for a more appropriate time to call back. The survey was carried out during momings, afternoons and evenings of 13 successive working days. About $73 \%$ of the households $(n=1406)$ participated in the study. Lack of time or lack of interest, were among the most frequently mentioned reasons for not participating. In 36 cases language problems occurred. Respondents were asked if there was a person within their own household who was dependent on the care of others. It was explained that the dependency had to be related to reasons of mental or physical health and that care could involve both formal and informal care. In 190 cases $(14 \%)$ a care-dependent person was part of the household. For the analyses in this article, only data from dependent adults (18 years of age or older) were used. This reduced the number of cases to $177(13 \%$ of 1406$)$. 


\subsubsection{Questionnaire}

The questionnaire used for the telephone survey addressed predisposing, enabling and need factors, diversity of care, continuity of care and client satisfaction. Apart from these five groups of potentially related factors, the clients' diagnoses or health problems were recorded for the purpose of describing the client group. Four predisposing factors were addressed. The respondents' sex, age, educational level and occupational level were registered. The educational level was scored as 'only primary school' or 'additional education'. The occupational level was classified into nine categories -9 being the highest possible score- using the Dutch standard classification of occupations (Centraal Bureau voor de Statistiek 1993). For the analyses in this study, occupational level was recoded as either 'low' (scores 1 to 3) or 'middle or high' (scores 4 to 9).

Only one enabling factor was used in the study. Record was kept of whether clients lived alone or shared a household with one or more others. Five variables were included to represent the need for care. A 5-point scale was used to estimate the respondent's perceived health. Here, a score of 1 represented the worst possible health, whereas a score of 5 represented excellent health. Impairment was measured using a scale ranging from 1 to 4,4 representing the highest level of impairment. Functioning with regard to Activities of Daily Living (ADL) and Instrumental Activities of Daily Living (IADL) was (stimated using a 16-item list including the topics: (a) getting in/out of bed, (b) washing, (c) dressing, (d) going to the bathroom, (e) eating and drinking, (f) walking around the house, (g) walking stairs, (h) making beds, (i) doing the laundry, (j) cleaning windows, ( $\mathrm{k}$ ) shopping, (l) cooking, $(\mathrm{m})$ washing dishes, (n) vacuum cleaning, (o) administrative activities and (p) visiting others. Factor andysis showed that ADL and IADL items could be combined in a one-factor scale (Eigenvalue 5.44), which is in line with results reported by Frederiks et al. (Frederiks, Te Wierik, Visser \& Sturmans 1991). Scores on the combined scale could vary from 0 to 16,16 indicating independence on all aspects of daily functioning. In this study Cronbach's alpha for the daily functioning scale was 0.86 . Perceived quality of life was measured using a three item list, derived from the work of Andrews and Whitey (1976). Items included happiness, satisfaction and a global estimation of one's own life in terms of good and bad. The alpha for this three item scale was 0.78 . Scores for quality of life could vary from 1 (lowest) to 5 (highest quality of life). Diversity of care was registered for professional, non-professional and total care. The diversity of formai care was measured by counting the number of different types of professionals involved. A maximum of 11 different professionals could be indicated. For informal care a maximum of five different informal care-givers could be mentioned. For both the amount of formal and informal care, two care-givers with the same background (e.g two nurses, two children) were counted as one. Scores for the diversity of total care were computed by adding the diversity of non-professional care to the diversity of professional care. Thus, a maximum of 16 different types of care-givers could be reported. 
The continuity of care was estimated by addressing five continuity aspects (Wall 1981). The two aspects 'accessibility' and 'care-givers keeping appointments' were addressed for all professionals and non-professionals. The aspect 'same professional over time' was addressed for professional caregivers only. The last two aspects 'receiving consistent information' and 'knowing where to find care' were measured as general items and not addressed for specific care-givers. Scores on the continuity aspects could be either 0 or 1, 1 being the positive score (eg. care-giver always accessible, always receiving consistent information). In the analyses for professional care and non-professional care 'on the whole', scores on the first three items were computed by adding scores for individual care-givers and dividing them by the total number of care-givers. Therefore, scores on these items could be any value between 0 and 1 . Since scores on these items were all skewed to the higher scores, scores were recoded to 0 (any number of discontinuities) or 1 (no discontinuities reported).

Finally, client satisfaction with individual care-givers was medsured along a six item scale including: sincere interest, sufficient time, friendliness, health related information, care related information and quality of services (Ware 1978). Satisfaction with individual care-givers was computed by adding the scores on the six items and recoding the result to 0 (one or more complaints) or 1 (completely satisfied). Satisfaction with both professional and non-professional care was computed by adding the scores for individual care-givers and dividing them by the actual number of care-givers. Again, the result was recoded to 0 or 1 . Alpha's for the satisfaction scales were high (e.g. satisfaction with non-professional care $\alpha=.79$; satisfaction with professional care $\alpha=.77$ ). Factor analysis revealed that the scale could be seen as ane-factor measure.

\subsubsection{Analyses}

Several analyses were used to identify correlates of satisfaction with professional and non-professional care. First, T-values and Chi-squares -depending on the type of variable involved-were computed to find variables that were significantly related to the satisfaction with specific care-givers. As a second step, logistic regression analyses were conducted to identify the most relevant correlates of satisfaction with specific care-givers. In these analyses, all potential correlates were entered. Apart from the analyses for satisfaction with specific care-givers, the same procedure was applied to satisfaction with total professional care and satisfaction with total non-professional care.

\subsection{Results}

\subsubsection{Background characteristics}

The mean age of the sample was about 64 years of age, $67 \%$ of the caredependent adults were females. Approximately half of the clients lived alone. 
Scores on the factors included in this study are shown in table 1. The educationall level of the total group was quite low, about half of the group only went through primary school. About $40 \%$ of the clients could be categorized among the lower professional levels. Among the most commonly reported diseases were diseases of the eye, ear or organ of balance (27\%), cardiovascular diseases $(26 \%)$, bone or joint diseases $(25 \%)$, chronic back-pain (12\%), lung diseases $(10 \%)$, diseases of the digestive system $(10 \%)$, psychiatric disorders $(9 \%)$ and trauma resulting from accidents $(6 \%)$. Other disorders were reported by less than $5 \%$ of the respondents. More than one disorder could be reported. However, $64 \%$ reported only one disease, $28 \%$ reported two and $8 \%$ reported three diseases or disorders.

\section{Table 1}

Scores on predisposing, enabling and need factors, diversity of care, and continuity of care $(n=177)$.

\section{Predisposing}

Female

Age

$\begin{array}{llll}\text { MEAN } & \text { SD } & \text { N } & \%\end{array}$

Only primary school

Low occupational level

Enabling

Living alone

Need

Health

$3.1 \quad 0.9$

Impairment

$3.0 \quad 0.9$

Quality of life

$3.7 \quad 0.8$

Daily functioning

$11.3 \quad 3.9$

Diversity of care

Diversity of non-professional care $\quad 2.1 \quad 1.6$

Diversity of professional care

Diversity of total care

$2.7 \quad 1.5$

$4.8 \quad 2.1$

\section{Continuity of care}

Non-professionals accessible

Non-profs keeping appointments

110 Professionals accessible

Professionals keeping appointments

Same professionals over time

Consistent information 
The clients perceived their health as 'moderate' (3.1) and perceived their quality of life as 'moderate' to 'good' (3.7). They perceived their impairment as relatively high. On a scale from 1 to 4 (4 representing the highest degree. of impairment), the average score was 3.0. The average respondent was independent on 11 of the 16 aspects of daily functioning. The respondents re. ported that they received care from 2.1 types of non-professional and 2.7 types of professional care-givers on average. As a consequence, the diversity of total care came to 4.8 , indicating that clients received care from caregivers with about five different professional or non-professional backgrounds. The percentages of clients who reported discontinuities varied from $17 \%$ for 'receiving consistent information' to $68 \%$ for 'same professionals over time'.

\subsubsection{Satisfaction with professional and non-professional care}

Large groups of clients had no complaints with regard to the care they received. The percentages of clients who were satisfied with the six aspects of the care that was provided by 11 different types of care-givers are given in table 2 . Although in some instances the number of clients was quite small, percentages were used to facilitate a comparison of scores. For both professionals and non-professionals, the number of complaints was highest for the aspect 'quality of services'. On the whole, satisfaction was somewhat higher for the care that was given by non-professionals.

\section{Table 2}

Clients' satisfaction (in \% no complaints) with aspects of care $(n=177)$.

$\begin{array}{lrrrrrrrr}\text { Children } & 98 & 89 & 89 & 95 & 98 & 88 & 77 & 117 \\ \text { Neighbours/friends } & 98 & 96 & 90 & 99 & 96 & 92 & 83 & 85 \\ \text { Partner } & 98 & 92 & 85 & 92 & 96 & 81 & 71 & 82 \\ \text { Parents } & 91 & 95 & 90 & 90 & 90 & 85 & 74 & 21 \\ \text { Other family members } & 97 & 95 & 94 & 97 & 98 & 94 & 89 & 62 \\ \text { Non-professionals } & 91 & 81 & 79 & 86 & 91 & 78 & 59 & 169 \\ & & & & & & & & \\ \text { Family physician } & 98 & 96 & 93 & 90 & 95 & 92 & 82 & 135 \\ \text { Medical specialist } & 95 & 88 & 92 & 91 & 92 & 83 & 73 & 109 \\ \text { Home help } & 97 & 97 & 95 & 93 & 95 & 90 & 79 & 62 \\ \text { Private cleaning lady } & 91 & 88 & 100 & 100 & 100 & 91 & 87 & 50 \\ \text { Physiotherapist } & 96 & 96 & 90 & 92 & 90 & 90 & 84 & 35 \\ \text { Community nurse } & 100 & 96 & 100 & 100 & 100 & 96 & 96 & 28 \\ \text { Professionals } & 78 & 75 & 77 & 71 & 74 & 68 & 47 & 167 \\ & & & & & & & & \end{array}$


Within the group of non-professionals, care from neighbours, friends and 'other' family members was more positively evaluated than care from closer relatives. Medical specialists were the professionals that received the highest proportion of complaints, while nearly all clients were completely satisfied with the services of community nurses. Many of the clients that reported complaints about the care they received, reported only one complaint. However, the numbers of clients who reported more than one complaint were not to be neglected. More than one complaint on the six satisfaction items was reported by $17 \%$ of the clients when evaluating non-professional care and by $24 \%$ of the clients when evaluating professional care. While on the whole the aspects of care were evaluated positively, it remains striking that the proportion of clients with one or more complaints is relatively high with regard to some aspects. Some examples of items with surprisingly high proportions of clients with complaints are 'professionals spending sufficient time' $(25 \%)$, 'friendliness of non-professionals' $(21 \%)$ and 'professionals giving health related information' $(29 \%)$.

Surprisingly, satisfaction scores for total professional and total non-professional care were not interrelated $\left(X^{2}=1,85 \mathrm{p}=.17\right)$. Obviously, satisfaction with non-professional care did not increase the chances of being satisfied with professional care and vice versa.

In the analyses for specific non-professionals, satisfaction data for partners, children and neighbours and friends were analyzed seperately. A trend was fiound for the relationship between the satisfaction with the care provided by partners and satisfaction with the care provided by children. The two satisfaction scores were positively related $\left(X^{2}=2.98 p=.08\right)$. There was no relation ship between satisfaction scores for partners and neighbours/friends $\left(X^{2}=.52\right.$ $\mathrm{p}=.47)$ and satisfaction scores for neighbours/friends and children $\left(\mathrm{X}^{2}=.17\right.$ $\mathrm{p}=.68$ ). Data for family physicians, home helpers and medical specialists were used in the analyses for specific professional care-givers. Satisfaction scores for family physicians and medical specialists were positively related $\left(X^{2}=4.65 p=03\right)$. Satisfaction scores for home helpers, however, were neither related to the clients' satisfaction with the care provided by family physicians $\left(\mathrm{X}^{2}=.01 \mathrm{p}=.94\right)$ nor with their satisfaction with the care provided by medical specialists $\left(\mathrm{X}^{2}=.70 \mathrm{p}=.40\right)$.

\subsubsection{Correlates of satisfaction with specific care-givers}

To yain some insight into correlates of satisfaction with specific care-givers, T-tests and Chi-square tests were conducted for six types of care-givers.

112 Parents, family members, community nurses and physiotherapists were excluded from these analyses, since fewer than 10 respondents voiced complaints about these cart-givers. The results for the others six types of caregivers are shown in table 3 . The continuity aspects that are given in this table are the separate items on which each type of care-giver was scored. The scores on these items represent scores for the specific type of care-giver. In other words, when the table shows that accessibility is positively related to satisfaction with the care that is provided by the partner, accessibility refers to the 'accessibility of the partner'. 


\section{Table 3}

Factors related to clients' satisfaction with six types of care-givers.

\section{Predisposing}

Female

Being older

Educational level

Occupational level

\section{Enabling}

Living alone

Need

Perceived health

Perceived impairment

Daily functioning

Perceived quality of life

Diversity of care

Diversity of total care

Diversity of non-prof care

Diversity of prof care

Continuity of care

Accessibility

Keeping appointments

Same profs over time

Consistent information

Knowing where to find care

$\%$ completely satisfied

$\begin{array}{cccccc}\text { SATISF } & \text { SATISF } & \text { SATISF } & \text { SATISF } & \text { SATISF } & \text { SATISF } \\ \text { PART- } & \text { CHILD- } & \text { NEIGH- } & \text { FAM } & \text { HOME } & \text { SPECl- } \\ \text { NER } & \text { REN } & \text { BOURS } & \text { PHYS } & \text { HELP } & \text { ALIST } \\ (N=75) & (N=111) & (N=78) & (N=126) & (N=58) & (N=103)\end{array}$
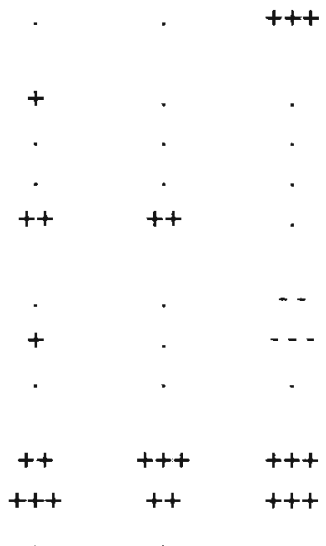

71

77

83

82

79

73

$+/$ - positive/negative relation $\mathrm{p} \leq .10,++/-\mathrm{p} \leq .05,+++/--\mathrm{p} \leq .01$

The results displayed in table 3 show quite some variation, indicating that the relevance of specific correlates varies with the type of care-giver involved. Whereas predisposing and enabling factors are obviously important to satisfaction with the care provided by neighbours and friends, they are not or hardly relevant in explaining satisfaction with care provided by the other five care-givers. With regard to the need factors, some factors appeared to be more relevant than others. Scores on daily functioning were not related to satisfaction with any of the six types of care-givers. Quality of life was the most important need factor. Clients with a higher quality of life were more 
satisfied with the care provided by partners, children and medical specialists. Perceived health and perceived impairment were related to one or two satisfaction scores, but were of limited importance.

Again, variation was found with regard to diversity of care. Diversity was not important for satisfaction with the care provided by children, family physicians and medical specialists. Satisfaction with care provided by the partner was positively, but weakly related to diversity with non-professional care. Other positive relationships were found for satisfaction with home helpers. The diversity of total and non-professional care was strongly, and diversion of professional care was weakly related to satisfaction with the care provided by home helpers. A negative relationship could be reported for the clients' satisfaction with care from neighbours and friends. Those with a higher diversity of non-professional and total care were less satisfied with the activities of neighbours and friends.

One or more indicators of the continuity of care were positively related to satisfaction scores for all of the six care providers. Satisfaction scores for home helpers were, however, somewhat exceptional. The clients' satisfaction with the care provided by home helpers was weakly related to the aspect 'knowing where to find care' and not related to any of the other aspects. Results were very consistent for the clients' satisfaction with the care provided by the three types of non-professionals. In all cases, satisfaction scores were positively related to the aspects of accessibility and keeping appointments. (Nearly) all aspects of continuity were relevant to the satisfaction with family physicians and medical specialists.

Regression analyses gave additional insight into the importance of the different factors explaining satisfaction with the six types of care-givers (table 4). Factors that were selected in the logistic analysis procedure, and that could stand the $95 \%$ interval test, were identified as the most important factors in explaining satisfaction scores. In those cases in which related factors were selected that could not stand the $95 \%$ test, one might speak of trends.

Indicators of continuity of care were among the selected correlates in all the regression models. For satisfaction with the care provided by partners, children and medical specialists, aspects of continuity of care were among the more significant correlates. None of the factors related to the satisfaction with the care provided by family physicians reached the significance level, but aspects of continuity of care seemed to be the most important factors. Satisfaction with care from neighbours and friends was best explained by the 114 clients' educational level. Finally, the diversity of care was significantly related to the clients' satisfaction with the care that was provided by home helpers.

Apart from satisfaction with care provided by neighbours, predisposing and enabling factors were not among the most important correlates. Need factors were strongly related to satisfaction with medical specialists only. A somewhat surprising result occurred for the need factor 'impairment'. Those who reported a higher level of impairment tended to be dissatisfied with family 


\section{Table 4}

Logistic regression analyses for satisfaction with six types of care-givers.

\section{Predisposing}

Female

Educational level

\section{Need}

Perceived health

Perceived impairment

Quality of life

\section{Diversity of care}

Diversity of non-prof care

Diversity of prof care

\section{Continuity}

Accessibility

Keeping appointments

Same profs over time

Knowing where to find care

$\begin{array}{cccccc}\text { SATISF } & \text { SATISF } & \text { SATISF } & \text { SATISF } & \text { SATISF } & \text { SATISF } \\ \text { PART- } & \text { CHILD- } & \text { NEIGH- } & \text { FAM } & \text { HOME } & \text { SPECIA- } \\ \text { NER } & \text { REN } & \text { BOURS } & \text { PHYS } & \text { HELP } & \text { LIST } \\ (n=75) & (n=111) & (n=78) & (n=126) & (n=58) & (n=103)\end{array}$

Odds R ODds R Odds R OdDSR OdDSR ODDS R (95\% intv) (95\% intv) (95\%intv) (95\%intv) (95\% intv) $(95 \%$ intv)

.29

$(.07 / 1.16)$
.08

$(.011 .77)$
1.71

(.93/3.16)

$\begin{array}{ccccc} & \cdot & .55 & \cdot & 2.29 \\ & & (.27 / 1.09) & & (1.16 / 4.52) \\ 1.91 & \cdot & \cdot & \cdot & 2.01 \\ (.97 / 3.76) & & & & (1.03 / 3.92)\end{array}$

1.83

(1.04/51.04)

\section{$4.36 \quad 5.18$}

(1.53/12.40) (.88/30.40)
11.07

(2.40/51.04)
7.67

(.90/65.34)) (.05/3.83)

2.70

(.82/8.87)

$\begin{array}{ccc}3.13 & 6.89 & 3.59 \\ (.97 / 10.12) & (.94 / 50.56)(1.12 / 11.46)\end{array}$

2.43

(.827.15)

1.62

(.88/2.96)
$(1.03 / 3.92)$

\subsection{7}

(.99/56.25)

physicians, but were more satisfied with the care provided by medical specialists. At the $95 \%$ reliability level, the diversity of non-professional care was related to the satisfaction with the care provided by partners. Clients with a higher diversity of non-professional care were more often satisfied with the care they received from their partners. 


\subsubsection{Satisfaction with non-professional care}

Nine of the potentially relevant were related to the satisfaction with non-professional care (table 5). Scores on satisfaction with non-professional care were related to the predisposing factors age and educational level.

Respondents who attended only primary school and respondents who were relatively older tended to be more satisfied. A significant relationship was also found for the enabling factor 'living arrangement'. Clients who lived alone were more satisfied with non-professional care than those who shared a household with others. Quality of life and perceived impairment were the two need factors that were related to satisfaction with non-professional care.

Clients with a higher quality of life and less impairment gave more favorable satisfaction scores. Significant relationships were found for the diversity of care and two continuity indicators that referred to non-professionals. Clients were more satisfied when there was less diversity in total and non-professional care, and when they had no complaints about the accessibility and reliability of non-professionals. A logistic regression analysis for satisfaction with non-professional care (table 6) showed that a model with three factors could be used to explain satisfaction scores. Educational level, the accessibility of non-professionals and whether or not non-professionals kept their appointments were included in this model. Whereas educational level and non-professionals keeping appointments could stand the $95 \%$ reliability test, the relationship between accessibility and satisfaction could only be described as a trend.

\subsubsection{Satisfaction with professional care}

Eight of the potentially relevant factors were related to the clients' satisfaction with total professional care (table 5). Two of these were predisposing factors. Satisfaction was higher for clients with lower occupational levels and for those who were older. With regard to the need factors, satisfaction was higher for clients with a higher quality of life. The enabling factor 'living arrangement' and the diversity of care were not related to satisfaction with professional care. However, the level of satisfaction was (strongly) related to all of the five relevant aspects of continuity of care. Positive scores on these aspects went together with being satisfied.

Logistic regression analysis (table 6) for satisfaction with professional care identified two significant correlates and two trends. 'Professionals keeping appointments' and 'knowing where to find care' were the two most important

116 continuity factors. Furthermore, the clients' occupational level and the aspect 'same professionals over time' were selected as correlates, but were not significant at the $95 \%$ level. 


\section{Table 5}

Factors related to satisfaction with professional and non-professional care ( $n=177)$.

SATISFACTION NON-PROF RELATION $\mathrm{CHI}^{2} \quad \mathrm{~T}$

\section{Predisposing}

Female

Being older

Educational level

Occupational level

Enabling

Living alone

Need

Perceived health

Perceived impairment

Daily functioning

Perceived quality of life

Diversity of care

Diversity of total care

Diversity of non-prof care

Diversity of prof care

\section{Continuity of care}

Non-professionals accessible

Non-profs keeping appointments

Professionals accessible

Professionals keeping appointments

Same professionals over time

Consistent information

Knowing where to find care

\section{$+++8.58$}

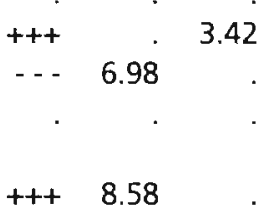

+++ 12.68

$+++27.08$
SATISFACTION PROF

RELATION CHI ${ }^{2} \quad \mathrm{~T}$

\section{Satisfaction measures}

Satisfaction non-prof care

Satisfaction prof care

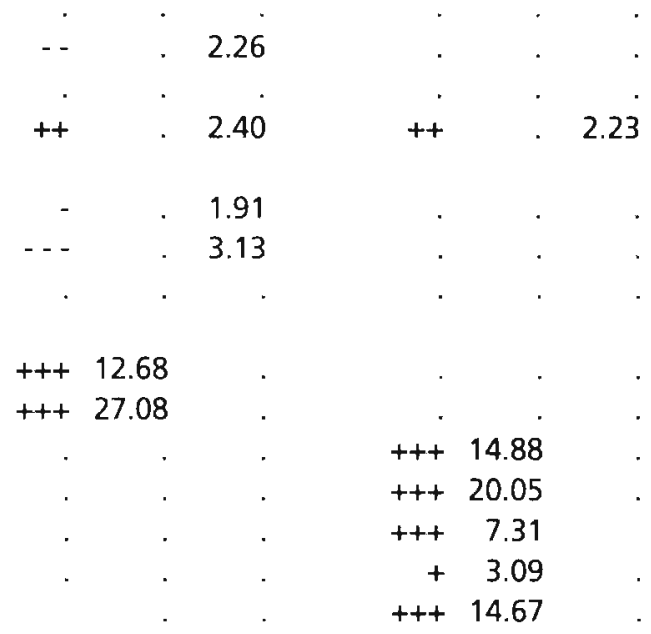

$+/-$ positive/negative relation $p \leq .10,++/-p \leq .05,+++/--p \leq .01$ 


\section{Table 6}

Logistic regression analyses for satisfaction with non-professional and satisfaction with professional care $(n=177)$.

$\begin{array}{ccc}\text { SATISF NON-PROF } & \text { SATISF PROF } \\ \text { ODDSR } & 95 \% \text { INTERVAL } & \text { ODDSR } \quad 95 \% \text { INTERVAL }\end{array}$

\section{Predisposing}

Educational level

$.38 \quad(.18 / .83)$

$.50 \quad(.24 / 1.06)$

Continuity

Non-profs accessible

$2.10 \quad(.93 / 4.74)$

Non-profs keeping appointments

$5.74(2.11 / 42.37)$

Professionals keeping appointments

$4.46 \quad(1.49 / 13.35)$

Same professionals over time

$2.01 \quad(.89 / 4.55)$

Knowing where to find care

$4.79(1.73 / 14.07)$

\subsection{Discussion}

In this study, a sample of the population of the Dutch community of Tegelen was used in an attempt to identify factors related to the clients' satisfaction with professional and non-professional community care. A care-dependent adult was identified in $13 \%$ of the households. Although comparisons are limited by differences in operationalizations, this percentage did not seem to deviate from those reported for other Dutch studies (De Boer, HessingWagner, Mootz \& Schoemakers-Salkinoja 1994, Tjadens \& Woldringh 1989). The group of clients that was selected for this study was a group that used many care facilities (nearly five types of care-givers on average). The selection of those who were care-dependent excluded those who might use community care services but were not classified as care-dependent. Therefore it can not automatically be assumed that the findings from this study apply to all community care clients.

The questionnaire addressed predisposing, enabling and need factors, diversity of care and continuity of care as potential correlates of client satisfaction.

118 Some other factors that can be important in the explanation of client satisfaction were not addressed. Other factors that are probably important with regard to client satisfaction are characteristics of the relationship between clients and care providers (Weiss 1988, Williams \& Calnan 1991b), aspects of patient-care provider communication (Bensing 1991, Ong, De Haes, Hoos \& Lammes 1995), provider skill or competence (Kurata, Watanabe, McBride, Kawai \& Andersen 1994, Williams \& Calnan 1991b) and clients' values and expectations (Linder-Pelz 1982). This implies that conclusions about the 
importance of these factors - when compared to significant factors identified in this study-cannot be drawn. Future studies might aim at combining or comparing these factors.

A first purpose of this study was to describe clients' satisfaction with professional and non-professional care. In general, it can be concluded that clients were satisfied with the care they received. Large percentages of clients had no complaints at all. These findings are very much in line with what is generally reported in earlier satisfaction studies (Pascoe 1983, Fox \& Storms 1981). Scores on client satisfaction scales tend to be skewed. This phenomenon has been observed for satisfaction with professional care, but here it can be concluded that it applies equally to satisfaction with non-professional care. This can either reflect that clients are truly satisfied, or it may indicate measurement problems. High satisfaction scores might be due to non-response of dissatisfied clients or to clients giving desirable answers. For this study, the fact that satisfaction with professional care and satisfaction with non-professional care were not interrelated indicates that clients did not give meaningless, desirable answers. Furthermore, the percentages of clients that were not satisfied with one or more aspects of the care they received were substantial. Thus, although it is difficult to draw final conclusions on the actual level of satisfaction, the scores can certainly be used in studying differences between respondents.

The second purpose of the study was to identify factors that could account for variations in clients' satisfaction scores. Aspects of continulty of care as derived from the work of Wall (Wall 1981) were the more important correlates of client satisfaction. In general, more continuity of care was strongly and positively related to higher levels of satisfaction. However, the relevance of specific aspects of continuity varied with the type of care involved. Whether or not care-givers kept their appointments was relevant to clients' satisfaction with both professional and non-professional care. Clients were less satisfied with professional care if they reported difficulties in 'knowing where to find care'; however this did not affect their satisfaction with the care provided by nonprofessionals. From this one might conclude that information on care options is expected from professionals and not so much from non-professiunals. The effect of the 'knowing where to find care' aspect could also be identified for the clients' satisfaction with medical specialists. Furthermore, satisfaction with the care provided by children was correlated to 'accessibility', while satisfaction with the care that was given by partners was related to the aspect 'keeping appointments'.

It is safe to conclude that continuity of care is relevant to satisfaction with both professional and non-professional community care, but the importance of different aspects might vary with the type of care involved.

With regard to the factors that were derived from the work of Andersen, it can be concluded that these factors were of limited importance in explaining 
client satisfaction. The educational level appeared to be an important factor in the explanation of clients' satisfaction with non-professional care in general and with care provided by neighbours in particular. Clients with a lower educational level were more satisfied with the care they received. The clients' educational level was also related to satisfaction with professional care, but was not selected as a significant factor in the regression analysis. The results for educational level are in line with the often reported effect that more experienced and better educated clients tend to express less satisfaction (Rees Lewis 1994). Effects of other predisposing factors than the educational level were absent or less consistent.

Other groups of factors that were derived from the works of Andersen -enabling and need factors and diversity of care- were only relevant to satisfaction with one or two specific care-givers. Some of these aspects were also related to satisfaction with professional and non-professional care in general, but were not selected in the regression procedures. A somewhat surprising result could be reported for 'perceived impairment'. Clients with more impairments tended to be less satisfied with the care provided by family physicians but seemed to be more satisfied with the care given by medical specialists. This effect may be explained by the fact that the need for specialized care increases with the level of impairment.

Many relationships that were identified in this study are in line with results from earlier satisfaction studies, even though these studies were often hardly comparable to the study that is reported here. As could be expected from the earlier studies, more continuity went together with higher levels of satisfaction; satisfaction was positively related to quality of life, and clients with lower educational levels were more satisfied with the care they received. The effect of other variables, however, varied with the type of care-giver involved. Perceived impairment and the diversity of care are examples of these variables.

On the whole, it can be concluded that -apart from educational level-predisposing, enabling and need factors and the diversity of care were in some instances related to client satisfaction, but were not important factors in explaining satisfaction scores. Continuity of care was obviously the most relevant factor with regard to client satisfaction, although there was some variation in the relevance of the aspects that were considered in this study. Satisfaction scores for specific care-givers had some related factors in com-

120 mon, but appeared to have 'unique' variation as well. Finally, it must be stressed that this study was not longitudinal. Therefore one should be cautious in assuming causality in relationships. In the future, longitudinal studies and more in-depth studies will be needed to determine the importance of the potential predictors identified in this study. 


\section{Acknowledgements}

Cooperation with the Noord-Limburg Foundation for Community Care, and a grant from the Province of Limburg made this study possible. The authors would like to thank care-givers and citizens of the community of Tegelen, and mrs. Marion Hekkink for their efforts and participation in this study. 


\section{References}

Andersen, R. (1995) Revisiting the behavioral model and access to medical care: Does it matter? Journal of Health and Social Behavior 36: 1-10.

Andrews, F.M. \& Whitey, S.B. (1976) Social indicators for well-being: Americans' perception of life quality. Plenum Press: New York.

Bensing, J. (1991) Doctor-patient communication and the quality of care. Social Science \& Medicine 32: 1301-1310.

Boer, A.H. de, Hessing-Wagner, J.C., Mootz, M. \& Schoemakers-Salkinoja, I.S. (1994) Informele zorg: Een verkenning van huidige en toekomstige ontwikkelingen (Informal care: A study of current and future developments). Sociaal en Cultureel Planbureau: Rijswijk, The Netherlands.

Centraal Bureau voor de Statistiek (1993) Standaard beroepenclassificatie 1992 (Standard classification of occupations 1992). SDU/CBS: 's Gravenhage, The Netherlands.

Centraal Bureau voor de Statistiek (1994) Bevolking de gemeenten van Nederland op 1 januari 1994 (Population of the municipalities in the Netherlands on January 1st 1994). SDU/C.BS: 's Gravenhage, The Netherlands.

Flynn, S.P. (1985) Continuity of care during pregnancy: the effect of provider continuity on outcome. Journal of Family Practice 21: 375-380.

Fox, J.G. \& Storms, D.M. (1981) A different approach to sociodemographic predictors of satisfaction with health care. Social Science \& Medicine 15a: 557-564.

Frederiks, C.M.A, Te Wierik, M.J.M., Visser, A.Ph. \& Sturmans, F. (1991) A scale for the functional status of the elderly living at home. Journal of Advanced Nursing 16: 287-292.

Gerace, T.M. \& Sangster, J.F. (1987) Factors determining patients' satisfaction in a family residency teaching centre. Journal of Medical Education 62: 485-490.

Hall, J.A. \& Dornan, M.C. (1990) Patient sociodemographic characteristics as predictors of satisfaction with medical care: A meta analysis. Social Science \& Medicine 30: 811-818.

Hall, J.A. \& Feldstein, M. (1990) Older patients' health status and satisfaction with medical care in an HMO population. Medical Care 28: 261-270.

Huil, F.M. \& Hull, F.S. (1934) Time and the general practitioner: The patient's view. Journal of the Royal College of General Practitioners 34: 7175.

Kurata, J.H., Watanabe, Y., McBride, C., Kawai, K. \& Andersen, R. (1994) A comparative study of patient satisfaction with health care in Japan and the United States. Social Science \& Medicine 39: 1069-1076.

L.inder-Pelz, S.L. (1982) Toward a theory of patient satisfaction. Social Science \& Medicine 16: 577-582. 
Linn, M.W., Linn, B.S. \& Stein, S.R. (1992) Satisfaction with ambulatory care and compliance in elderly patients Medical Care 20: 606-614.

Marquis, M.S., Davies, A.R. \& Ware, J.E. (1983) Patient satisfaction and change in medical care provider. Medical Care 21: 821-829.

Ong, L.M.L., De Haes, J.C.J.M., Hoos, A.M. \& Lammes, F.B. (1995) Doctorpatient communication: a review of the literature. Social Science \& Medicine 40: 903-918.

Pascoe, G.C. (1983) Patient satisfaction in primary health care: A literature review and analysis. Evaluation and Program Planning 6: 185-210.

Rees Lewis, J. (1994) Patient views on quality in general practice: literature review. Social Science \& Medicine 39: 655-670.

Roberts R.E., Pascoe, G.C. \& Attkisson, C.C. (1983) Relationship of service satisfaction to life satisfaction and perceived well-being. Evaluation and Program Planning 6: 373-383.

Tjadens, F.L.J. \& Woldringh, C.L. (1989) Informele zorg in Nederland: Zelfzorgproblemen behoefte aan hulp en praktisch instrumentele onderlinge hulp (Informal care in the Netherlands: Self-care deficits, care demands and mutual practical support). Instituut voor Toegepaste Sociale Wetenschappen: Nijmegen, The Netherlands.

Waal, A.E. van der, Casparie, A.F. \& Lako, C.J. (1996) Quality of care: a comparison of preferences between medical specialists and patients with chronic diseases. Social Science \& Medicine 42: 643-649.

Wall, E.M. (1981) Continuity of care and family medicine: Definition, determinants, and relationship to outcome. The Journal of Family Practice 13: 655-664.

Ware, J.E., Davies-Avery, A. \& Stewart, A.L. (1978) The measurement and meaning of patient satisfaction. Health and Medical Care Services Review 1: $1-15$.

Weiss, G.L. (1988) Patient satisfaction with primary medical care: Evaluation of sociodemographic an predispositional factors. Medical Care 26: 383392.

Williams, S.J. \& Calnan, M. (1991a) Key determinants of consumer satisfaction with general practice. Family Practice 8: 237-242.

Williams, S.J. \& Calnan, M. (1991b) Convergence and divergence: assessing criteria of consumer satisfaction across general practice, dental and. hospital care settings. Social Science \& Medicine 33: 707-716.

Zastowny, T.R., Roghmann, K.J. \& Kafferata, G.L. (1989) Patient satisfaction and the use of health services. Medical Care 27: 705-723. 


\section{4}




\section{6}

PREDICTORS OF CLIENT

SATISFACTION IN CARE-

DEPENDENT ADULTS:

A LONGITUDINAL ANALYSIS

Theo van Achterberg,

Fred C.J. Stevens,

Harry F.J.M. Crebolder

\& Hans Philipsen.

Submitted for publication. 


\section{Abstract}

The study that is described in this article was aimed at identifying predictors of the course of client satisfaction with both professional and non-professional community care. Client satisfaction and variables that represented the potential predictors were measured twice, with an interval of eight months. Groups of potential predictors were derived from the work of Andersen (1995) and Wall (1981). Respondents were adults who were dependent on the community care that was provided by professionals (family physicians, community nurses etc.) and/or non professionals (partners, children etc.). These 'clients' were randomly selected from a rural-urban community in the province of Limburg, The Netherlands. Data were collected by means of a telephone survey.

A group of 134 care-dependent adults participated in both the initial interview and the follow-up after eight months. Changes in the diversity and continuity of care were significantly related to the course of client satisfaction with both professional and non-professional care. Less diversity and more continuity of care went along with increased client satisfaction. Developments in client satisfaction were not related to sociodemographic (predisposing and enabling) variables, but some effects were found for impairment and quality of care. It was concluded that the measurement of client satisfaction was meaningful, since the course of client satisfaction scores was indeed related to changes in client care. 


\subsection{Introduction}

Although the importance of client satisfaction with community care is generally acknowleged, knowledge of the predictors of client satisfaction is still limited. Furthermore, client satisfaction studies are mostly cross sectional studies and are often restricted to medical care. This study describes predictors of the course of client satisfaction scores. Client satisfaction is not only addressed for medical care services, but includes satisfaction with several professional and non-professional services.

Client satisfaction is often seen as an important indicator of quality of care. In some studies, the terms 'quality of care' and 'client satisfaction' are even used as synonyms. This seems to imply that every aspect of quality of care could be covered by the client's level of satisfaction. However, since quality of care can also refer to the quality of aspects that cannot be judged by the average client (e.g. therapeutic or medical technical aspects) it is more appropriate to see client satisfaction as one possible operationalization of quality of care. Therefore, we will refer to client satisfaction in this text. Several studies have already focused on the identification of predictors of client satisfaction. There is some evidence that the client's age and sex can be used to predict the level of satisfaction (Ware 1978, Fox \& Storms 1981, Weiss 1988, Hull \& Hull 1984). Studies that identify age and sex as predictors conclude that satisfaction with care is higher for women and those who are older. However, there are some studies that report no effects for sex and age (Zastowny, Roghmann \& Kafferata 1989, Hall \& Feidstein 1990, Hall $\&$ Dornan 1990). Results are more consistent when it comes to the client's educational level and whether or not the client lives alone. There is hardly any evidence that these factors are relevant to client satisfaction.

Whether or not there is an effect of educational level is less clear. No effect is reported in some studies (Hall \& Feldstein 1990, Linn, Linn \& Stein, 1982 Weiss 1988), whereas others report lower levels of satisfaction for those with lower educational levels (Fox \& Storms 1981, Zastowny Roghmann \& Kafferata 1989, Fitzpatrick 1991, Ware 1978). Similar findings occur for the relationship between health and client satisfaction. While some authors report lower levels of satisfaction for the less healthy (Hall \& Feldstein 1990. Linn, Linn \& Stein 1982, Weiss 1988), others find no relationship between health and satisfaction (Fox \& Storms 1981, Zastowny, Roghmann \& Kafferata 1989). Although one might assume a positive relationship between the client's satisfaction with the care received and the quality of life as perceived by the client, there are only a few studies that focus on this relationship (Roberts, Pascoe and Attkinson 1983, Weiss 1988).

The relationship between the diversity or the amount of care received and the client's level of satisfaction remains unclear (Zastowny, Roghmann \& Kafferata 1989). Although one might expect to find a positive relationship between the diversity of care and client satisfaction, this is not often reported (Hull \& Hull 1984). Others conclude that diversity is negatively related to client satisfaction (Linn, Linn \& Stein 1982), while it is even suggested that satisfaction is highest when the number of services is neither high nor low. 
It is commonly believed that continuity in care providers has a positive influence on client satisfaction. Some studies have indeed identified continuity of care providers as a predictor of satisfaction (Marquis, Davies \& Ware 1983, Weiss 1988, Pascoe 1983). Other aspects that refer to the continuity of care and that were identified as predictors of client satisfaction are the accessibility of care providers and services (Flynn 1985, Williams \& Calnan 1991, Pascoe 1983), the availability (Williams \& Calnan 1991, Gerace \& Sangster 1987, Pascoe 1983) and the continuity in location and geographical distance (Fox \& Storms 1981).

Three problems occur when drawing conclusions about earlier studies that focused on predictors of client satisfaction. A first problem is that the different studies used a wide variety of approaches. Studies differ with regard to the exact client group, with regard to the operationalization of client satisfaction and with regard to the operationalizations of some of the predictors. This makes an adequate comparison of the outcomes of these studies impossible. Secondly, the studies only refer to professional care. In many instances professional care is even further restricted to medical care. This implies that it is not possible to draw conclusions with regard to non-professional care and with regard to professional care in general. Finally, most of the studies use a cross-sectional design. This implies that most studies deal with 'correlates' rather than 'predictors'. Therefore conclusions about possible causal relationships cannot be drawn.

For the longitudinal study that is described in this article, five groups of potential predictors were used in an attempt to explain the course of client satisfaction with professional and non-professional community care.

Predisposing, enabling and need factors were derived form the work of Andersen $(1975,1995)$. A fourth factor that was derived from the Andersen model was the diversity of care. The fifth group of potential predictors, continuity of care, was derived from the works of Ware (1978).

The five groups of potential predictors were used in an attempt to gain information with regard to the central research question:

Can predisposing, enabling and need factors and can the diversity and continuity of care be used as predictors of deterioration or improvement in client satisfaction?

\subsection{Methods}

\subsubsection{Sample}

A telephone survey was carried out in the Dutch community of Tegelen $(+19,000$ inhabitants). The survey was announced in two local newspapers and on two local radio stations. A total number of 1932 randomly selected 
households were contacted by a team of trained interviewers. If tho first attempt at contacting the household was fruitless, new attempls were made until a member of the household was reached. In those cases where potential respondents were caught at an inconvenient moment, an appointment for a more appropriate time was made. The survey was carried out during mornings, afternoons and evenings of 13 successive working days. About $73 \%$ of the households $(n=1406)$ participated in the study. Lack of time or lack of interest were among the most frequently mentioned reasons for those who did not want to participate. In 36 cases language problems occurred.

Respondents were asked if there was a person within their own household who was dependent on the care of others. It was explained that the dependency had to be related to reasons of mental or physical health and that care could involve both formal and informal care. In 190 cases $(14 \%)$ the household contained a care-dependent person. For the analyses in this article only data from dependent adults were used. This reduced the number of cases to $177(13 \%$ of 1406$)$.

The 177 care-dependent adults were approached once more after a period of eight months. About $76 \%$ of the respondents were interviewed a second time. Of the 43 clients that did not cooperate a second time 10 had moved to a nursing home, a home for the elderly or a hospital, 5 were deceased and 5 were no longer care-dependent. Of the remaining 21 clients, three wern unable to cooperate at the time, 12 refused further cooperation and 10 could not be reached at the time. It is not unlikely that some of these last 10 clients were temporarily admitted to a hospital.

Significant differences between the 134 clients that were interviewed on two occasions and the 43 clients who dropped out after the first interview, were found for the variables age and occupational level. Clients who only participated once were older ( 68 versus 62 years of age, $T=1.97 \mathrm{p}=.05$ ) and more often had a lower professional level (74 versus $\left.50 \%, X^{2}=7.42 p=.01\right)$ than clients who participated twice. There were no differences between the two groups of clients with regard to health, the diversity of professional and nonprofessional care, continuity aspects, client satisfaction or any other variables that were taken along in the study.

\subsubsection{Questionnaire}

An identical questionnaire was used for both interviews. The questionnaire addressed predisposing, enabling and need factors, diversity of care, continuity of care and client satisfaction. Apart from these five groups of potential predictors, the clients' diagnosis or health problems were recorded for the purpose of describing the client group.

Client satisfaction with individual care-givers was measured along a six item scale including: sincere interest, sufficient time, friendliness, health related information, care related information and quality of services (Ware, DaviesAvery \& Stewart 1978). The satisfaction with individual care-givers was computed by adding the scores on the six items and recoding the result to 0 lone or more complaints) or 1 (completely satisfied). 
Professional care was defined as all medical and non-medical care that is provided by persons who are trained, organized and/or paid for. Non-professional care was described as all informal care by persons from the own social/informal network. The satisfaction with professional and non-professional care 'on the whole' was computed by adding the scores for individual care-givers and dividing by the actual number of care-givers. Again the result was recoded to 0 or 1 . Alpha's for the satisfaction scales were high (e.g. satisfaction with non-professional care $\alpha=.79$; satisfaction with professional care $\alpha=.77$ at baseline). Factor analysis revealed that the scale could be seen as a one-factor measure. There was no significant relationship between satisfaction with professional care and satisfaction with non-professional care at baseline.

Four predisposing factors were addressed. The respondents' sex, age, educational level and occupational level were registered. The educational level was scored as 'only primary school' or 'additional education'. The occupational level was classified into nine categories -9 being the highest possible scoreusing the Dutch standard classification of occupations (Centraal Bureau voor de Statistiek 1993). For the analyses in this study, occupational level was recoded as either 'low' (scores 1 to 3 ) or 'middle or high' (scores 4 to 9 ). Only one enabling factor was taken along in the study. Registration was made of whether clients lived alone or shared a household with one or more others. Five variables were included to represent the need for care. A 5-point scale was used to estimate the respondent's perceived health. Here, a score of 1 represented the worst possible health, whereas as score of 5 represented optimal health. Impairment was measured using a scale ranging from 1 to 4 , 4 representing the highest level of impairment. Functioning with regard to Activities of Daily Living (ADL) and Instrumental Activities of Daily Living (IADL) was estimated using a 16-item list including the topics: getting in/out of bed, washing, dressing, going to the bathroom, eating and drinking, walking around the house, walking stairs, making beds, doing the laundry, cleaning windows, shopping, cooking, washing dishes, vacuum cleaning, administrative activities and visiting others. Factor analysis showed that ADL and IADL items could be combined in a one-factor scale (Eigenvalue 5.44 at t1), which is in line with results reported by Frederiks et al. (Frederiks, Te Wicrik, Visser \& Sturmans 1991). Scores on the combined scale could vary from 0 to $16 ; 16$ indicating independence on all aspects of daily functioning. For the first interview Cronbach's alpha for the daily functioning scale was 0.86 , at $\mathrm{t} 2$ this was 0.85 . Perceived quality of life was measured using a three

130 item list, derived from the work of Andrews and Whitey (1976). Items included happiness, satisfaction and a global estimation of one's own life in terms of good and bad. The alpha for this three item scale was 0.78 both at baseline and after 8 months. Scores for quality of life could vary from 1 (lowest) to 5 (highest quality of life). Diversity of care was registered for professional, non-professional and total care. The diversity of formal care was measured by counting the number of different types of professionals involved. A maximum of 11 different professionals could be indicated. For infor- 
mal care, a maximum of five different informal care-givers could be mentioned. For both the amount of formal and informal care, two care-givers with the same background (e.g two nurses, two children) were counted as one. Scores for the diversity of total care were computed by adding the diversity of non-professional care to the diversity of professional care. Thus, a maximum of 16 different types of care-givers could be reported.

Finally, the continuity of care was estimated by addressing five continuity aspects (Wall 1981). The two aspects 'accessibility' and 'care-givers keeping appointments' were addressed for all professionals and non-professionals. The aspect 'same professional over time' was addressed for professional caregivers only. The last two aspects 'receiving consistent information' and 'knowing where to find care' were measured as general items and not addressed for specific care-givers. Scores on the continuity aspects could be either 0 or 1, 1 being the positive score (e.g. care-giver always accessible, always receiving consistent information). In the analyses for professional care and non-professional care 'on the whole', scores on the first three items were computed by adding scores for individual care-givers and dividing them by the total number of care-givers. Therefore, scores on these items could be any value between 0 and 1 . Since scores on these items were all skewed to the higher scores, scores were recoded to 0 (any number of discontinuities) or 1 (no discontinuities reported).

\subsubsection{Analyses}

For the purpose of identifying factors that could predict improvement and deterioration in client satisfaction, the total client group was divided into subgroups.

This division was made for both satisfaction with professional care and satisfaction with non-professional care. Predictors of deterioration in client satisfaction were identified by comparing clients who were satisfied on both occasions with clients who shifted from being satisfied to being dissatisfied between baseline ( $\mathrm{t} 1$ ) and 8 months ( 2 ).

Improvement in client satisfaction was studied for all clients who were not. satisfied at $\mathrm{t} 1$ and whose scores could actually improve. Here, clients who still had complaints after 8 months were compared with clients who no longer had complaints at the time of the second interview.

The potential predictors could be categorized according to three types. The first type of variables were dichotomous, ordinal or interval variables that showed no or hardly any variation between $\mathrm{t} 1$ and $\mathrm{t} 2$. Predisposing and enabling variables were categorized as this type of variables. For these variables T-test or Chi-square test were computed to study their influence on deterioration or improvement in professional and non-professional care. Only original. t1 scores were used.

the second type of variables were variables at the ordinal or interval level, that varied between $\mathrm{t} 1$ and $\mathrm{t} 2$. All need and diversity of care variables could fit this description. For these variables both the original $t 1$-scores and 12 minus 11 change scores were used as predictors of improvement or deteriora- 
tion in client satisfaction. T-test were used to test for the effect of both $\mathrm{t} 1$ scores and $\mathrm{t} 2$ minus $\mathrm{t} 1$ change scores.

Finally, all continuity aspects were a third type of variables: dichotomous variables that varied between $\mathrm{t} 1$ and $\mathrm{t} 2$. For these variables, the original $\mathrm{t} 1$ scores were used, but change scores could not be computed. Instead, four groups were constructed to cover the possible variation between $t 1$ and $t 2$ : (1) complaints at $\mathrm{t} 1$ and $\mathrm{t} 2$; (2) complaints at $\mathrm{t} 1$, satisfied at $\mathrm{t} 2$; (3) satisfied at $\mathrm{t} 1$, complaints at $\mathrm{t} 2$ and (4) satisfied on both occasions. Chi-square tests were used to test for the effects of both the $t 1$ scores and the $t 2 / \mathrm{t} 1$ variation groups.

\section{Table 1}

Scores on predisposing, enabling and need factors, care-type, use of care, continuity of care and client satisfaction at the first interview ( 11 ) and after 8 months ( $t 2$ ) $(n=134)$.

\section{Predisposing}

Female

Age

$62.1 \quad 1.5$

Only primary school

Low occupational level

Enabling

Living alone

$\begin{array}{rrrrrrrr}\mathrm{t} 1 & \mathrm{t} 1 & \mathrm{t} 1 & \mathrm{t} 1 & \mathrm{t} 2 & \mathrm{t} 2 & \mathrm{t} 2 & \mathrm{t} 2 \\ \text { MEAN } & \text { SD } & \# & \% & \text { MEAN } & \text { SD } & \# & \%\end{array}$

Need

Health

Impairment

$3.1 \quad 0.9$

$94 \quad 70$

Quality of life

3.10 .9

$3.7 \quad 0.8$

Daily functioning

Diversity of care

Diversity of non-prof care

$11.5 \quad 3.7$

$64 \quad 48$

$60 \quad 45$

$66 \quad 49$

Diversity of prof care

$2.1 \quad 1.2$

$2.7 \quad 1.5$

Diversity of total care

$4.8 \quad 2.1$

$\begin{array}{ll}3.1 & 0.9\end{array}$

$3.1 \quad 1.0$

3.90 .8

$11.6 \quad 3.4$

$2.0 \quad 1.2$

$2.5 \quad 1.6$

$4.6 \quad 2.2$

\section{Continuity of care}

Non-professionals accessible

$85 \quad 67$

$82 \quad 66$

Non-profs keeping appointments

Professionals accessible

$99 \quad 78$

$71 \quad 76$

$84 \quad 67$

$89 \quad 73$

Profs keeping appointments

$97 \quad 77$

$107 \quad 88$

Same profs over time

$37 \quad 30$

$26 \quad 21$

Consistent information

$106 \quad 80$

109

105

Knowing where to find care

$95 \quad 72$

Satisfaction

Satisfied with prof care 


\subsection{Results}

\subsubsection{Background characteristics}

The mean age of the 134 respondents was 62 years of age at the first interview. About $70 \%$ of the sample was female, half of the respondents lived alone. An overview of the characteristics of the sample is given in table 1. Half of the clients had lower educational and occupational levels. Clients perceived their health as 'moderate' (3.1) and reported 'quite some' impairments as result of their health problems (again 3.1). Quality of life was perceived as 'average' to 'good' (3.7 on average). The most commonly reported disorders were cardiovascular diseases (31\%), diseases of the eye, ear or organ of balance $(21 \%)$, bone or joint diseases $(17 \%)$, chronic back-pain $(14 \%)$, lung diseases $(12 \%)$, diseases of the digestive system $(8 \%)$, trauma resulting from accidents (8\%) and psychiatric disorders (7\%). Clients were independent on 11 or 12 of the 16 aspects of daily functioning.

\section{Table 2}

Factors related to satisfaction with professional and non-professional care at $t 1$ $(n=177)$.

SATISFACTION NON-PROF RELATION $\mathrm{CH}^{2} \quad \mathrm{~T}$
SATISFACTION PROF RELATION $\mathrm{CH}^{2} \quad T$

\section{Predisposing}

Being older

Educational level

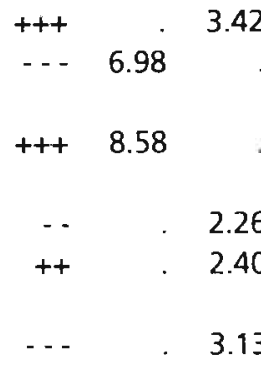

Enabling

Living alone

Need

Perceived impairment

Perceived quality of life

Diversity of care

Diversity of non-prof care

Continuity of care

Non-professionals accessible

$+++12.68$

Non-profs keeping appointments

$+++27.08$

Professionals accessible

Professionals keeping appointments

Same professionals over time

Consistent information

Knowing where to find care

$++\quad 2.06$

- 5.91

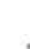

$++$

$+/-$ positive/negative relation $p \leq 10,++/ \cdots p \leq 05,+++1-\cdots \leq 01$ 
On average, clients received care from nearly 5 types of care-givers: two types of non-professionals and two or three types of professional care-givers. A clear majority was satisfied with nearly all the continuity of care aspects. The only exception was the aspect 'same professionals over time'. About $70 \%$ of the clients at $t 1$ and $79 \%$ of the clients at $t 2$ were confronted with several professionals within the different disciplines (e.g. more than one community nurse, family physician or home helper).

An overview of t1-relationships between client satisfaction with professional and non-professional care on the one hand and continuity of care and predisposing, enabling, and need factors on the other hand is given in table 2 . At t1, continuity of care was clearly related to both satisfaction with professional and satisfaction with non-professional care. Positive scores on continuity aspects went along with higher levels of satisfaction. Furthermore, satisfaction with both types of care was related to the clients' age, educational level and quality of life. Older clients, clients with lower educational levels and clients with a higher quality of life reported higher levels of satisfaction. Perceived impairment and diversity of care were only relevant to satisfaction with non-professional care. Clients who perceived more impairment and clients who received more non-professional care were less satisfied than others.

\subsubsection{Developments in client satisfaction}

Client satisfaction with non-professional care at both moments could be registered for 120 clients. The remaining 14 clients did not receive non-professional care at one or both moments, or gave incomplete scores. A group of 46 clients was completely satisfied at both moments (table 3 ), while 32 clients reported one or more complaints on both occasions. Of the remaining 42 clients, 24 were satisfied at $t 1$ but reported complaints after eight months and 18 persons started with complaints but were satisfied with care at $t 2$.

\section{Table 3}

Satisfaction with professional and non-professional care at $t 1$ ( 0 months) and $t 2$ (8 months) ( $n=134)$.

NON-PROFESSIONAL CARE

t2

DISSATISFIED SATISFIED

$\mathrm{t} 2$

TOTAL
PROFESSIONAL CARE t2 $t 2 \quad t 2$

DISSATISFIED SATISFED TOTAL

$\begin{array}{lrrrrrr}\mathrm{t} 1 \text { dissatisfied } & 32 & 18 & 50 & 34 & 31 & 65 \\ \mathrm{t} 1 \text { satisfied } & 24 & 46 & 70 & 20 & 32 & 52 \\ \mathrm{t} 1 \text { total } & 56 & 64 & 120 & 54 & 63 & 117\end{array}$


A total number of 117 clients had complete scores for satisfaction with professional care. Here, 34 clients were dissatisfied and 32 clients were satisfied on both occasions. A group of 31 clients started out with complaints but were satisfied after eight months, while 20 clients were satisfied at $t 1$ and reported complaints at $\mathrm{t} 2$.

\subsubsection{Deterioration in client satisfaction with professional care}

Two $\mathrm{t} 2$ - $\mathrm{t} 1$ change scores were related to deterioration in client satisfaction with professional care (table 4). Diversity of professional care was positively related to deterioration in client satisfaction. An increase in the diversity of professional care occurred parallel to more deterioration in client satisfaction. Furthermore, clients who did not develop any complaints with regard to the continuity aspect 'same professionals over time' were less likely to show deterioration in satisfaction with professional care. Deterioration in satisfaction with professional care could not be predicted by $\mathrm{t} 1$ scures or $\mathrm{t} 2$-t 1 change? scores for any of the predisposing, enabling or need variables.

\subsubsection{Improvement in client satisfaction with professional care}

Two original $\mathrm{t} 1$ scores and two $\mathrm{t} 2$ - $\mathrm{t} 1$ change scores were identified as predictors of improvement in client satisfaction with professional care (table 4). Clients who were more impaired at baseline were less likely to improve their satisfaction scores between $\mathrm{t} 1$ and $\mathrm{t} 2$. On the other hand, clients with a higher quality of life at $\mathrm{t} 1$ were more likely to show improved satisfaction. Furthermore, improvement in client satisfaction with professional care was less likely to occur for those whose diversity of professional care had in-

\section{Table 4}

Predictors of deterioration ( $n=52)$ and improvement $(n=65)$ in client satisfaction with professional care.

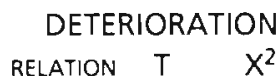

RELATION T $X^{2}$

Need

Impairment +1

Quality of life $t 1$

Diversity of care

Diversity prof care $t 2-t$

Continuity of care

Professionals accessible $t 2 / t 1$

Same profs over time $t 2 / t$

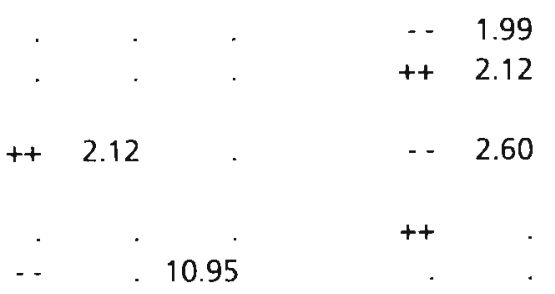

$+/-p \leq .10++/--p \leq .05+++/--p \leq .01$ 
creased between $t 1$ and $t 2$. Thus, improvement in satisfaction occurred together with a decrease in the diversity of professional care.

Changes in the continuity aspect 'accessibility of professional care-givers' were positively related to improvement in client satisfaction. Improvement in satisfaction was found less often for those who complained about the accessibility of professionals at both $\mathrm{t} 1$ and $\mathrm{t} 2$ and occurred more often for those who reported improvement in the accessibility of professionals between $t 1$ and $t 2$. Improvement in satisfaction with professional care was not related to any of the original t1 scores for the predisposing and enabling variables.

\subsubsection{Deterioration in satisfaction with non-professional care}

Deterioration in client satisfaction with non-professional care was correlated to two $\mathrm{t} 2$ - $\mathrm{t} 1$ change scores and two $\mathrm{t} 1$ scores (table 5). First, a decline in satisfaction scores was more likely to occur for those who had a higher quality of life and who received consistent information from their care-givers at baseline. Secondly, deterioration in satisfaction with non-professional care went along with an increasing diversity of non-professional care. Apparently, more diversity of care can result in a setback in client satisfaction. Finally, clients who developed complaints with regard to the continuity aspect 'non-professionals keeping appointments' during the eight months interval, showed deterioration in satisfaction scores more often.

\section{Table 5}

Predictors of deterioration $(n=70)$ and improvement $(n=50)$ in client satisfaction with non-professional care.

\begin{tabular}{ccccc} 
DETERIORATION & \multicolumn{3}{c}{ IMPROVEMENT } \\
RELATION $T$ T $X^{2}$ & RELATION $T \quad X^{2}$
\end{tabular}

Need

Impairment t2-t1

Quality of life $t 1$

$\begin{array}{rrrrr}\cdot & . & & + & 1.89 \\ - & 2.08 & \cdot & \cdot & \\ ++ & 3.04 & . & & -1.76\end{array}$

Continuity of care

Non-prof accessible t2-t 1

136 Non-profs keep appointments $\mathrm{t2}-\mathrm{t} 1 \quad$ - $\quad .9 .04$

Consistent information $\mathrm{t} 1$

Consistent information $\mathrm{t} 2$ - $\mathrm{t} 1$

Knowing where to find care $\mathrm{t} 2-\mathrm{t} 1$

2.71

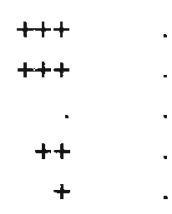




\subsubsection{Improvement in satisfaction with non-professional care}

Six of the potential predictors were actually related to improvement in client satisfaction with non-professional care (table 5). None of these, however, were $\mathrm{t} 1$ scores. First of all increased impairment and decreased diversity of non-professional care were related to improvement in client satisfaction with non-professional care. Furthermore, improved satisfaction was related to positive changes in the four continuity aspects. For all these aspects, clients with improved satisfaction scores had shifted from 'complaints' to 'no complaints' more often, or developed complaints with regard to continuity of care less often.

\subsection{Discussion}

The study that has been described in this article was designed to study the predictors of improvement or deterioration in client satisfaction with professional and non-professional community care. Although literature on client satisfaction is not scarce, the study was exploratory in nature. This exploratory design is justified by the fact that satisfaction with non-professional care and satisfaction with non-medical services is not or not often addressed in other studies. Furthermore, there is a lack of longitudinal studies that identify predictors of changes in satisfaction scores.

Potential predictors were derived from the works of Andersen (1995) and Wall (1981). Predisposing, enabling and need factors and the diversity and continuity of care were addressed in both the $t 1$ and $t 2$ questionnaires. The results of this study can only apply to these factors. As a consequence, conclusions cannot be drawn with regard to other potentially relevant predictors of client satisfaction such as the clients' values and expectations (Linder-Pelz 1982) and the quality of the relationship between clients and care providers (Weiss 1988).

For the purpose of identifying predictnrs of deterioration or improvement in client satisfaction, a population survey was conducted in the Dutch community of Tegelen. At $t 1$, the sample consisted of 1406 households (73\% of those who were approached). In $13 \%$ of these cases $(n=177)$, a care-dependent adult was part of the household. This percentage did not seem very deviant from figures that were reported for other Dutch studies (De Boer, HessingWagner, Mootz \& Schoemakers-Salkinoja 1994, Tjadens \& Woldringh 1989). After eight months, about $76 \%(n=134)$ of the clients could be interviewed for the second time. Clients who participated on both occasions were relatively young and had higher occupational levels, when compared to those who dropped out after the first interview. However, there were no selection effects with regard to the dependent variables (client satisfaction with professional and non-professional care) and all other potential predictors of client satisfaction. The selection for age and occupational level might be interpreted as 
'natural' since the elderly are more likely' to be institutionalized or deceased, and lower occupational levels were more often found for those who were older.

A first result from this study was that baseline demographic scores for predisposing and enabling variables were not related to the development of client satisfaction over time. Client characteristics such as age, sex, occupation, education and living arrangement were not relevant when predicting deterioration or improvement in client satisfaction. These findings are in line with the results from (overview) studies by Hall and Dornan (1990) and Weiss (1988), who concluded that sociodemographic variables such as age, sex and occupation are relatively unimportant to the explanation of client satisfaction. It should be noted however, that the population of this study consisted of care-dependent adults. One cannot be sure that these findings would equally apply to all community care clients.

\section{Client satisfaction with professional care}

Need variables were not related to deterioration in satisfaction with professional care. However, improvement in clients satisfaction with professional services occurred more often for clients who were less impaired and had a higher quality of life at baseline. Obviously, clients were more likely to become more satisfied when they were less dependent on professional care providers and when their quality of life was higher from the start. The development of satisfaction with professional care was negatively related to changes in the diversity of professional care. An increase in the diversity of care implied more deterioration and less improvement. Apparently, the quality of care is more endangered when more types of care-givers become involved. Finally, improved continuity of care was negatively related to deterioration and positively related to improvement in satisfaction with professional care. Whereas deterioration could be predicted by discontinuity in professional care providers, improvement was related to an increased accessibility of professionals.

\section{Client satisfaction with non-professional care}

The need factors quality of life and impairment were related to developments in client satisfaction with non-professional care. While more impairment predicted improved satisfaction, a higher quality of life at baseline made the occurrence of deterioration less likely.

138 Results for diversity of care showed that increased diversity was strongly related to deterioration in the satisfaction with non-professional care. Also, a trend was identified that increased diversity of non-professional care would make the improvement of satisfaction scores less likely to occur.

Developments in continuity were positively related to the development of satisfaction scores. Deterioration in satisfaction scores was found less often for clients with positive change or baseline scores for continuity of care. 
Positive changes in continuity occurred together with more improvement in satisfaction scores.

With regard to the five groups of factors that were taken into account in this study, it can be concluded that two, the predisposing and enabling factors, are irrelevant when predicting the course of client satisfaction scores in a population of care-dependent adults. The results for the third factor, need, were not clear-cut. While less impairment at baseline had positive effects on the course of clients' satisfaction with professional care, increased impairment was found more often for clients who reported improved satisfaction with non-professional care.

With regard to the effects of diversity of care, one should note that although it seems obvious that increased diversity gives clients more chances to complain, the results were not that obvious. In computing satisfaction scores, a correction for the number of care-sources was applied. Therefore, the findings that higher diversity of care results in lower 'relative' satisfaction scores are meaningful and significant. Findings with regard to continuity of care were in line with what one might expect. Cox et al. (1994) noted that there is a lack of research that describes continuity of care and its supposed positive effects. The results of this study prove, however, that continuity aspects are relevant to the course of both client satisfaction with professional and non-professional care. Continuity of care does indeed increase client satisfaction.

Finally, it can be concluded that measuring client satisfaction is meaningful and valuable. As should be expected, the course of client satisfaction scores is indeed related to changes in care. The results for diversity and continuity of care can be seen as a demonstration of the validity of the client satisfaction measure. 


\section{References}

Andersen, R. (1995) Revisiting the behavioral model and access to medical care: Does it mater? Journal of Health and Social behavior 36: 1-10.

Andersen, R., Kravits, J. \& Anderson, O.W. (1975) Equity in health services: Empirical analyses in social policy. Cambridge: Ballinger Publishing Company.

Boer, A.H. de, Hessing-Wagner, J.C., Mootz, M. \& Schoemakers-Salkinoja, I.S. (1994) Informele zorg: Een verkenning van huidige en toekomstige ontwikkelingen (Informal care: A study of current and future developments). Rijswijk, The Netherlands: Sociaal en Cultureel Planbureau.

Centraal Bureau voor de Statistiek (1993) Standaard beroepenclassificatie 1992 (Standard classification of occupations 1992). 's Gravenhage, The Netherlands: SDU/CBS.

Cox, K., Peeters-Niemantsverdriet, S., Philipsen, H., Neumann, M., Van Campen, C. \& Huyer-Abu Saad, H. (1994) Onderzoekprogramma kwaliteit van zorg 3: Overzichtstudie discontinuïteiten in de thuiszorg, aantasting van de kwaliteit van zorg? (Research program quality of care 3: Overview study discontinuities in community care, endangering the quality of care?). Den Haag, The Netherlands: Nederlandse Organisatie voor Wetenschappelijk Onderzoek.

Fitzpatrick, R. (1991) Surveys of patient satisfaction: I Important general considerations. British Medical Journal 302: 887-889.

Flynn, S.P. (1985) Continuity of care during pregnancy: The effect of provider continuity on outcome. Journal of Family Practice 21: 375-380.

Fox, J.G. \& Storms, D.M. (1981) A different approach to sociodemographic predictors of satisfaction with health care. Social Science \& Medicine 15a: 557-564.

Frederiks, C.M.A., Te Wierik, M.J.M., Visser, A.Ph. \& Sturmans, F. (1991) A scale for the functional status of elderly living at home. Journal of Advanced Nursing 16: 287-292.

Gerace, T.M. \& Sangster, J.F. (1987) Factors determining patients' satisfaction in a family residency teaching centre. Journal of Medical Education 62: 485-490.

Hall, J.A. \& Dornan, M.C. (1990) Patient sociodemographic characteristics as predictors of satisfaction with medical care: A meta analysis. Social Science \& Medicine 30: 811-818.

140 Hall, J.A. \& Feldstein, M. (1990) Older patients' health status and satisfaction with medical care in an $\mathrm{HMO}$ population. Medical Care 28: $261-270$.

Hull, F.M. \& Hull, F.S. (1984) Time and the general practitioner: The patient's view. Journal of the Royal College of General Practitioners 34: 71 75.

Linn, M.W., Linn, B.S. \& Stein, S.R. (1992) Satisfaction with ambulatory care and compliance in elderly patients. Medical Care 20: 606-614. 
Marquis, M.S., Davies, A.R. \& Ware, J.E. (1983) Patient satisfaction and change in medical care provider. Medical Care 21: 821-829.

Pascoe, G.C. (1983) Patient satisfaction in primary health care: A literature review and analysis. Evaluation and Program Planning 6: 185-210.

Roberts, R.E., Pascoe, G.C. \& Attkisson, C.G. (1983) Relationship of service satisfaction to life satisfaction and perceived well-being. Evaluation and Program Planning 6: 373-383.

Tjadens, F.L.J. \& Woldringh, C.L. (1989) Informele zorg in Nederland:

Zelfzorgproblemen, behoefte aan hulp en praktisch instrumentele onderlinge hulp (Informal care in the Netherlands: Self-care deficits, care demands and mutual practical support). Nijmegen, the Netherlands: Instituut voor Toegepaste Sociale Wetenschappen.

Wall, E.M. (1981) Continuity of care and family medicine: Definition, determinants and relationship to outcome. The Journal of Family Practice 13: 655-664.

Ware, J.E., Davies-Avery, A. \& Stewart, A.L. (1978) The measurement and meaning of patient satisfaction. Health and Medical Care Services Review 1: $1-15$.

Weiss, G.L. (1988) Patient satisfaction with primary medical care: Evaluation of socio-demographic and predispositional factors. Medicul Care 26: 383 392.

Williams, S.J. \& Calnan, M. (1991) Key determinants of consumer satisfaction with general practice. Family Practice 8: 237-242.

Zastowny, T.R., Roghmann, K.J. \& Kafferata, G.L. (1989) Patient satistartion and the use of health services. Medical Care 27: 705-723. 


\section{Summary}

This thesis describes two studies that focussed on community care for those who are chronically ill or care-dependent. In both studies, community care was not restricted to the care that is provided by professionals. Informal or non-professional care, given by members from the client's social network was seen as an essential part of total community care. Whereas the first study describes the implementation and the effects of coordination of care, the second studies addresses correlates of the diversity of care and (the course of) client satisfaction.

Chapter 1 gives an overview of both studies. In this chapter the overall research model is presented, methods and results of the two studies are summarized and limitations, conclusions and implications of the study are discussed. The overall research model was derived from a combination of theoretical) insights. Alter \& Hage's Conceptual Framework for Studying Interorganizational Networks provided the framework for this model (Aiter \& Hage 1993). The concepts within the model were derived from the works of Andersen (1995), Litwak (1985), and Wall (1981). Coordination of care, predisposing, enabling and need factors, diversity of care, care-tasks, continuity of care and client satisfaction are the building blocks of the research model. In chapter 1 , the concepts are introduced and proposed relationships are discussed.

Chapter 2 describes the implementation of coordination of care for chronically ill, elderly community care clients. Coordination of care was implemented by appointing care-coordinators in specific client situations. Only those professional and non-professional care-givers who were already involved in the client situation were eligible for the role of care-coordinator. All coordinators were instructed to perform five basic tasks: (1) introducing themselves as coordinators; (2) making a care-inventory; (3) making a care-plan; (4) execution of the care-plan and monitoring care, and (5) evaluation of the care-plan. As potential tools, a care-inventory form, a care-plan form, a logbook (a tool in monitoring daily care) and coordinator guidelines were introduced. Coordinators were asked to perform their tasks for the period of one year. A total of 19 professionals and 19 non-professionals acted as the coordinators for one or more clients during a period of at least six months. The implementation of coordination of care was evaluated using minutes from group meetings with coordinators, used care-plans and logbooks, and interviews with coordinators. Interviews with coordinators were 'open interviews', addressing topics such as specific client situations, task performance, potential effects of the intervention and potential problems.

Nearly all coordinators performed well on the tasks of 'making a care-inventory' and 'execution of the care-plan and monitoring care'. Performance was reasonable with regard to the 'introduction' and the 'making of a care-plan', while the 'evaluation' was executed reasonably by professionals and poorly by non-professionals. Professionals and non-professionals used different coordinator styles. Whereas professionals presented themselves as 'care 
managers', non-professionals became 'client advocates'. On the whole, however, there were few differences in task performance of professionals and non-professionals. Therefore it was concluded that both professionals and non-professionals might function as care-coordinators.

Chapter 3 offers a description of the results of the coordination of care intervention. The interviews with 19 professionals and 19 non-professionals who functioned as coordinators and interviews with 72 clients, who participated during the intervention period of one year, were used to evaluate the intervention's effects. Whereas interviews with coordinators had an open structure, prestructured questions and answers were used in client interviews, dealing with topics such as health, functioning, diversity of care and satisfaction.

Professionals who functioned as coordinators perceived more effects than non-professionals who performed the same tasks. The seven coordinators who reported no effects were all non-professionals. Coordinators mentioned many effects that referred to interpersonal continuity; 24 out of 38 coordinators believed that the intervention had positive effects on relationships between clients and care providers. Positive results with regard to informational an interdisciplinary continuity were reported by half of the coordinators. Interviews with clients revealed hardly any effects of the coordination of care intervention. Only a short term effect on client satisfaction could be reported. After six months of coordination of care, clients with coordinators reported less complaints with regard to the care-givers involved than clients who received only regular care.

Chapter 4 is the first of three chapters that describe the second study, a study of the correlates of diversity of care and (the course of) client satisfaction scores. In this chapter, the results of a cross sectional study, describing the correlates of the diversity of professional, non-professional and total care is presented. A group of 177 care-dependent community care clients (adults) was identified by means of a large scale telephone survey among randomly selected households. Care-tasks, predisposing, enabling and need factors, diversity of care, continuity of care and client satisfaction were addressed in the prestructured client interviews. The results for client satisfaction and continuity of care were used for the description of correlates of client satisfaction in chapters 5 and 6 . Nearly all clients in the sample received both professional and non-professional care. On average clients received care from nearly five different types of professional or non-professional care-givers. The diversity of total care was at best explained by a function of quality of life,

144 daily functioning, and the care-tasks emotional support and informational support. Age, living arrangement, quality of life, emotional support, and diversity of professional care were significant factors in the explanation of variance in the diversity of non-professional care. Finally, a significant proportion of the variance in the diversity of professional care could be explained by scores for non-professional care, practical and informational support, daily functioning and sharing a household with others. 
Chapter 5 describes the correlates of client satisfaction with professional and non-professional community care. For this part of the second study, the same cross-sectional data for the group of 177 care-dependent adults were used. Client satisfaction was registered for specific types of care-givers (e.g. children, home helpers and medical specialists) and professional and non-professional care in general. Although there was some variety in the results for specific care-givers, aspects of continuity of care were generally among the most important correlates of client satisfaction. More continuity of care went along with higher levels of client satisfaction. With regard to the other factors it was reported that the level of client satisfaction could partially be explained from the clients' educational level. Lower educational levels implied more client satisfaction.

Chapter 6 is dedicated to predictors of developments in client satisfaction scores. In this last chapter longitudinal data from 134 of the original 177 care-dependent adults were used. These 134 respondents participated in a second interview round, eight months after the first interview took place. Predictors of the course of client satisfaction scores were studied for both professional and non-professional care. Changes in the diversity of care and developments in the continuity of care were the best predictors of deteriorations and improvements in client satisfaction. Increased diversity of care and decreased continuity of care went along with negative developments in client satisfaction scores. The course of client satisfaction scores was further related to the clients' impairment and quality of life. A higher quality of life at baseline was related to positive developments in client satisfaction, whereas the results for impairment were somewhat contradictory.

Conclusions were drawn, following the proposed relationships in the original research model. From study I conclusions were drawn with regard to the effects of the appointment of care-coordinators. Whereas results from coordinator interviews confirmed the proposed relationship between coordination and continuity of care, effects on the diversity of care were not identified as a result from the coordination of care intervention. It is suggested that the absence of effects on the diversity of care could result from the nature or the incompleteness of the intervention. Nevertheless, the appointment of carecoordinators is seen as beneficial, when aiming at the improvement of the continuity of care.

From the second study it was concluded that predisposing, enabling and need factors were useful in the explanation of diversity of care. Still, adding the concept of 'care-tasks' should be considered when developing a model that aims at an explanation of the variety in the diversity of professional and non-professional community care.

While some effects of predisposing, enabling and need factors were reported, these factors were relatively unimportant in the explanation of (developments in) client satisfaction. Continuity of care aspects were very relevant to both the level of, and developments in client satisfaction. Although the diversity of 
care is relatively unimportant in the explanation of current levels of satisfaction, increasing diversity of care is a serious threat to the level of client satisfaction.

Apart from general conclusions, limitations and practical implications of the two studies are given in the last section of chapter 1 . The results from study I implied that both professionals and non-professionals are suitable candidates for the role of care-coordinator. However, future interventions should give more attention to training potential coordinators in systematic working. With regard to the training of non-professionals, some additional assertiveness training and learning strategies in mobilizing other care-givers can be appropriate. Whereas the appointment of care-coordinators can result in improved continuity of care, interventions that involve formal arrangements and/or client budgets might be more effective when aiming at the improvement of client care.

Findings from the second study implied that care-givers should pay more attention to potential care deficits in the 'frail' elderly, clients who are older, live alone, are more impaired and report a relatively low quality of life.

Furthermore, the results for this study further revealed that client satisfaction scores are meaningful and that the level of client satisfaction is threatened by a high complexity of care. Therefore, coordination of care is all the more relevant in situations with a high diversity of care.

\section{References}

Alter, C. \& Hage, J. (1993) Organizations working together. Newbury Park, CA: SAGE.

Andersen, R. (1995) Revisiting the behavioral model and access to medical care: Does it matter? Journal of Health and Social Behavior 36: 1-10.

Litwak, E. (1985) Helping the elderly: The complementary roles of informal networks and formal systems. New York: Guilford Press.

Wall, E.M. (1981) Continuity of care and family medicine: Definition, determinants and relationship to outcome. The Journal of Family Practice 13: 655-664. 


\section{Samenvatting}

In dit proefschrift wordt verslag gedaan van twee studies binnen de thuiszorg voor chronisch zieken of zorg-afhankelijken. Daarbij werd het onderwerp van studie niet beperkt tot de thuiszorg die door professionele hulpverleners wordt geleverd; ook de hulpverlening door mantelzorgers werd in beide studies nadrukkelijk belicht. De eerste van de twee studies beschrijft de implementatie en de effecten van (een specifieke variant van) coördinatie van zorg. In de tweede studie wordt gekeken naar factoren die samenhangen met de diversiteit van zorg en (het beloop van) de tevredenheid van clienten. Hoofdstuk 1 geeft een overzicht van de twee studies. In dit hoofdstuk wordt een onderzoeksmodel voor de twee studies gepresenteerd, worden methoden en resultaten van de twee studies samengevat en worden beperkingen, conclusies en aanbevelingen beschreven. In het ondoryoeksmodel is een aantal theoretische inzichten gecombineerd. Het raamwerk voor het model is afgeleid van het 'Conceptual Framework for Studying Interorganizational Networks' volgens Alter en Hage (1993). Het raamwerk werd verder ingevuld aan de hand van concepten van Andersen (1995), Litwak (1985) en Wall (1981).

Coördinatie van zorg, predisponerende, gelegenheids- en behoeftenfactoren, diversiteit van de zorgverlening, zorgtaken, continuiteit van zorg en de tevredenheid van cliënten waren centrale concepten in dit model. In hoofdstuk 1 worden deze concepten geintroduceerd en worden mogelijke relaties tussen de concepten besproken.

Hoofdstuk 2 is een beschrijving van de implementatie van coördinatie van zorg in de thuiszorg voor chronisch zieke ouderen. In specifieke cliënt situaties werd één van de hulpverleners die al bij de zorg voor de cliënt betrokken was voor de periode van één jaar als zorgcoördinator aangewezen. Zowel professionele hulpverleners als mantelzorgers kwamen voor de rol van zorgcoördinator in aanmerking. Van alle coördinatoren werd verwacht dat ze vijf taken uitoefenden: (1) introductie als zorgcoördinator; (2) zorginventarisatie; (3) maken van een zorgplan; (4) uitvoeren van het zorgplan en bewaken van de zorg en (5) evalueren van het zorgplan. Een zorginventarisatie-formulier, een zorgplan, een logboek en een korte handleiding voor de zorgcoördinator werden als hulpmiddelen meegegeven. Een groep van 19 professionals en 19 mantelzorgers coördineerde voor een periode van tenminste 6 maanden. De implementatie van coördinatie van zorg werd geëvalueerd âan de hand van notulen van bijeenkomsten met zorgcoördinatoren, open interviews met coördinatoren en gebruikte zorgplannen en loghoeken. Het uitvoeren van een zorginventarisatie en het uitvoeren van het zurgplan en bewaken van de zorg waren taken die door nagenoeg alle coördinatornn goed werden uitgevoerd. De introductie en het maken van een zorgplan waren taken die matig werden uitgevoerd, terwijl taak 5, de evaluatie, door professionals matig en door mantelzorgers slecht werd uitgevoerd. Verder verschilden professionals en mantelzorgers in hun benadering van het coördinatorschap. Waar professionals zich vaak als 'zorg managers' profileerden, wierpen mantelzorgers 
zich op als 'belangenbehartiger' voor hun cliënt. Over het algemeen waren er echter weinig, of alleen kleine verschillen tussen professionals en mantelzorgers. Daarom werd geconcludeerd dat beide soorten hulpverleners als zorgcoördinatoren zouden kunnen functioneren.

In hoofdstuk 3 worden de resultaten van de interventie beschreven. Voor de effect-evaluatie werden naast de interviews met 19 professionals en 19 mantelzorgers ook interviews met 72 cliënten die gedurende het hele project deelnamen gebruikt. De interviews met cliënten waren voorgestructureerde interviews waarin onderwerpen zoals gezondheid, functioneren, diversiteit van de hulpverlening en de tevredenheid van cliënten aan bod kwamen. Professionals die als zorgcoördinator optraden rapporteerden meer effecten dan mantelzorgers die dezelfde taken uitvoerden. De zeven coördinatoren die geen enkel effect noemden waren allen mantelzorgers. Coördinatoren noemden vooral veel effecten die verwezen naar interpersoonlijke continuïteit; 24 van de 38 coördinatoren gaven aan dat de relaties tussen cliënten en hulpverleners als gevolg van de interventie verbeterd waren. Positieve effecten op de continuiteit van de informatievoorziening en de interdisciplinaire contacten werden door ongeveer de helft van de hulpverleners gerapporteerd. De interviews met cliënten lieten alleen een korte termijn effect op de tevredenheid van cliënten zien. Na zes maanden van coördinatie van zorg rapporteerden cliënten in de interventiegroep minder klachten over hulpverleners, maar dit effect werd na 12 maanden niet meer teruggevonden.

Hoofdstuk 4 is het eerste van drie hoofdstukken die tezamen de tweede studie beschrijven. In deze studie werd gezocht naar factoren die samenhangen met de diversiteit van de zorgverlening en (ontwikkelingen in) de tevredenheid van cliënten. In hoofdstuk 4 wordt aan de hand van een transversale studie beschreven welke factoren samenhangen met de diversiteit van professionele zorg, mantelzorg en de totale zorg.

Een groep van 177 zorg-afhankelijken werd geselecteerd door middel van een telefonische enquête onder een aselecte steekproef van huishoudens. In interviews met deze zorg-afhankelijken of cliënten kwamen onderwerpen als zorgtaken, predisponerende, gelegenheids- en behoeftenfactoren, diversiteit en continuilteit van de zorg en de tevredenheid van cliënten aan de orde. De resultaten met betrekking tot continuiteit en de tevredenheid van cliënten zijn beschreven in de hoofdstukken 5 en 6 . Bijnd alle cliënten ontvingen zowel professionele als mantelzorg. Daarbij ging het gemiddeld om vijf verschillende typen hulpverleners. Kwaliteit van leven, dagelijks functioneren

148 en de zorgtaken emotionele en informationele steun waren de factoren met de belangrijkste hijdrago aan de verklaring van de diversiteit van de totale zorgverlening. Leeftijd, woonsituatie, kwaliteit van leven, emotionele steun en de diversiteit van professionele hulpverlening waren de belangrijkste factoren bij de verklaring van de diversiteit van mantelzorg. De diversiteit in professionele zorg viel tonslotte hot beste te verklaren aan de hand van de factoren praktische en informationele steun, dagelijks functioneren, woonsituatie en de diversiteit van mantelzorg. 
In hoofdstuk 5 wordt de samenhang tussen de tevredienheid met professionele en mantelzorg en een aantal mogelijk verklarende factoren bestudeerd. Ook voor dit deel van de studie werden de gegevens van 177 zorg-afhankelijken gebruikt. De tevredenheid van cliënten werd zowel per hulpverlener als voor het totaal van professionele en mantelzorg in kaart gebracht. Aspecten van de continuiteit van zorg hadden in het algemeen een belangrijke bijdrage aan de verklaring van de tevredenheid van cliënten. Meer continuïteit in de zorg ging daarbij samen met meer tevredenheid. Verder was met name het opleidingsniveau van cliënten relevant. Cliënten met een lager opleidingsniveau waren vaker tevreden met de ontvangen zorg. Hoofdstuk 6 is gewijd aan voorspellers van ontwikkelingen in de tevredenheid van cliënten. Voor dit laatste hoofdstuk werden longitudinale gegevens van 134 van de 177 zorg-afhankelijken gebruikt. Deze 134 cliënten konden, 8 maanden na het eerste interview, voor een tweede maal geinterviewd worden. Voorspellers van ontwikkelingen in tevredenheid werden voor zowel professionele als mantelzorg bestudeerd. Veranderingen in de diversiteit en de continuïteit van zorg waren de beste voorspellers van verbeteringen of verslechteringen in de tevredenheid van cliënten. Een toename in de diversiteit en een teruggang in de continuiteit van zorg hing samen met een verslechtering in de tevredenheid van cliënten. Verder waren beperkingen en de kwaliteit van leven van clienten gerelateerd aan ontwikkelingen in tevredenheid. Daarbij waren de resultaten met betrekking tot de beperkingen van cliënten niet consistent, terwijl een hogere kwaliteit van leven op het eerste meetmoment duidelijk samenhing met positieve ontwikkelingen in de tevredenheid met de zorgverlening.

Aan de hand van het in hoofdstuk 1 gepresenteerde onderzucksmodel kon. den conclusies voor beide studies gegeven worden. Uit de resultaten van studie I viel een aantal conclusies over het aanwijzen van zorgcordinatoren voor individuele cliënten te trekken. Terwijl de veronderstelde relatie tussen coördinatie en continuiteit van zorg werd aangetroffen, resulteerde het aanwijzen van zorgcoördinatoren niet in veranderingen in de diversiteit van de zargverlening. Dit gebrek aan effecten is mogelijk te verklaren vanuit de aard of de onvolledige implementatie van de interventie. Desondanks wordt het aanwijzen van zorgcoördinatoren als zinvol gezien, met name wanneer verbeteringen in de continuteit van zorg beoogd worden.

Uit de resultaten van studie II volgde de conclusie dat predisponerende, gelegenheids- en behoeftenfactoren relevant zijn bij het verklaren van de diversiteit in de zorgverlening. Desondanks verdient het zeker aanbeveling om zorgtaken in het oog te houden bij de verklaring van de diversiteit van professionele zorg en mantelzorg.

Predisponerende, gelegenheids- en behoeftenfactoren waren relatief onbelangrijk bij het verklaren van (ontwikkelingen in) de tevredenheid van cliënten. Aspecten van continuiteit van zorg waren van belang voor zowel het niveau van als ontwikkelingen in de tevredenheid van clienten. Hoewel de diversiteit van de zorgverlening niet direct van belang was voor de tevreden- 
heid op een bepaald moment, werd geconcludeerd dat een toename in de diversiteit van zorgverlening meer kans op ontevredenheid van cliënten met zich meebrengt.

Naast een aantal conclusies, werden in het laatste deel van hoofdstuk 1 ook verschillende aanbevelingen geformuleerd. De resultaten van studie I maakten duidelijk dat zowel professionals als mantelzorgers geschikte kandidaten voor de rol van zorgcoördinator zijn. In toekomstige interventies dient echter extra aandacht aan het systematisch werken van potentiële zorgcoördinatoren gegeven te worden. Mantelzorgers zouden bovendien extra begeleiding moeten krijgen waar het gaat om assertiviteit en het mobiliseren van (nieuwe) hulpverleners. Hoewel het aanwijzen van zorgcoördinatoren al kan resulteren in een verbeterde continuïteit van de zorgverlening, heeft een coördinator voor het daadwerkelijk veranderen van de hulpverlening wellicht formele bevoegdheden en financiële middelen (cliënt gebonden budget) nodig.

De resultaten van de tweede studie wijzen uit dat hulpverleners meer aandacht zouden moeten geven aan de meer 'kwetsbare' groepen cliënten: cliënten die ouder zijn, alleen wonen, meer beperkt zijn en een lagere kwaliteit van leven rapporteren. Verder wezen de resultaten van deze studie uit dat tevredenheidsscores van cliënten betekenisvol zijn en dat de tevredenheid van cliënten bedreigd wordt door een gebrek aan continuilteit en door een toename in de diversiteit van de hulpverlening. Coördinatie van zorg is daarom des te meer relevant in die gevallen waar veel verschillende hulpverleners bij de zorg voor de cliënt betrokken zijn.

\section{Verwijzingen}

Alter, C. \& Hage, J. (1993) Organizations working together. Newbury Park, CA: SAGE.

Andersen, R. (1995) Revisiting the behavioral model and access to medical care: Does it matter? Journal of Health and Social Behavior 36: 1-10.

Litwak, E. (1985) Helping the elderly: The complementary roles of informal networks and formal systems. New York: Guilford Press.

Wall, E.M. (1981) Continuity of care and family medicine: Definition, determinants and relationship to outcome. The Journal of Family Practice 13: 655-664. 


\section{Appendix}

Relationships* between predisposing, enabling and need factors, diversity of care and aspects of the continuity of care in study $/ /$ ( $n=177$ ).

Predisposing

1 Sex (female)

2 Age

3 Ediucational level

4 Occupational level Enabling

\section{Living alone.}

Need

6 Perceived health

7 Perceived impairment

8 Daily functioning

9 Perceived quality of life Care lasks

10 Practical support

11 Emotional support

12 Informational support

Diversity ol care

13 Diversity non-prof care

14 Diversity prof care

15 Diversity total care

Continuity of care

16 Non-prots accessible

17 Non-profs keep appointments

18 Profs accessible

19 Profs accessible

20 Same profs over time

21 Consistent information

22 Knowing where to find care

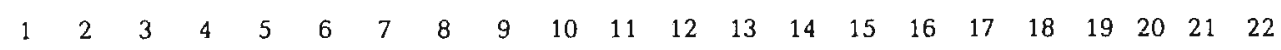

$x$

$3+$

3- 3- $x$

ns $3+3+x$

$3+3+3-$ ns $x$

$2+$ ns 3- ns $3+x$

ns $2-3+$ ns 2 - $3-x$

ns $3-$ ns ns ns $3+3-$

$2+$ ns ns ns ns $3+3-1+x$

$3+3+2-2-2+2-$ ns 3 . ns $x$

ns 3. $2+$ ns ns ns $1+$ ns ns ns $x$

ns 2- ns ns ns ns ns nis ns 1- ns $x$

ns $3=3+$ ns $3-$ ns $1+$ ns $1+$ ns $3+$ ns $x$

ns ns ns $1+$ ns ns ns 1 . ns ns $1+3+3+x$

ns 2 - $2+$ ns 2 - ns $1+$ ns $2+$ ns $3+3+3+3+$ x

ns $3+3-$ ns $2+$ ns ns 1 - ns $2+1$ - ns $3-$ ns $3=x$

ns $3+1$ - ns $3+$ ns ns ns ns ns 3 - ns 3 - ns 3 - $3+$ x

nsi $3+3^{-}$ns $3+$ ns ns ns ns ns 3- 2- 2- 3- 3- $2+$ ns $x$

nsi $2+3-1-$ ns ns ns ns ns ns $1-2-$ ns $3-3-$ ns ns $3+$ -

nsi ns nsi ns ns ns ns ns ns ns ns ns $3-3-3-$ ns $2+3+3+x$

$\mathrm{ns} 3+\mathrm{ns}$ ns ns ns 2 . ns $2+$ ns ns ns ns ns ns ns ns $2+$ ns ns $x$

2+. $1+n s$ ns ns ns 1 . ns $3+n s$ ns ns ns ns ns ns ns $1+1+2+3+x$

$\begin{array}{llllllllllllllllllllll}1 & 2 & 3 & 4 & 5 & 6 & 7 & 8 & 9 & 10 & 11 & 12 & 13 & 14 & 15 & 16 & 17 & 18 & 19 & 20 & 21 & 22\end{array}$ 


\section{Met dank aan:}

Begeleidingsgroepen projecten I en II

Ton van Beers, Henk Berkvens, Harry Crebolder, Els Damsma,

Yvonne Helsen, Anke Huppertz, Thieu Klaassen, Theo Mangnus,

Hans Philipsen, Martin Schrijver, Henk Steenbekkers,

Leden STEL Noord-Limburg, Fred Stevens, Luc de Witte, Frans Vocking

Collega's en oud-collega's

Vakgroep Medische Sociologie en Vakgroep Verplegingswetenschap,

Universiteit Maastricht;

Vakgroep Huisarts-, Sociale en Verpleeghuisgeneeskunde,

Katholieke Universiteit Nijmegen

Medewerkers/ondersteuners projecten I en II

Jan van Dalen, Hetty Dokter, Enquete service MEMIC, Carla Frederiks,

Marion Hekkink, Marie-Louise Neumann, Bregje Philipsen,

Loran van Roessel, Vonca Schaffers, Wilma Scholte op Reimer,

Frans Theunissen, Nandus Vierhout, Dries Willems

Nimfen

Ate Frans de Bruin, Annemie Courtens

Opdrachtgevers/subsidiegevers

Nederlands Instituut voor Zorg en Welzijn (NIZW), Provincie Limburg,

Stichting Eerste Lijn Noord-Limburg (STEL)

Promotoren/co-promotor

Hans Philipsen, Harry Crebolder, Fred Stevens

Respondenten

Hulpbehoevenden en hulpverleners in de gemeenten Echt,

Meerssen, Tegelen en Venray

Supporters

Jacqueline, Sjoerd, Ineke, Els, Emmy, Hannie, Josephine, Theo sr.,

Madeleine, Gerjo 


\section{Curriculum Vitae}

Theo van Achterberg was born in 1966, in the city of Breda. In Breda, he went to the 'St Joseph' and 'Doornroosje' kindergartens, the 'Clemens Maria Hofbouwer' primary school, and the 'Newman College' highschool from which he graduated in 1984. From 1984 till 1988 he studied Health Sciences at the Maastricht University, where he completed the curriculum of Nursing Science and followed part of the curriculum of Health Education and Promotion.

As an alternative to militairy service, he worked as an assistent researcher at the department of Nursing Science (Maastricht University) from December 1988 till June 1990. During the five years and four months that followed, he was employed as a researcher at the department of Medical Sociology of the same university. Here, he worked on the two community care projects that are described in this dissertation. After this period, he returned to the department of Nursing Science, where he worked on a project that aimed at testing a pressure sore risk scale from October 1995 till September 1996.

Theo van Achterberg is currently an assistent professor in Nursing Science at the University of Nijmegen. 
